\title{
Increasing self-efficacy in student midwives for physiological childbirth
}

\author{
Citation for published version (APA):
}

Thompson, S. M. (2020). Increasing self-efficacy in student midwives for physiological childbirth: The design and development of a midwifery education initiative - the ESSENTIAL programme. [Doctoral Thesis, Maastricht University]. Maastricht University. https://doi.org/10.26481/dis.20200508st

\section{Document status and date:}

Published: 01/01/2020

DOI:

10.26481/dis.20200508st

Document Version:

Publisher's PDF, also known as Version of record

\section{Please check the document version of this publication:}

- A submitted manuscript is the version of the article upon submission and before peer-review. There can be important differences between the submitted version and the official published version of record.

People interested in the research are advised to contact the author for the final version of the publication, or visit the DOI to the publisher's website.

- The final author version and the galley proof are versions of the publication after peer review.

- The final published version features the final layout of the paper including the volume, issue and page numbers.

Link to publication

\footnotetext{
General rights rights.

- You may freely distribute the URL identifying the publication in the public portal. please follow below link for the End User Agreement:

www.umlib.nl/taverne-license

Take down policy

If you believe that this document breaches copyright please contact us at:

repository@maastrichtuniversity.nl

providing details and we will investigate your claim.
}

Copyright and moral rights for the publications made accessible in the public portal are retained by the authors and/or other copyright owners and it is a condition of accessing publications that users recognise and abide by the legal requirements associated with these

- Users may download and print one copy of any publication from the public portal for the purpose of private study or research.

- You may not further distribute the material or use it for any profit-making activity or commercial gain

If the publication is distributed under the terms of Article $25 \mathrm{fa}$ of the Dutch Copyright Act, indicated by the "Taverne" license above, 


\section{INCREASING SELF-EFFICACY IN STUDENT MIDWIVES FOR PHYSIOLOGICAL CHILDBIRTH}

The design and development of a midwifery

education initiative - the ESSENTIAL programme 


\section{Colophon}

Designed by: Heinz de Jongh \& Danny Kieneker | www.heinz.nu

Printed by: Ridderprint BV, Ridderkerk

Copyright (C) 2020, Suzanne M Thompson

ISBN 978-94-6375-879-6

All rights reserved. No part of this book may be reproduced, stored in a retrieval system, or transmitted, in any form or by any means, electronic, mechanical, photocopying, recording, or otherwise, without the prior written consent of the author.

Financial support by the Royal Dutch Organisation of Midwives for the publication of this thesis is gratefully acknowledged. 


\title{
INCREASING SELF-EFFICACY IN STUDENT MIDWIVES FOR PHYSIOLOGICAL CHILDBIRTH
}

The design and development of a midwifery

education initiative - the ESSENTIAL programme

\author{
THESIS \\ To obtain the degree of Doctor at Maastricht University \\ on the authority of the Rector Magnificus, Prof. Dr. Rianne M Letchert \\ In accordance with the decision of the Board of Deans \\ To be defended in public on May $8^{\text {th }}$ at 12.00
}

By

Suzanne Marie Thompson

Date of birth: 11th April 1970, Exeter, England 
Supervisor.

Co-supervisors:

Assessment Committee:
Prof. Dr. R. de Vries

Prof. Dr. M. Nieuwenhuijze

Prof. Dr. L. Kane Low

Prof. Dr. G.D.E.M. van der Weijden, chairwoman

Prof. Dr. C.P.M. van der Vleuten

Prof. Dr. S. Downe, University of Central Lancashire, England

Dr. M.J.B. Govaerts

Dr. M. Hollander, Radboud UMC 


\section{Contents}

Chapter

$2 \quad$ Exploring Dutch midwives' attitudes to promoting physiological childbirth: A qualitative study

3 "A Powerful Midwifery Vision"

Dutch Student Midwives' Educational Needs as Advocates of Physiological Childbirth

$4 \quad$ Midwifery students' perspectives on how role models contribute to becoming a midwife: A qualitative study

5 Creating an Optimality Index - Netherlands: a validation study

6 Creating guardians of physiological birth:

The development of an educational initiative for student midwives in the Netherlands

7 Evaluating the effect of an educational intervention on student midwife self-efficacy for their role as physiological childbirth advocates

8 General Discussion

9 Summary

10 Samenvatting

$11 \quad$ Valorisation 


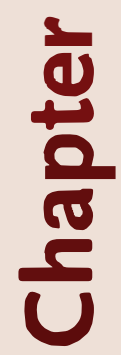

Good beginnings make a positive difference in the world, so it is worth our while to provide the best possible care for mothers and babies throughout this extra-ordinarily influential time ${ }^{1}$

- Ina May Gaskin - 


\section{Introduction}

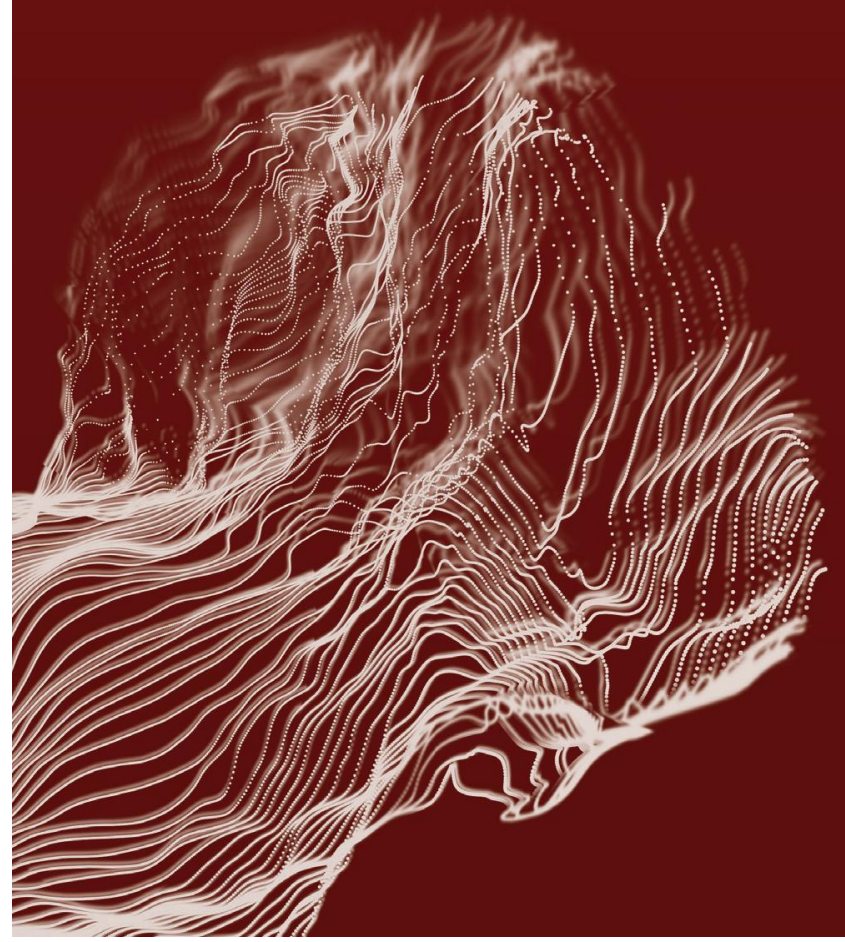




\section{| Chapter 1}

\section{The power of midwifery}

There is increasing international consensus on the efficacy of midwifery care for women and their families. ${ }^{2,} 3$ A landmark series, published in the Lancet 2, 4.6, focusing on the contributions of midwifery care to global health provided an evidence-based framework defining quality midwifery care. Moreover, this series emphasized the value and effectiveness of maternity care that begins with a focus on the needs of women and their families, rather than on identifying and responding to pathology. The philosophy that drives high quality care for childbearing women and their families is one in which biological, psychological, and social processes are optimized, a woman's capacity for childbirth and her subsequent role as a mother is strengthened, and obstetric interventions are used only when indicated. ${ }^{2}$ Midwifery care recognizes that, for most women, childbirth is a healthy, physiological life event. The role of midwives is to support healthy physiology during the reproductive period. The focus of care at childbirth is shifting from mere survival, toward the recognition of childbirth as a powerful and transformative experience in a woman's life. 7 This implies that, for most women, birth is about more than a series of medical procedures and that 'good beginnings', as described by Gaskin ${ }^{1}$ in the quote above, have a lasting impact on women, far beyond the physical act of the birth of their child. The importance of positive, woman-centred experiences in childbirth has been recognized by researchers ${ }^{8}$, policy-makers ${ }^{9}$, and, in their recent publication of guidelines for antenata ${ }^{10}$ and intrapartum ${ }^{11}$ care, by the World Health Organization (WHO).

\section{The value of physiological childbirth}

Women value being able to rely on their own capacity to give birth without needing technological or pharmacological assistance, while at the same time acknowledging the unpredictability of birth and the need to adapt if birth becomes pathological. ${ }^{8}$ According to the International Confederation of Midwives (ICM), physiological childbirth is characterized by: 1) labour beginning on its own and progressing until 2) the spontaneous birth of a term baby in a vertex position, 3) without the need for medical or pharmacological intervention and is followed by 4) immediate skin-toskin contact between mother and baby and 5) the facilitation of early breastfeeding. ${ }^{12}$ This dynamic process between woman and foetus is a complex interplay of hormones that facilitate foetal readiness for birth, enhanced labour effectiveness, the release of endorphins to cope with pain and stress, the transition to extra-uterine life, and the optimization of infant feeding and maternal and child bonding. ${ }^{13}$

Together with physiological processes, there are also psychological and social factors at play in the childbirth experience. Important to women is the maintenance of a sense of control and the ability to influence decision-making during childbirth. ${ }^{8}$ 
Women are aware that childbirth can be unpredictable, but a sense of control is an important factor in how childbirth is experienced. Women who report negative or traumatic childbirth experiences often attribute these to feeling a lack of control. ${ }^{14}$ Furthermore, positive childbirth experiences facilitate healing from previous trauma. ${ }^{15}$ Participation in, and control over, the care received in childbirth together with a facilitating environment induces feelings of empowerment ${ }^{16}$, important for the subsequent transition to parenthood.

\section{The challenges of the bio-medical childbirth paradigm - for women and for midwives}

Greater equity in health care, together with advances in maternity care - such as the availability of antibiotics and technological developments in perinatology - have undoubtedly contributed to safer births ${ }^{17}$ for many women. However, the bio-medical approach to maternity care that has gone hand-in-hand with these advancements has resulted in a sharp increase in the non-evidence based use of interventions in birth. This is despite evidence that routine, but often unnecessary, interference in the birth process leads to iatrogenic harm and significantly increases the cost of maternity care. ${ }^{18,19}$

The likelihood of over-medicalising birth is increased when maternity care is perceived through a cognitive frame focused on 'lurking risk. ${ }^{20}$ This perspective is contrary to the midwifery framing of childbirth that views birth as a fundamentally natural and healthy process. Despite the confirmed value of midwifery, ${ }^{2-6}$ other professionals in the reproductive and maternity care domain are not fully aware of the benefits of midwifery care. ${ }^{21}$ Obstetricians, who, for the most part, attend pathological births, express concern that over-emphasis on physiological childbirth overlooks risks to mothers and babies. ${ }^{22}$

Concerns about the medicalisation of childbirth are not new - historians have shown that midwives were worried about the increasing influence of man-midwives and doctors and the diminishment of the embodied and intuitive knowledge of midwifery as early as the 17 th century. ${ }^{23}$ In the 19 th century, Dutch midwives expressed unease about the influence of a new breed of General Practitioners on domiciliary midwifery. ${ }^{24}$ More recent histories have explored the medicalisation that resulted from a consumer-driven demand for improved maternity care ${ }^{25}$ underscored by a policy shift towards hospital birth in the late 20th century. ${ }^{26}$

This historical struggle between two approaches to childbirth has threatened the creation of equitable relationships between those who provide care in pregnancy and 


\section{| Chapter 1}

birth. Midwives - as members of a profession made up mostly of women and with fewer years of education than physicians - typically are accorded lower status in the medical hierarchy. The result is often a lack of agency and resignation to the status quo, which, in turn, can jeopardize the professional identity of midwifery.

Diminishment of the professional identity of midwives is concerning, particularly in light of recent developments in maternity care in the Netherlands, where midwives have been granted a high degree of autonomy in their practice. ${ }^{27}$ One of the key recommendations of the report 'Een Goed Begin'" was the development of an integrated approach to maternity care where midwives and obstetricians work in close collaboration. Integrale zorg, (integrated care) ${ }^{28}$ was seen as a means to place women at the centre of care and improve perinatal outcomes. Integrated care is now being implemented in different formats throughout the various regions of the Netherlands, making it critically important to consider how these new forms of collaboration will affect the professional identity of midwives in the Netherlands, particularly in light of challenges faced by midwives elsewhere. ${ }^{22}$

As noted above, relationships between midwives and obstetricians are influenced by the history of maternity care, varying perceptions of status, problems in communication, and knowledge gaps about the effectiveness of midwifery. Recent research in the Netherlands shows that midwives perceive themselves to have a lower status than medical professionals and that midwives feel pessimistic about collaborating with obstetricians. ${ }^{29}$ Obstetricians, on the other hand, rate their collaborations with members of the maternity care team more positively than do their colleagues with a perceived lower status, ${ }^{30}$ including midwives, nurses, and maternity care assistants. Furthermore, midwives experience an imbalance in power in their professional relationships with obstetricians. ${ }^{31,32}$ This imbalance is evident in styles of communication. Powerful communication styles, used by those who are certain of their status, uses assertive, concise language, rather than language that reflects uncertainty or doubt. Midwives tend to use communication styles that reinforce the perception of themselves as lower in status. ${ }^{33}$ This is reflected in gendered language when referring to other midwives - an example of this is referring to other members of the midwifery team 'the girls'; language not observed in relation to female medical colleagues. ${ }^{33}$ Lastly, it is not clear that obstetricians understand the value of midwifery. Van der Lee et al ${ }^{31}$ have shown that obstetricians do not fully appreciate or understand physiological childbirth, the centre of midwifery's expertise. 
Good collaboration is not an end in itself. Poor collaboration results in substandard care. ${ }^{34,35}$ One way to improve collaboration is to balance the power of the caregivers that are collaborating. For this reason, it is important that midwives do not relinquish their autonomy or their trust in physiological childbirth and that they possess the personal agency needed to question and challenge differing approaches to care in childbirth. Good collaboration, and the well-being of mothers and babies, depends on a strong sense of professional identity on the part of midwives. The coming generation of midwives must learn how to develop and maintain the personal agency needed to uphold and express the unique midwifery professional identity in equitable and collaborative relationships with obstetricians.

\section{Education as a vehicle for change}

The international definition of a midwife created by the International Confederation of Midwives (ICM) ${ }^{36}$, and nationally recognized policy documents ${ }^{37,38}$ emphasizes the value of midwifery education for the promotion of physiological childbirth, with a focus on curriculum content (knowledge, skills and attitude). ${ }^{39}$ While this curriculum provides an essential knowledge and skills base, there is insufficient focus on the articulation of a professional midwifery identity and the competencies needed to advocate for the births that women want. On the other hand, the document, 'Strengthening quality midwifery education for universal health coverage 2030'40, moves the focus of midwifery education from task-based and life-saving skills to an approach that emphasizes the value of midwifery care. This approach is designed to create professionals who can function autonomously, be knowledgeable, skilled, and capable of providing compassionate and respectful care in partnership with interprofessional teams when necessary. ${ }^{40}$ This strategy also recognizes the need to strengthen midwifery leadership and improve the alignment between midwifery stakeholders. This will result in improved outcomes for women and newborns, improved access to maternity care, and the creation of a body of evidence for the cost-effectiveness of midwifery care..$^{40}$

In order for midwifery educators to meet the challenge set out in this global strategy on midwifery education, we must rethink the way midwives are educated to collaborate with other professions in the provision of maternity care. Education for midwives must include professional socialization and the internalization of the midwifery philosophy care ${ }^{41,42}$ so that women are placed at the centre of care and their expressed needs for the childbirth experience can be facilitated.

In addition, care must be taken to address the power imbalance between midwives and obstetricians ${ }^{31}$ that often emerges during professional socialization. 


\section{| Chapter 1}

The work contained in this thesis is a necessary first step to creating a curriculum for midwifery students that will help them develop genuine, collaborative relationships based on principles of equity, respect and mutual recognition, without depreciating midwifery professional identity as a result.

\section{This thesis}

In 2015, the Academie Verloskunde Maastricht introduced a new bachelor of midwifery curriculum, designed to prepare students for the challenges of midwifery practice in the twenty-first century. We recognized that, in addition to preparing student midwives for professional registration and practice ${ }^{43}$ by meeting the stipulations of European ${ }^{44}$ and Dutch directives ${ }^{45}$, a new curriculum should prepare students for working within an integrated model of maternity care ${ }^{28,} 46$ characterized by interprofessional collaboration. Part of this preparation, we felt, needed to provide student midwives with the tools they need for their role as advocates for physiological childbirth while recognizing the power imbalance described by van der Lee et al. ${ }^{31}$ We aimed to create an educational focus that would ameliorate this power imbalance by strengthening midwifery agency. We also recognized the speed at which change is occurring - the implementation plan for integrated maternity care was published in $2016^{47}$ and its implementation is underway in the Netherlands. It was therefore necessary to identify a methodology for the rapid design of an educational initiative that took the dynamic environment of midwifery in the Netherlands into account.

\section{Rapid Prototyping (RP) Design Methodology}

The studies presented in this thesis were guided and informed by Rapid Prototyping Design methodology. ${ }^{48}$ In a fast-paced and knowledge-based world, those who wish to develop interventions must be efficient with both time and human resources. This is particularly true in the field of professional education where an ever-expanding knowledge base demands more of the limited time available in student schedules.

Rapid Prototyping (RP) has its origins in software design, where expeditious design solutions - prototypes - for a rapidly changing environment were of key importance. 48 It has since been used as a method for designing and developing of educational curricula, programmes, and individual courses. ${ }^{49}$ The RP methodology includes a comprehensive needs analysis followed by the creation of a prototype and involves stakeholders throughout the entire process. The prototype is modified in iterative cycles, in order to create a final product that is ready for real-world testing..$^{50}$ Each iterative cycle allows for the participation of stakeholders including their step-by-step 
feedback on the developing prototype, thereby increasing stakeholder feelings of ownership of, and support for, the end product. Furthermore, its iterative nature replaces the linear and time-consuming sequence approaches often used in the development of curricula, such as Analyze-Design-Develop-Implement-Evaluate (ADDIE), reducing both development time and costs. ${ }^{51}$

\section{General aim and research questions}

The general aim of this thesis, then, is to design, develop and pilot-test a midwifery educational initiative that supports student midwives in developing personal agency for the promotion of physiological childbirth. Rapid Prototyping design methodology informed and guided this process. In order to meet this objective, a number of specific research questions were generated, namely,

1. What are Dutch midwives' attitudes toward, and motivations for, the promotion of physiological childbirth and what factors facilitate or inhibit them in this role?

2. What are Dutch student midwives' attitudes and motives with regard to promoting physiological childbirth and what do they feel they need from educational programmes in order to effectively fulfil this role?

3. What is the opinion of student midwives about the value of role models in midwifery education in the Netherlands?

4. Could a Dutch Optimality Index be a valid and reliable instrument for measuring the application of evidence based care to support physiological childbirth and thus be available for use as an assessment of care practices provided by midwifery students?

5. What would an educational initiative need to do in order to strengthen student midwife agency?

6. What effect does a pilot educational initiative have on student midwife agency for their role as promotors of physiological childbirth?

The six studies presented in this thesis used various methodological approaches to explore these questions (figure 1). 


\section{| Chapter 1}

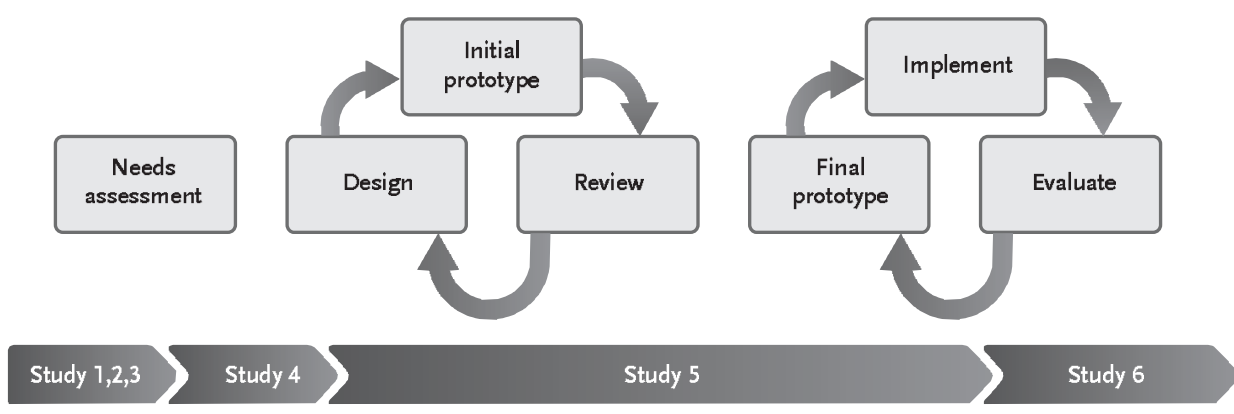

Figure 1: The use of Rapid Prototyping Design methodology in this thesis

In accordance with RP design methodology, the first three research questions (above) form a comprehensive needs assessment, offering valuable insights into what midwives and student midwives need to be able to function as advocates of physiological childbirth. In these three studies, important stakeholders - community-based and hospital-based midwives from various parts of the Netherlands and student midwives from each of the three Universities of Applied Sciences (in four locations throughout the Netherlands) - shared valuable insights with us. These insights guided us in the further development of the educational initiative.

In order to meet a key educational need - identified by both midwives and student midwives - for a tool to reflect upon optimal, evidence-based childbirth care processes and outcomes, we found a framework, the Optimality Index, ${ }^{52}$ and validated it for use in the Dutch setting, creating the Dutch Optimality Index (OI-NL). Once validated, it could be incorporated into midwifery education as an assessment tool to measure the implementation of care practices consistent with the paradigm of physiological childbirth.

Using the iterative design process central to RP, we worked with stakeholders - in this case, practicing midwives from community and hospital settings, midwifery education managers and lecturers and student midwives - to design and develop a prototype for an educational initiative aimed at increasing the agency of student midwives as advocates for physiological childbirth. This prototype initiative was subsequently implemented in the third year of our four year Bachelor programme in order to observe and test its effect. Subsequently, we evaluated this prototype programme by measuring change in student midwife self-efficacy, generating valuable input for adjusting and adapting the prototype. 


\section{Outline of this thesis}

Following this introduction, chapter $\mathbf{2}$ presents the findings of a focus group study exploring Dutch midwives' attitudes to physiological childbirth and factors that inhibit and facilitate midwives in assuming this role in hospital and community settings.

Chapter 3 presents the findings of a focus group study exploring Dutch student midwives' attitudes to their future professional role as promotors of physiological childbirth and explores what student midwives feel they need from midwifery education in order to fulfil their role as midwives.

Chapter 4 reports individual interviews and focus groups with student midwives on their specific need for role models in midwifery practice.

Chapter 5 reports the process of validating the Optimality Index-United States for the specific context of Dutch maternity care, creating a Dutch Optimality Index (OI-NL).

Chapter 6 describes the creation of a prototype educational initiative, aimed at increasing agency of student midwives for their role as advocates for physiological childbirth, using Rapid Prototyping design methodology and involving key stakeholders.

Chapter 7 describes the results from a study in which the effect on the self-efficacy of student midwives at a Dutch university of Applied Sciences was assessed.

In chapter 8, we discuss the main findings of the studies contained within this thesis and we reflect on the methodological strengths and limitations of those studies. Finally, we discuss the implications of our work for midwifery education and suggest directions for further research. 


\section{| Chapter 1}

\section{References}

1. Gaskin I. Birth Matters. A Midwife's Manifesta. 1st ed: Pinter and Martin; 2011.

2. Renfrew MJ, McFadden A, Bastos MH, Campbell J, Channon AA, Cheung NF, et al. Midwifery and quality care: findings from a new evidence-informed framework for maternal and newborn care. The Lancet. 2014;384(9948):1129-45.

3. Sandall J, Soltani H, Gates S, Shennan A, Devane D. Midwife-led continuity models versus other models of care for childbearing women. Cochrane Database of Systematic Reviews. 2016(4).

4. Homer C, Friberg I, Dias M, ten Hoope-Bender P, Sandall J, Speciale A, et al. The projected effect of scaling up midwifery. Lancet. 2014; 384.

5. van lerberghe W, Matthews Z, Achadi E, Ancona C, Campbell J, Channon A, et al. Country experience with strengthening of health systems and deployment of midwives in countries with high maternal mortality. Lancet. 2014; 384.

6. ten Hoope-Bender P, de Bernis L, Campbell J, Downe S, Fauveau V, Fogstad H, et al. Improvement of maternal and newborn health through midwifery. The Lancet. 2014; 384(9949): 1226-35.

7. Olza Fernandez I, Leahy-Warren P, Benyamini Y, Kaźmierczak M, Karlsdóttir S, Spyridou A, et al. Women's psychological experiences of physiological childbirth: a metasynthesis. BMJ Open. 2018: 20347.

8. Downe S, Finlayson K, Oladapo OT, Bonet M, Gülmezoglu AM. What matters to women during childbirth: A systematic qualitative review. PLoS One. 2018; 13(4):e0194906-e.

9. van der Velden, J. A Good beginning: safe care around pregnancy and birth. Advice of the steering group pregnancy and birth. 2009.

10. World Health Organization. WHO recommendations on antenatal care for a positive pregnancy experience. 2016.

11. World Health Organization. WHO recommendations: intrapartum care for a positive childbirth experience. 2018.

12. International Confederation of Midwives. ICM Core Document. Philosophy and Model of Midwifery Care. Den Haag: ICM; 2014.

13. Buckley SJ. Executive Summary of Hormonal Physiology of Childbearing: Evidence and Implications for Women, Babies, and Maternity Care. J Perinat Educ. 2015; 24(3):145-53.

14. Hollander MH, van Hastenberg E, van Dillen J, van Pampus MG, de Miranda E, Stramrood CAI. Preventing traumatic childbirth experiences: 2192 women's perceptions and views. Archives of Women's Mental Health. 2017;20(4): 515-23.

15. Reed R, Barnes M, Rowe J. Women's Experience of Birth: Childbirth as a Rite of Passage. International Journal of Childbirth. 2016; 6(1): 46-56.

16. Nieuwenhuijze M, Leahy-Warren P. Women’s empowerment in pregnancy and childbirth: A concept analysis. Midwifery. 2019; 78:1-7.

17. Centres for Disease Control and Prevention. Ten great public health achievements--United States, 1900-1999. MMWR Morb Mortal Wkly Rep. 1999;48(12): 241-3.

18. Requejo J, Victora C, Bryce J. Countdown to 2015: Maternal, Newborn and Child Survival. International Journal of Epidemiology. 2014; 43(2):586-96. 
19. Topçu S, Brown P. The impact of technology on pregnancy and childbirth: creating and managing obstetrical risk in different cultural and socio-economic contexts. Health, Risk \& Society. 2019; 21(3-4):89-99.

20. Regan M, Liaschenko J. In the Mind of the Beholder: Hypothesized Effect of Intrapartum Nurses' Cognitive Frames of Childbirth Cesarean Section Rates. Qualitative Health Research. 2007;17(5): 612-24.

21. Renfrew MJ, Ateva E, Dennis-Antwi JA, Davis D, Dixon L, Johnson P, et al. Midwifery is a vital solution - What is holding back global progress? Birth. 2019; 46(3):396-9.

22. Keating A, Fleming VEM. Midwives' experiences of facilitating normal birth in an obstetric-led unit: a feminist perspective. Midwifery. 2009; 25(5):518-27.

23. Allotey JC. English midwives' responses to the medicalisation of childbirth. Midwifery. 2011;27(4): 532-8.

24. Marland H. Questions of Competence: The Midwife Debate in the Netherlands in the EarlyTwentieth Century. Medical History [Internet]. 1995 22nd November 2019; 39:[317-37 pp.].

25. Al-Gailani S, Davis A. Introduction to "Transforming pregnancy since 1900". Stud Hist Philos Biol Biomed Sci. 2014;47 Pt B(Pt B):229-32.

26. Richmond C. Sir John Peel. BMJ : British Medical Journal. 2006; 332-366.

27. De Vries R. A Pleasing Birth: Midwives and Maternity Care in the Netherlands: Temple University Press; 2005.

28. Nederland Zorgstandaard Integrale Geboortezorg. Versie 11. Utrecht. 2016.

29. Cronie D, Rijnders M, Jans S, Verhoeven CJ, de Vries R. How good is collaboration between maternity service providers in the Netherlands? Journal of multidisciplinary healthcare. 2019; 12:21 - 30 .

30. Romijn A, Teunissen PW, de Bruijne MC, Wagner C, de Groot CJM. Interprofessional collaboration among care professionals in obstetrical care: are perceptions aligned? BMJ Qual Saf. 2018;27(4):279-86.

31. van der Lee N, Driessen EW, Scheele F. How the past influences interprofessional collaboration between obstetricians and midwives in the Netherlands: Findings from a secondary analysis. Journal of Interprofessional Care. 2016; 30(1):71-6.

32. Schölmerich VL, Posthumus AG, Ghorashi H, Waelput AJ, Groenewegen P, Denktaş S. Improving interprofessional coordination in Dutch midwifery and obstetrics: a qualitative study. BMC Pregnancy and Childbirth. 2014;14(1):145.

33. Pollard K. How midwives' discursive practices contribute to the maintenance of the status quo in English maternity care. Midwifery. 2011; 27:612-9.

34. Kirkup B. The report of the Morecombe Bay Investigation. An independent investigation into the management, delivery and outcomes of care provided by the maternity and neonatal services at the University Hospitals of Morecambe Bay NHS Foundation Trust from January 2004 to June 2013. . 2015.

35. Morgan S, Pullon S, McKinlay E. Observation of interprofessional collaborative practice in primary care teams: An integrative literature review. International Journal of Nursing Studies. 2015;52(7):1217-30.

36. International Confederation of Midwives. Definition of the Midwife. Core Document. The Hague. 2017. 


\section{| Chapter 1}

37. Aitink M, Goodarzi B, Martijn L. Beroepsprofiel Verloskundige. 2014.

38. American College of Nurse-Midwives. Supporting healthy and safe physiologic birth: A consensus statement by ACNM, MANA and NAPCM. Journal of Midwifery and Women's Health [Internet]. 2012; 57:529-32

39. International Confederation of Midwives. Essential Competencies for Midwifery Practice. 2018 : Update. The Hague; 2019.

40. ICM/UNfPA. Strengthening quality midwifery education for Universal Health Coverage 2030: framework for action. 2019.

41. Ulrich S. First Birth Stories of Student Midwives: Keys to Professional Affective Socialization. Journal of midwifery \& women's health. 2004; 49:390-7.

42. Weis D, Schank MJ. Professional values: Key to professional development. Journal of Professional Nursing. 2002; 18(5):271-5.

43. Wet op de beroepen in de individuele gezondheidszorg, (1993).

44. DIRECTIVE 2005/36/EC OF THE EUROPEAN PARLIAMENT AND OF THE COUNCIL of 7 September 2005 on the recognition of professional qualifications (2005).

45. Besluit Opleidingseisen en Deskundigheidsgebeid Verloskundigen, (2008).

46. Perdok H, Jans S, Verhoeven C, Henneman L, Wiegers T, Mol BW, et al. Opinions of maternity care professionals and other stakeholders about integration of maternity care: a qualitative study in the Netherlands. BMC pregnancy and childbirth. 2016; 16(1):188-.

47. College Perinatale Zorg. Implementatieplan van de Zorgstandaard Integrale Geboortezorg. 2016.

48. Tripp SD, Bichelmeyer B. Rapid prototyping: An alternative instructional design strategy. Educational Technology Research and Development. 1990; 38(1):31-44.

49. Luca B, Lorenzo C, Benedetto L, Stefano T. Fast Prototyping as a Communication Catalyst for E-Learing Design. Making the Transition to E-Learning: Strategies and Issues. Hershey,

PA, USA: IGI Global; 2007. p. 266-83.

50. Desrosier J. Rapid Prototyping Reconsidered. The Journal of Continuing Higher Education. 2011;59:135-45.

51. Daugherty J, Teng Y-T, Cornacchione Jr E. Rapid Prototyping Instructional Design: Revisiting the ISD Model. Online Submission. 2007.

52. Murphy PA, Fullerton JT. Measuring Outcomes of Midwifery Care: Development of An Instrument To Assess Optimality. Journal of Midwifery \& Women’s Health. 2001; 46(5):274-81 
Introduction | 


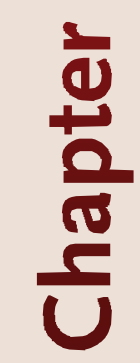

SM Thompson

MJ Nieuwenhuijze

L Kane Low

$\mathrm{R}$ de Vries

Midwifery 2016, 42: 67-73 


\section{Exploring Dutch midwives' attitudes to promoting physiological childbirth: A qualitative study}

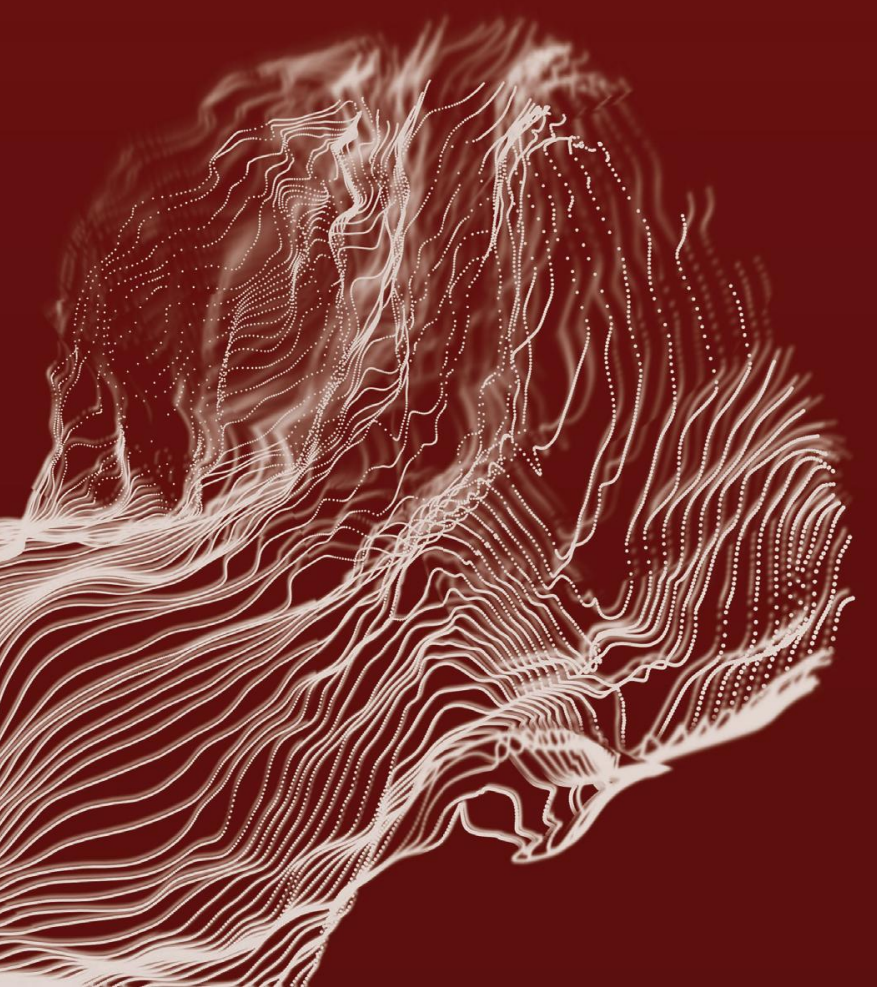




\title{
| Chapter 2
}

\begin{abstract}
Objective: To describe Dutch midwives' attitudes toward, and motivations for, the promotion of physiological childbirth and to identify factors associated with those attitudes and motivations.
\end{abstract}

Design: Exploratory, qualitative design using focus groups

\section{Setting: The Netherlands}

Participants: Hospital- and community-based midwives

Findings: Four themes emerged: Physiological birth as a continuum, navigating the settings, woman-centeredness and competence and confidence.

Midwives view the safeguarding and promotion of physiological childbirth as central to their role. They define physiological childbirth along a continuum that is related to the context of their practice. Hospital culture is seen as an inhibitor of practices that promote physiological birth.

Midwives believe that woman-centered ways of working and challenging practices that are not evidence-based will promote physiological childbirth.

Key conclusions: In order to become competent and confident practitioners of physiological childbirth midwives need to be aware of the factors that inhibit and encourage practices that support this way of giving birth.

Implications for practice: Midwives should consciously employ strategies that promote physiological birth in both home and hospital settings. Midwifery education and midwifery science research should focus on developing strategies that support midwives in this endeavor.

Keywords: physiological childbirth, home, hospital, women-centeredness, competence, confidence 
Exploring Dutch midwives' attitudes to promoting physiological childbirth: A qualitative study |

\section{Introduction}

In high-income countries, one of the great public health achievements of the 20th century was the dramatic improvements in the health of pregnant women and their babies. Developments included the availability of antibiotics, greater access to health care and technological advances in perinatal medicine, all of which contributed to safer births. ${ }^{1}$ In Europe, in particular, improvements were as a consequence of the development and accessibility of midwifery techniques ${ }^{2}$ together with active national strategies for the training of midwives. ${ }^{3}$

Medicalisation of childbirth is a phenomenon in all high income countries ${ }^{4}$ despite, evidence demonstrating that routine intervention in the birthing process creates iatrogenic harm to women and babies ${ }^{5}$ and adds substantial economic costs to health care systems. ${ }^{6}$

More recently both women and midwives criticized the medicalisation of childbirth, rejecting unnecessary interventions ${ }^{7,8}$ and encouraging a view of birth as a physiological, life event. Contemporary evidence supports the physiological approach to birth as an optimal means to improve the health of women and their babies.? Moreover, midwifery-led models of care are associated with both fewer medical interventions and increased satisfaction with the birthing experience. ${ }^{10}$

In most industrialized countries, the pervasive obstetric argument for the safety and efficacy of hospital birth was coupled with the devaluation of domiciliary midwifery services. ${ }^{11}$ The Netherlands, on the other hand, maintained a system in which community-based midwifery played a dominant and essential role ${ }^{12}$ and where home birth remains an accepted and well-integrated part of the maternity care system. ${ }^{4}$ Maternity care in the Netherlands is based on the principle that pregnancy and childbirth are fundamentally physiological processes. Independent midwives provide care to healthy women with uncomplicated pregnancies, referred to as midwife-led care. Midwives refer women to obstetrician-led care when there are complications or an increased risk of complications, as defined by the List of Obstetric Indications, a national guideline developed cooperatively by all the professions involved in maternity care. ${ }^{13}$

Whilst there is increasing consensus on the effectiveness of midwifery care ${ }^{9}$ 10, 14 and the strengthening of midwifery internationally, ${ }^{14}$ the Dutch system of midwifery care is changing. There has been a shift in the birth culture, with increasing numbers of women opting for hospital birth. ${ }^{15}$ This is possibly the result of concerns about seemingly high levels of perinatal mortality at home compared to the 


\section{| Chapter 2}

hospital. ${ }^{16}$ Following the publication of this report, subsequent media attention linked the seemingly high levels of perinatal mortality with the way in which midwifery care is organized. ${ }^{17}$ Research has demonstrated a considerable rise in the rate of intrapartum referrals from midwifery to obstetrician-led care, without significant improvement in perinatal safety. ${ }^{18}$ As a result of this transfer of care, women who begin labour in midwife-led primary care are experiencing increased use ofobstetric interventions. ${ }^{19}$ Interestingly, there is a wide variation in the rate of referrals between midwifery practices, predominantly among non-urgent referrals during the intrapartum period, with rates varying between 9.7 and $63.7 \%$. This variation cannot be explained by maternal characteristics alone: it is clear that factors relating to the way in which midwives practice play a significant role. Differences in management of the first stage of labour, the use of non-supine birthing positions or regional hospital policy may be influencing factors..$^{20}$ Another factor is the perception of risk among midwives. ${ }^{21}$ Offerhaus et al. ${ }^{21}$ found that midwives have a tendency to over-estimate the likelihood of risk and under-estimate the probability of a spontaneous vaginal birth.

The experience of physiological childbirth can be life changing for women, ${ }^{22}$ and the midwife is a powerful facilitator for the provision of empowering, woman-centered care. ${ }^{23}$ Dutch midwives have a role to play in creating and strengthening opportunities for physiological childbirth, but they are not always aware of, or choose not to use, strategies that promote physiological birth outcomes. ${ }^{20}$

In this study, we explore Dutch midwives' attitudes and motives with regard to promoting physiological childbirth and identify the factors that encourage or inhibit this.

\section{Methods}

\section{Design}

We used focus groups to explore midwives' attitudes regarding promoting physiological childbirth, asking participants to reflect on the factors that encourage and inhibit practices that promote physiological birth. In order to focus our discussion, we asked participants about their use of non-supine birthing positions as an exemplar of a physiological approach to care. 
Exploring Dutch midwives' attitudes to promoting physiological childbirth: A qualitative study |

\section{Setting and participants}

We initially held focus group discussions with three groups of hospital-based midwives (H-B, n=14) in late 2013. On the basis of the findings from the first three focus groups, we subsequently decided to extend the research to include community midwives, thus reflecting both work settings of midwives in the Netherlands. Four focus groups were conducted with community-based midwives (C-B, n=23) in early 2015.

In the Dutch maternity care system, hospital-based midwives are salaried employees whilst community midwives are self-employed and work independently in small, group practices. The seven groups were homogenous in terms of their work setting but were mixed in terms of age, work experience and educational background (see table 1). The focus groups ranged in size from three to nine participants, adequate to ensure discussion. ${ }^{24}$ Written informed consent was obtained and ethical approval was granted (Atrium-Orbis-Zuyd number 13-N-34).

\section{Data collection}

We used the Attitude, Subjective Norms and (self) Efficacy (ASE) model ${ }^{25}$ to create a semi-structured focus group script. This model offers a framework for exploring how attitudes, norms and self-efficacy facilitate or inhibit new behaviour. The script was pilot-tested on a group of midwifery lecturers to confirm clarity and open-endedness of the questions. Using their feedback, we made minor edits to the script.

The focus groups lasted between 65 and 90 minutes. The discussions were audio recorded and transcribed verbatim by the first author. Transcripts were checked against audio-recordings for accuracy. Participants were assigned a pseudonym in order to maintain anonymity.

\section{Analysis}

Data analysis was carried out concurrently with data collection, allowing the authors (ST, MN) to reflect upon the viewpoints of participants and learn from them. This led to small modifications of questions or the sequencing of questions in subsequent focus groups. When data collection was complete, we began thematic analysis, as described by Braun and Clarke. ${ }^{26}$ Transcripts were read and re-read in order to become familiar with the data. Following this, the first author attached codes to small segments of the transcripts. Codes were then reviewed by the second author. Themes emerging from the data were identified and these were checked to determine relevance in relation to the data. This was done visually, utilizing thematic networks. ${ }^{27}$ Candidate themes were refined and reviewed, going back to the data to establish coherent patterns ${ }^{26}$ and these were reviewed again by the second author. 


\section{| Chapter 2}

\section{Findings}

Thirty-seven midwives participated in this study. Participants were mixed, in terms of age, years since qualification, and work experience and were trained in the Netherlands, Belgium and the United Kingdom.

\section{Table 1 Characteristics of participants}

\begin{tabular}{|c|c|c|}
\hline Demographic factor & $\begin{array}{l}\text { Hospital-based midwives } \\
\text { (H-B), } n=14) \\
\text { Mean (range) }\end{array}$ & $\begin{array}{l}\text { Community-based } \\
\text { midwives (C-B), } n=23^{*} \text { ) }\end{array}$ \\
\hline Age (years) & $44.5(27-62)$ & $42.8(26-59)$ \\
\hline $\begin{array}{l}\text { Qualification as midwife } \\
\text { (years) }\end{array}$ & $10.7(3-28)$ & $15.4(4-33)$ \\
\hline $\begin{array}{l}\text { Work experience in } \\
\text { present setting (years) }\end{array}$ & $10.7(3-28)$ & $15.4(4-33)$ \\
\hline $\begin{array}{l}\text { Midwifery education } \\
\text { (country) }\end{array}$ & $\begin{array}{l}10 \text { Dutch trained } \\
4 \text { Belgian trained }\end{array}$ & $\begin{array}{ll}13 & \text { Dutch trained } \\
2 & \text { Belgian trained } \\
1 & \text { British trained }\end{array}$ \\
\hline
\end{tabular}

*No demographics recorded for 6 participants

We found four major themes: 1) physiological birth as a continuum, 2) navigating diverse settings: community, transfer and hospital, 3) woman-centeredness, and 4) competence and confidence. We discuss each below.

\section{Physiological childbirth as a continuum}

Midwives' definitions of physiological childbirth were broadly similar, with participants linking it to the natural state and to the absence of complications. Some participants added that the terms physiological childbirth or normal birth, are more complex than they may appear:

Karen (H-B): Defining physiological childbirth...it's a...it seems a simple question but it's actually a complicated question. 
Exploring Dutch midwives' attitudes to promoting physiological childbirth:

A qualitative study |

Interestingly, there was a tendency among the participants to define physiological childbirth by what it was not. It is not pathology or it is the absence of complications or medical intervention. Many found it difficult to define without reference to its opposite: pathology.

Midwives in both community and hospital settings saw their role as protectors and promoters of physiology. One hospital midwife, for example, pointed out that she promoted physiological childbirth by sharing her knowledge with colleagues who are new to the hospital setting:

Rachel (H-B): New people, new doctors, I tell them what physiology

is and that it's not physiological to have a woman on her back, take a deep breath in and push down...

Community midwives assumed similar roles with regard to promoting and safeguarding physiological childbirth. They considered that this seemed to be more achievable for an autonomous midwife attending a home birth in the Netherlands. However, while recognizing that much was possible in the home setting, the possibility of transfer to hospital was something they often considered. Offerhaus et al. ${ }^{18}$ researched the trends in obstetric referrals from midwife-led care among primiparous women $(n=37,166)$ and multiparous women $(n=46,989)$ during labour in the Netherlands. 21,333 primiparous women $(57.4 \%)$ were transferred during labour or the early postpartum period, with the greatest likelihood of transfer occurring in the first stage of labour and for non-urgent reasons - 15,126 women in all (40.7\%). Multiparous women were less likely to be transferred - 10,949 multiparous women $(23.3 \%)$ were transferred to obstetric care, again with the majority of these $-7,753$ women $(16.5 \%)$ in the first stage of labour and for non-urgent reasons, such as requests for pain relief, progress or meconium-stained liquor, etc. ${ }^{13}$ Given the likelihood of transfer, as detailed by Offerhaus et $a 1 .{ }^{18}$ midwives feel it necessary to prepare women for the restrictions of the medical setting in case of transfer to hospital. This was seen as especially true with regard to birthing positions:

Sylvia: It's good to tell them (the client) because otherwise they assume that they (non-supine birthing positions) are possible in hospital when they arent.

The midwives in this study were inclined to contextualize physiological childbirth to their own practice setting. Hospital midwives viewed physiological childbirth as existing along a broad continuum. They illustrated this point by describing cases where some form of obstetric intervention was necessary, such as augmentation of labour, but which could nevertheless be normalized by enhancing the physiological aspects of the case. This open characterization of physiology helps explain why 


\section{| Chapter 2}

Karen, the hospital-based midwife quoted above, found the definition of physiology complicated.

When assigning meaning to the term physiological childbirth, community midwives, also linked physiological childbirth to the setting of their practices:

Angela (C-B): Physiological childbirth? At home, without a load of fuss...

Midwives in both hospital and home settings described working with physiology, in order to realize a physiological childbirth. With reference to birth positioning, the second stage of labour was described as a dynamic process, in which movement and changing positions took place. Most midwives described using some form of non-supine positioning with birthing stools being particularly favoured but squatting and all fours positions also employed. There was variation in the group as to whether the actual birth should take place in a non-supine position, with some midwives choosing to move the woman to a supine position once crowning occurred.

The use of physiological positioning as a means of preventing pathology was a concept common to all participating midwives. Non-supine birthing positions were employed either as a means to stimulate a delayed second stage or as an attempt to avoid instrumental delivery.

Saskia (H-B): Where I used to work, us midwives had the motto that there wouldn't be an instrumental delivery before we'd had the woman pushing upright on a birthing stool.

\section{Navigating the settings: community, transfer and hospital}

Midwifery in the Netherlands is an autonomous profession; midwives are not supervised by physicians or any other health professional. ${ }^{17}$ This autonomy is at odds with the hierarchical and routine-based culture of the hospital, a relatively new setting for midwives. ${ }^{28}$ When speaking of their work in the clinical setting, many of the midwives in our study reported feelings of having to account for their actions, including those associated with promoting physiological childbirth.

In most cases, midwives reported feeling accountable to obstetricians, who, it was felt, are in charge of the hospital setting and were described in terms such as boss or supervisor by hospital midwives. Community midwives were not immune to this. Despite their autonomous position in the home setting, their independence was challenged in the hospital. When transferring clients for obstetric care, commu- 
Exploring Dutch midwives' attitudes to promoting physiological childbirth:

A qualitative study |

nity midwives noted that they are no longer in charge. Some described feelings of inadequacy when faced with the subtleties of the hospital hierarchy, sensing that they lacked the capacity to challenge obstetric practices. A hospital midwife comments:

Ruth (H-B): I'm not good at discussions. And you need to be. But I find it very difficult in the workplace, discussions...

Somewhat unexpectedly, we found that these feelings of accountability extended to obstetric nurses. The obstetric nurse is a traditional part of the Dutch hospital landscape and fulfills nursing duties that midwives in other countries often assume in the hospital setting. Hospital midwives noted that obstetric nurses often need encouragement in supporting women using non-supine birthing positions,

Barbara (H-B): The nurses are trained for intervention, for calamities... their willingness to try anything different is limited.

Midwives noted that nursing routine often took priority, with concerns such as mess or mixed up CTG cables offered as reasons for keeping women in bed in supine positions.

Midwives described a variety of strategies for responding to the medicalized orientation of the hospital setting. In explaining her increased willingness to resist hospital routines, one midwife detailed using evidence-based medicine as a strategy to underpin midwifery practice and challenge non-evidence based ways of working:

Johanna (H-B): I never used to, but now I...I don't believe everything that they say, whereas in the past, I would have been overwhelmed, but now I think: Is that true, what you say? And I say, it sounds interesting, but where did you find this?

Others, however, experienced having to challenge practice as an obstacle. Some midwives had strategies to address this, including choosing the right moment to challenge practices that do not support physiological childbirth. This entailed picking a time for discussions towards the end, rather than at the beginning of a shift, or choosing or avoiding challenging practice, depending on which colleagues were on duty. Other midwives opted to avoid discussion altogether:

Rena (H-B): I find it exhausting, accounting for every step. You know, I'd rather not, so I try and stay as safe as possible by following the guidelines. 


\section{| Chapter 2}

The midwives in this study identified the particular challenges associated with the use of non-supine birthing positions in the hospital. The arrangement of the labour room, with its centrally positioned bed, was often mentioned as a barrier to using non-supine positions. Midwives described this layout as encouraging women to lay down and become patients, surrendering their personal autonomy. Both hospital and community midwives remarked that a shift is needed in the way in which the hospital birth environment is furnished in order to facilitate the use of non-supine birthing positions,

Margaret (C-B): It would make a difference (for out-patient births) if there wasn't $a$ bed in the middle of the room but a Skippy ball or a birthing stool.

The midwives in this study noted that, whilst hospital culture influenced their practice, it was also possible for their practices to influence others. One hospital midwife reported that obstetricians, influenced by midwifery practice, had starting conducting breech births in upright positions. Another hospital midwife described her reaction upon learning of an obstetrician who used a non-supine birthing position:

Mariska (H-B): We had an obstetrician who also used the birthing stool and then I knew...OK, they do that too and I took that on board. So, if I knew she was on duty, then I would act accordingly.

Notice, however, that the midwife tailored her approach based on the obstetrician on duty.

\section{Woman-Centeredness}

Supporting women to trust in the physiological processes of birth and enabling them to make choices about their births was seen as an essential midwifery role and key to promoting physiological childbirth. Hannah (C-B) told us:

I's important that they know they have choices and that we'll support them whichever way, but that they make the choices.

Community midwives in particular described the on-going process of developing trust between themselves and the woman during pregnancy, with the aim of empowering the woman to feel confident in her own ability to give birth.

This process appeared to be reciprocal with one midwife commenting that, by encouraging women to trust in physiological childbirth, she empowered herself 
Exploring Dutch midwives' attitudes to promoting physiological childbirth:

A qualitative study |

to promote it. Most midwives felt that they could do more to enable physiological birth. Hospital midwives, whose remit it is to provide medium- and high-risk maternity care in collaboration with obstetricians, experienced in particular, the conflict of wanting to do more to facilitate physiological birth against the backdrop of the clinical setting,

Helena (H-B): There's a gap between what I'd like to do and what I actually do...in fact, I run from one room to another, from induction to induction...

For community midwives, shared decision-making was considered an important vehicle for ensuring that women are made aware of the choices that may increase the likelihood of physiological childbirth. The increasing use of birth plans was noted to be a useful tool for conducting dialogues with the women around choices in childbirth,

Emma (C-B): We're into shared decision making now: we tell a lot more, more information and of course, the birth plan.

Both hospital and community midwives noted a lack of knowledge among women regarding the use of non-supine birthing positions as a means of achieving a physiological birth. They felt that they often had to persuade or convince women to try these during second stage labour. Others were wary of this, concerned that they may be imposing midwifery philosophy upon women who do not seem oriented towards physiological childbirth. Barbara (H-B) expressed,

... The women just aren't physiological. So you can say that it should be, but the question is, if you're imposing your own views on them.

In some cases, midwives' physical limitations restricted their ability to offer non-supine birthing positions. Back and knee problems or being pregnant themselves, limited midwives, particularly in regard to squatting positions and use of the birthing stool.

\section{Competence and confidence}

Concepts of competence and clinical confidence were identified by most of the midwives as a factor in using or changing positions during the second stage of labour. Lack of either or both of these was associated with not using non-supine birthing positions. Many midwives described the default position for birth as supine and 


\section{| Chapter 2}

noted that, in situations where they feel anxious or feel a need to control the birthing process, they often revert to the supine position:

Angela (C-B): When I feel less confident then I'm inclined to steer towards positions that are easiest for me.

Others noted that, despite a lack of education about, or experience with, non-supine birth, they wanted to be able to offer this. To achieve this, some started by experimenting with non-supine birthing positions, or by asking for help from colleagues.

The freedom to experiment with different birthing positions appeared significant for midwives and this seemed to be associated with working in the community setting, where there is a greater degree of autonomy. However, with the expansion of hospital midwifery in the last few years, more midwives are opting to work in hospitals following graduation, without having practiced in the community first. One midwife expressed concern,

Carina (H-B): Our younger colleagues, they don't dare to do births in different positions. I think, yes, perhaps earlier, I was like that too!

Hospital midwives, particularly the more senior midwives, considered it their role to set an example to their midwifery, nursing and medical colleagues. This was done by using informal teaching opportunities or by having discussions in the ward.

Community midwives, despite their autonomous practice, also considered it important to support colleagues in the use of non-supine birthing positions. They described sharing their enthusiasm with colleagues in the form of inter-colleague supervision, where cases are discussed. Some of the community midwives described looking to colleagues with more experience for support and learning opportunities in order to become competent in using non-supine birthing positions as a means of promoting physiological childbirth.

\section{Discussion}

Midwife-led care, with its focus on the promotion of physiological childbirth may reduce the likelihood of unnecessary intervention in the birth process ${ }^{10}$ and contribute to positive outcomes for women and their babies. ${ }^{14}$ The midwives in this study viewed the protection and promotion of physiological childbirth as central to their role. It was difficult for our participants to give a precise definition of physiological childbirth, reflecting the diversity of definitions in the literature. ${ }^{29}, 30,7,31,32$ 
Exploring Dutch midwives' attitudes to promoting physiological childbirth:

A qualitative study |

Whilst challenging to define, physiological childbirth was inextricably linked to the practice setting. For community midwives, physiological childbirth was linked to home birth and the absence of medical intervention, whilst hospital midwives created a continuum, along which birth could be normalized, following medical intervention. This reflects an approach to birth that takes into account the social, medical and obstetric background of the woman and strives for the best possible outcome with the least amount of intervention. ${ }^{33}$ For the hospital midwives in particular, this approach provides an appropriate framework for the physiological childbirth continuum they described.

Midwives reported that aspects of medical and hospital culture inhibit the promotion of physiological childbirth. Feelings of accountability towards obstetricians, described by the midwives in this study, appeared to be at odds, not only with the autonomy of the community midwife ${ }^{34}$ but also with the skills required by the Dutch hospital midwife. ${ }^{35}$ The midwife-obstetrician relationship can be a place where deep-seated professional rivalry exists. ${ }^{36}$ Moreover, midwives experience both power imbalances and lack of trust on the part of obstetricians in professional interactions, illustrated by feelings of being treated as an inferior partner. ${ }^{37}$ Whilst the role division between midwives and obstetricians in the Dutch homebirth setting is relatively clear ${ }^{34}$, Cronie et al's $\mathrm{s}^{35}$ study is the first that offers insights into the role and sphere of practice of the midwife within the Dutch hospital setting, although they do not describe inter-professional relationships between midwives, obstetricians and nurses in detail. Helmond et a1. ${ }^{38}$ described the concepts of good collaboration between maternity care professionals, citing expertise, partnership, context, attitude, trust and communication styles as explicit and implicit pre-requisites to positive collaboration. The feelings of accountability that the midwives in this study described, in particular with regard to obstetricians, appear contrary to some of the aspects of positive collaboration, in particular concepts of partnership and trust.

The midwives in this study felt that high workloads were inhibitive of practices that promote physiological birth. Whilst the standard caseload for Dutch midwives has decreased, ${ }^{39}$ midwives report experiencing high workloads, particularly non-client related work. Reductions in this area would free up more time to devote to the needs of the individual client, ${ }^{40}$ including interventions that promote physiological birth.

Surprisingly, the relationship between midwives and obstetric nurses emerged as an area of difficulty for some midwives Kennedy \& Lyndon ${ }^{41}$ described the midwife-nurse relationship, noting philosophical differences between the two professions. These differences appeared rooted in cultural and structural differences between these two groups. Culturally, nurses seemed more inclined to frame birth 


\section{| Chapter 2}

as a risky event requiring medical interventions, ${ }^{42}$ perhaps because of their exposure to births only in medical settings. ${ }^{41}$ Structurally, there is a significant difference in the professional autonomy of nurses and midwives, ${ }^{41}$ which influences their accountability in the hospital hierarchy.

The hospital birth environment was described by our participants as inhibitive for non-supine birth, reflecting findings elsewhere in the literature. ${ }^{43}$ The bed, a potent symbol of medicalisation ${ }^{44}$ was associated with advancements in medical knowledge ${ }^{45}$ and historical male dominance in obstetrics. ${ }^{44}$ Foureur et al..$^{46}$ noted that the design and layout of the birth setting have ramifications for the behaviour of both women and midwives, a finding echoed by the midwives in our study.

The midwives in this study described some of the strategies they used to facilitate physiological childbirth in both the home and hospital settings. Community midwives in particular described how they used shared decision-making during pregnancy and birth to empower women. Central to this empowerment is the development of a trustful relationship. ${ }^{47}$ The midwives in this study described this relationship and indicated its' importance in enabling women to make choices in birth care. Working in partnership with women to promote physiological birth is a key component of midwifery practice and is set out as such in the internationally accepted definition of a midwife. ${ }^{48}$

Charles et al. ${ }^{49}$ pointed out that the principle of shared decision-making developed in reaction to the paternalistic approach towards the provision of health care. In a concept analysis ${ }^{50}$ they defined shared decision-making as a process involving both caregiver and client, where both parties participate in a decision-making process, based on information-sharing and resulting in decisions about treatment or care that both parties agree on. This definition demonstrated that there is more to shared decision-making than telling or offering more information. As a strategy for promoting physiological childbirth, more needs to be done by midwives. In their study of birthing positions, Nieuwenhuijze et al. ${ }^{51}$ suggested that midwives appear to play a minor role in offering women information about non-supine positions during antenatal care and making them aware of the options available. It was in the antenatal classes where women get their information. During birth women who preferred non-supine positions were less likely to use these preferred positions then women who preferred supine positions.

Whilst the evidence suggests that a majority of women want to give birth as naturally as possible, without unnecessary medical intervention, ${ }^{52}$ some of the midwives in our study expressed concerns about imposing physiological childbirth on women It is possible that these concerns stem from the way in which midwives cognitively 
Exploring Dutch midwives' attitudes to promoting physiological childbirth:

A qualitative study |

frame, or think about physiological birth. Regan and Liaschenko, ${ }^{42}$ in a study of obstetric nurses, described three cognitive frames: birth as a natural process, a lurking risk and a risky process. Whilst the cognitive framing of birth as a natural process appears to be a concept match with midwifery philosophy, it is possible that the practice setting and the culture within that setting influence midwifery framing, particularly given the risk narrative over the last half century, ${ }^{11}$ leading to midwives viewing childbirth as a lurking risk, rather than an inherently natural process. Recent findings about risk perception by midwives ${ }^{21}$ corroborate this.

An important finding of this study is the relationship between the ability to facilitate physiological childbirth and the clinical competence and confidence of the midwife. We found that midwives who felt they were lacking in clinical competence and confidence were less likely to utilize non-supine birthing positions as a means of promoting physiological childbirth. Page and Mander ${ }^{53}$ highlight the dichotomy between medicalized and physiological birth and note that experience - which promotes competence and confidence - allows midwives to cope more effectively with the uncertainties of physiological childbirth. The midwives in this study, who associated the autonomous community setting with opportunities to experiment with and become confident in facilitating physiological childbirth, confirmed Page and Mander's finding. Elsewhere, it is reported that experienced midwives are more likely to use supine, rather than non-supine positions, ${ }^{45}$ contrary to what is indicated by our study. It is unclear why these findings differ, although it is possible that the differences in practice setting - the majority of midwives in the UK work in hospital settings, so may never have experienced the space to experiment - may account for this.

Experienced midwives can make an important contribution in supporting less experienced colleagues in becoming confident practitioners of physiological birth. Role modeling is an important aspect of learning and autonomous practitioners can be appropriate and influential role models, ${ }^{54}$ providing that the approach to care is consistent with the midwifery philosophy of care. ${ }^{55}$ Unlike many other countries, the Netherlands does not have a formal system of mentorship for new graduates to midwifery, due in part, both to the strong focus in midwifery education on autonomous practice ${ }^{17}$ and the relatively recent expansion of Dutch midwifery into the hospital setting. ${ }^{28}$ Informal mentorship for inexperienced midwives could be beneficial for the development of professional confidence.

This study has a number of strengths. The focus group method was an appropriate method for investigation of midwifery attitudes towards promoting physiological childbirth. Attention was paid to the auditability of the findings, with a reflective journal being kept by the first author and all key decisions during data collection and analysis being peer reviewed by the second author (MN). A limitation of the study 


\section{| Chapter 2}

is the self-selection of the study participants. It may be that the participants had an affinity with the subject matter, making them potentially less representative of the midwifery population as a whole.

Our research has a number of important implications for midwifery practice. Most important is the need for a proactive approach towards promoting physiological childbirth in both community and hospital settings in the Netherlands in particular and in other developed countries as well. Midwives in this study expressed awareness and concern about the impact of the hospital setting on physiological approaches to childbirth. The challenge for midwives is to find ways to use strategies to support women regardless of setting, enabling them to facilitate, rather than manipulate physiological childbirth. ${ }^{44}$

Meeting this challenge will require that midwives develop the competence and confidence necessary to support and promote physiological birth, including not only midwifery skills, but the ability to effectively challenge non-evidence-based care. Experienced midwives must become role models for less experienced colleagues, helping them to find ways to champion physiological childbirth effectively. Midwifery education must have at its core an ethos of normality 32 that includes the cognitive framing of birth as a natural process. In addition, students need to understand how the hospital setting influences both the birthing woman and the midwife. Teaching midwives about the impact of the hospital setting - and the subtle and not-so-subtle hierarchies within it - will ensure that midwives are effectively equipped to promote physiological birth regardless of where they choose to work after graduation. Finally, programmes should embrace the teaching of strategies that enable and empower midwives, giving them the ability to influence the practices of their nursing and obstetric colleagues. Inter-professional education is one such strategy, allowing future midwives, nurses and obstetricians to share both learning and discussion opportunities thereby encouraging the fostering of equitable relationships with colleagues in birth care. Whilst there is promising research about the benefits of midwife-obstetrician collaboration, ${ }^{38}$ further research is necessary if we are to develop strategies for strengthening the ability of midwives to promote physiological childbirth irrespective of the place of birth.

\section{References}

1. Centers for Disease Control and Prevention. Ten great public health achievements--United States, 1900-1999. MMWR Morb Mortal Wkly Rep. 1999;48(12):241-3.

2. De Brouwere V, De Brouwere V, Tonglet R, Van Lerberghe W. Strategies for reducing maternal mortality in developing countries: what can we learn from the history of the industrialized West? Tropical Medicine \& International Health. 1998;3(10):771-82. 
Exploring Dutch midwives' attitudes to promoting physiological childbirth:

A qualitative study |

3. De Brouwere VvL, W. Safe Motherhood strategies: A review of the evidence. Studies in Health Services Organization and Policy [Internet]. 2001; 17

4. Christiaens W, Nieuwenhuijze MJ, de Vries R. Trends in the medicalization of childbirth in Flanders and the Netherlands. Midwifery. 2013;29(1):e1-e8.

5. Requejo J, Victora C, Bryce J. Data Resource Profile: Countdown to 2015: Maternal, New born and Child Survival. International Journal of Epidemiology. 2014; 43(2):586-96.

6. McIntyre MJ, Chapman Y, Francis K. Hidden costs associated with the universal application of risk management in maternity care. Australian Health Review. 2011; 35(2):211-5.

7. Maternity Care Working Party. Making normal birth a reality: Consensus statement from the Maternity Care Working Party. 2007.

8. American College of Nurse-Midwives. Supporting healthy and safe physiologic birth: A consensus statement by ACNM, MANA and NAPCM. Journal of Midwifery and Women's Health [Internet]. 2012; 57:[529-32 pp.].

9. Renfrew MJ, McFadden A, Bastos MH, Campbell J, Channon AA, Cheung NF, et al. Midwifery and quality care: findings from a new evidence-informed framework for maternal and newborn care. The Lancet. 2014;384(9948):1129-45.

10. Sandall J, Soltani H, Gates S, Shennan A, Devane D. Midwife-led continuity models versus other models of care for childbearing women. Cochrane Database of Systematic Reviews. 2016(4).

11. Cahill HA. Male appropriation and medicalization of childbirth: An historical analysis. Journal of Advanced Nursing. 2001;33(3):334-42.

12. De Vries R. A Pleasing Birth: Midwives and Maternity Care in the Netherlands: Temple University Press; 2005.

13. Zorgverzekeringen CVvhCv. Verloskundig Vademecum 2003.

14. ten Hoope-Bender P, de Bernis L, Campbell J, Downe S, Fauveau V, Fogstad H, et al. Improvement of maternal and newborn health through midwifery. The Lancet. 2014;384(9949):1226-35.

15. Centraal Bureau voor de Statistiek. Drie Quart Bevallingen in het Ziekenhuis. 2011.

16. European Perinatal Health Report [Internet]. 2004. Available from: http://www.europeristat.com.

17. De Vries R, Nieuwenhuijze M, Buitendijk SE. What does it take to have a strong and independent profession of midwifery? Lessons from the Netherlands. Midwifery. 2013;29(10):1122-8.

18. Offerhaus PM, Hukkelhoven CWPM, de Jonge A, van der Pal-de Bruin KM, Scheepers PLH, Lagro-Janssen ALM. Persisting Rise in Referrals During Labor in Primary Midwife-led Care in The Netherlands. Birth. 2013;40(3):192-201.

19. Offerhaus PM, de Jonge A, van der Pal-de Bruin KM, Hukkelhoven CWPM, Scheepers PLH, Lagro-Janssen ALM. Change in primary midwife-led care in the Netherlands in 2000-2008: A descriptive study of caesarean sections and other interventions among 789,795 low risk births. Midwifery. 2014;30(5):560-6.

20. Offerhaus PM, Geerts C, de Jonge A, Hukkelhoven CWPM, Twisk JWR, Lagro-Janssen ALM. Variation in referrals to secondary obstetrician-led care among 


\section{| Chapter 2}

primary midwifery care practices in the Netherlands: a nationwide cohort study. BMC Pregnancy and Childbirth. 2015;15(1):42.

21. Offerhaus PM, Otten W, Boxem-Tiemessen JCG, de Jonge A, van der Pal-de Bruin KM, Scheepers PLH, et al. Variation in intrapartum referral rates in primary midwifery care in the Netherlands: A discrete choice experiment. Midwifery. 2015;31(4):e69-e78.

22. Humenick SS. The Life-Changing Significance of Normal Birth. J Perinat Educ. 2006;15(4):1-3.

23. Kennedy HP. The Midwife as an "Instrument" of Care. American Journal of Public Health. 2002;92(11):1759-60.

24. Morgan D. Planning Focus Groups. Morgan DK, RA, editor: Sage Publications Inc.; 1998.

25. de Vries H, Dijkstra M, Kuhlman P. Self-efficacy. the third factor besides attitude and subjective norm as a predictor of behavioural intentions. Health Education Research. 1988;3(3):273-82.

26. Braun V, Clarke V. Using thematic analysis in psychology. Qualitative Research in Psychology. 2006;3(2):77-101.

27. Attride-Stirling J, Humphrey C, Tennison B, Cornwell J. Gathering data for health care regulation: learning from experience in England and Wales. J Health Serv Res Policy. 2006;11(4):202-10.

28. van Hassell DTP KA, Kenens RJ. Cijfers uit de registratie van verloskundigen, peiling 2013. Utrecht: Nederlands instituut voor onderzoek van de gezondheid; 2014.

29. Organization WH. Care in normal birth: A practical guide. Geneva: Department of reproductive health and reseach; 1997.

30. Gould D. Normal labour: a concept analysis. Journal of Advanced Nursing. 2000;31(2):418-27.

31. Downe S. From being to becoming: Reconstructing childbirth knowledge. In: Normal Childbirth: Evidence and debate. Edinburgh London New York: Churchill Livingstone Elsevier, 2004.

32. Kennedy HP, Grant J, Walton C, Shaw-Battista J, Sandall J. Normalizing Birth in England: A Qualitative Study. Journal of Midwifery \& Women’s Health. 2010;55(3):262-9.

33. Kennedy HP. A Concept Analysis of Optimality in Perinatal Health. Journal of Obstetric, Gynecologic \& Neonatal Nursing. 2006;35(6):763-9.

34. Amelink-Verburg MP, Buitendijk SE. Pregnancy and labour in the Dutch maternity care system: what is normal? The role division between midwives and obstetricians. J Midwifery Womens Health. 2010;55(3):216-25.

35. Cronie D, Rijnders M, Buitendijk S. Diversity in the Scope and Practice of Hospital-Based Midwives in the Netherlands. Journal of Midwifery \& Women’s Health. 2012;57(5):469-75.

36. Reiger KM, Lane KL. Working together. collaboration between midwives and doctors in public hospitals. Australian Health Review. 2009;33(2):315-24.

37. van der Lee N, Driessen EW, Scheele F. How the past influences interprofessional collaboration between obstetricians and midwives in the Netherlands: Findings from a secondary analysis. Journal of Interprofessional Care. 2016;30(1):71-6.

38. Helmond I, Korstiens I, Mesman J, Nieuwenhuijze M, Horstman K, Scheepers H, et al. What Makes for Good Collaboration and Communication in Maternity Care? 
Exploring Dutch midwives' attitudes to promoting physiological childbirth:

A qualitative study |

A Scoping Study. International Journal of Childbirth. 2015;5:210-23.

39. Wiegers TA, Warmelink JC, Spelten ER, Klomp T, Hutton EK. Work and workload of Dutch primary care midwives in 2010. Midwifery. 2014;30(9):991-7.

40. Warmelink JC, Hoijtink K, Noppers M, Wiegers TA, de Cock TP, Klomp T, et al. An explorative study of factors contributing to the job satisfaction of primary care midwives. Midwifery. 2015;31(4):482-8.

41. Kennedy HP, Lyndon A. Tensions and Teamwork in Nursing and Midwifery Relationships. Journal of Obstetric, Gynecologic \& Neonatal Nursing. 2008;37(4):426-35.

42. Regan M, Liaschenko J. In the Mind of the Beholder: Hypothesized Effect of Intrapartum Nurses' Cognitive Frames of Childbirth Cesarean Section Rates. Qualitative Health Research. 2007;17(5):612-24.

43. Priddis H, Dahlen H, Schmied V. Juggling Instinct and Fear: An Ethnographic Study of Facilitators and Inhibitors of Physiological Birth Positioning in Two Different Birth Settings. International Journal of Childbirth. 2011;1(4):227-41.

44. Walsh D. Evidence and skills for normal labour and birth, A guide for midwives. 2nd ed. London New York: Routledge; 2012.

45. Coppen, R. Birthing Positions: Do midwives know best? London: Quay Books; 2005.

46. Foureur M, Davis D, Fenwick J, Leap N, Iedema R, Forbes I, et al. The relationship between birth unit design and safe, satisfying birth: Developing a hypothetical model. Midwifery. 2010;26(5):520-5.

47. Hermansson E, Mårtensson L. Empowerment in the midwifery context—a concept analysis. Midwifery. 2011;27(6):811-6.

48. International Confederation of Midwives. International Definition of the Midwife. Core Document. The Hague. 2017.

49. Charles C, Gafni A, Whelan T. Decision-making in the physician-patient encounter: revisiting the shared treatment decision-making model. Social Science \& Medicine. 1999;49(5):651-61.

50. Charles C, Gafni A, Whelan T. Shared decision-making in the medical encounter: What does it mean? (or it takes at least two to tango). Social Science \& Medicine. 1997;44(5):681-92.

51. Nieuwenhuijze M, Jonge Ad, Korstjens I, Lagro-Jansse T. Factors influencing the fulfillment of women's preferences for birthing positions during second stage of labor. Journal of Psychosomatic Obstetrics \& Gynecology. 2012;33(1):25-31.

52. Kringeland T, Daltveit AK, Møller A. What characterizes women who want to give birth as naturally as possible without painkillers or intervention? Sexual \& Reproductive Healthcare. 2010;1(1):21-6.

53. Page M, Mander R. Intrapartum uncertainty: A feature of normal birth, as experienced by midwives in Scotland. Midwifery. 2014;30(1):28-35.

54. Bluff R, Holloway I. The efficacy of midwifery role models. Midwifery. 2008;24(3):301-9.

55. Lange G, Kennedy HP. Student Perceptions of Ideal and Actual Midwifery Practice. Journal of Midwifery \& Women's Health. 2006;51(2):71-7. 


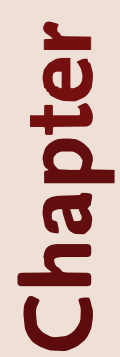

SM Thompson

MJ Nieuwenhuijze

L Kane Low

$\mathrm{R}$ de Vries

Women and Birth, 2019, 32(6): e576-e583 


\section{"A Powerful Midwifery Vision"}

Dutch Student Midwives' Educational Needs as Advocates of Physiological Childbirth

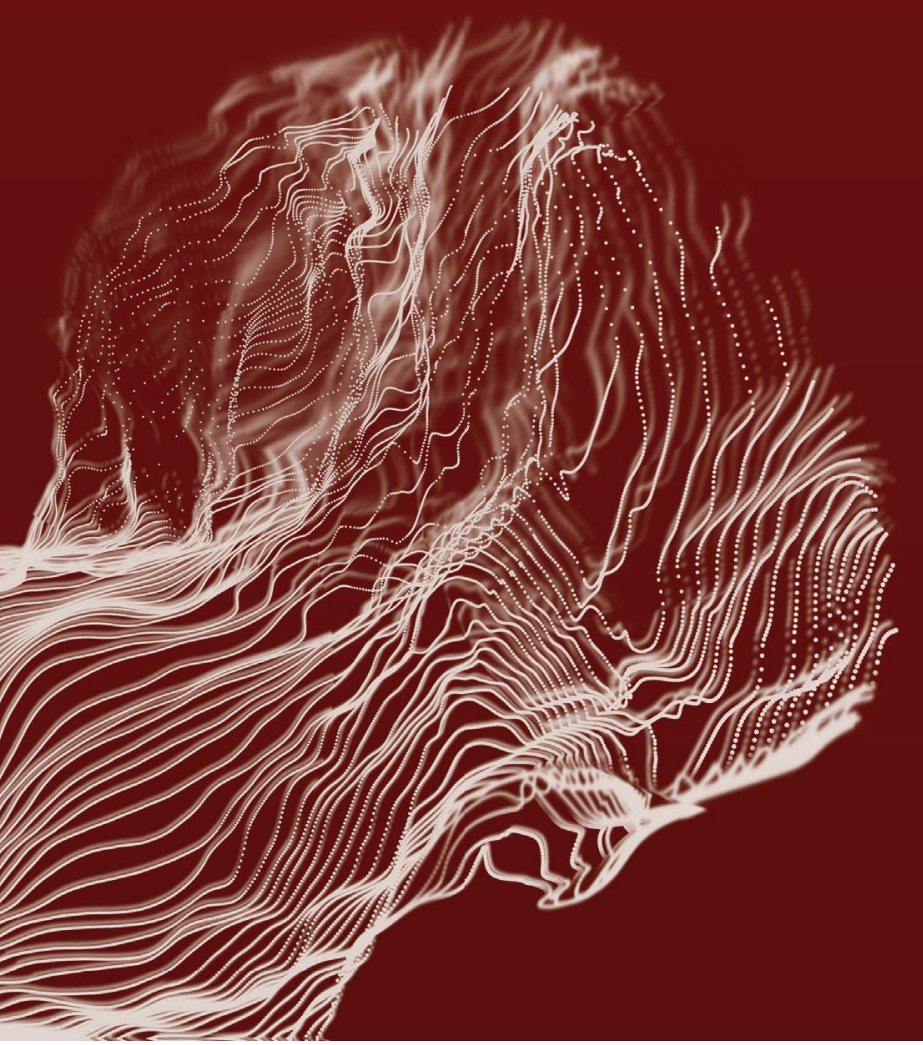




\section{| Chapter 3}

\section{Abstract}

\section{Background}

In order to internalize the midwifery philosophy of care and to learn how to advocate for physiological childbirth, student midwives in the Netherlands need learning experiences that expose them to physiological childbirth practices. Increased hospital births, wide variation in non-urgent referrals and escalating interventions impact on learning opportunities for physiological childbirth. Midwifery educators need to find ways to support student agency in becoming advocates of physiological childbirth.

\section{Objective}

To gather students' opinions of what they need to become advocates of physiological childbirth.

\section{Methods}

Focus groups with student midwives ( $n=37)$, examining attitudes regarding what educational programmes must do to support physiological childbirth advocacy.

\section{Results}

Students reported feelings of personal power when the midwifery philosophy of care is internalized and expressed in practice. Students also identified dilemmas associated with supporting woman-centred care and promoting physiological childbirth. Perceived hierarchy in clinical settings causes difficulties, leading students to practice in accordance with the norms of midwife preceptors. Students are supported in the internalization and realization of the midwifery philosophy of care, including physiological childbirth, if they are exposed to positive examples of care in practice and have opportunities to discuss and reflect on these in the classroom.

\section{Key conclusion}

Midwifery education should focus on strategies that include navigating dilemmas in practice and helping students to express the midwifery philosophy of care in communication with other professionals and with women. Preceptors need to be supported in allowing student midwives opportunities to realize the midwifery philosophy of care, also when this differs from preceptor practice.

Key words: Physiological childbirth; student midwives; midwifery philosophy of care; power; collaboration; role models. 


\section{Statement of significance}

\section{Problem or issue}

Medicalisation of childbirth reduces student midwife exposure to physiological childbirth and may affect agency to advocate for physiological childbirth.

\section{What is already known}

Lack of exposure to physiological childbirth causes difficulties for students to internalize and work according to the midwifery philosophy of care.

\section{What this paper adds}

Internalizing and expressing the midwifery philosophy of care allows students to feel powerful and students need positive role models.

\section{Implications for practice}

Preceptors need to be supported in allowing students opportunities to realize a midwifery philosophy of care, also when this differs from preceptor practice. 


\section{| Chapter 3}

\section{Introduction}

In the Netherlands, midwives in primary care are responsible for care provision to healthy women with uncomplicated pregnancies. They refer women to obstetrician-led care (secondary care) when there are complications or an increased risk of complications. ${ }^{1}$ Increasingly, midwives are also working in hospitals under the supervision of obstetricians, where they care for the majority of women, including women who have been referred because of complications in pregnancy or birth. ${ }^{2}$ The education of midwives in the Netherlands follows a four-year, direct-entry Bachelor of Science programme. Graduation from this allows admittance to the professional register (BIG register). Approximately half of the curriculum is comprised of clinical placements in communities or hospitals throughout the country, where students are supervised by preceptors who are registered midwives.

The midwifery philosophy of care ${ }^{1,3}$ advocates physiological childbirth and Dutch midwives in all settings consider a physiological approach to childbirth as fundamental to their role. ${ }^{4}$ However, this perspective appears at odds with quantitative studies from the Netherlands that demonstrate increasing numbers of non-urgent referrals to obstetric-led care in the intrapartum period and a wide diversity in referral rates between midwifery practices, varying between 9.7 and $63.7 \% .^{5}$ There is also wide variation in specific areas of midwifery practice, including large differences in the use of episiotomy between primary care midwives. ${ }^{6}$ It is unlikely that the variation in practice is the result of different population characteristics; it is more likely that the observed variation is caused by differences in midwife perceptions of the probability of adverse events in birth ${ }^{7}$ and variation in habitual patterns of practice.

At present, the Dutch midwifery system is moving towards an integrated model of care. ${ }^{8}$ This model includes an extended remit for midwives to provide care to women defined as low and medium risk. While rates of obstetric interventions, e.g. caesarean section, in the Netherlands remain low compared to other industrialized countries, ${ }^{9}$ there is concern among midwives and others that an integrated model of care may lead to more interventions ${ }^{10}$ increasing the cost of care and introducing the possibility of harm to the health and well-being of women and their babies. ${ }^{10,11}$

Changes to the maternity care system inevitably impact on the way in which Dutch midwives are educated. Midwifery curricula have been optimized in order to reflect the extended remit of the midwife within an integrated model of care. Evidence suggests that students entering midwifery programmes are motivated to do so from feelings of altruism and the desire to 'support and empower' women and safeguard the birth experience by promoting physiological birth and reducing unnecessary 
medical interventions. ${ }^{12}$ Learning a new profession involves cognitive and affective processes - the acquisition of knowledge and skills and the acceptance of a set of professional values and beliefs. ${ }^{13}$ For student midwives, part of professional socialization involves internalizing, or value embodiment, of a set of professional beliefs ${ }^{14}$ - the midwifery philosophy of care, including the promotion of physiological childbirth. The opportunity to observe 'hallmark midwifery behaviour, such as non-intervention in the birth process in the absence of pathology, is significantly associated with student self-efficacy in assuming such behaviours themselves. ${ }^{15}$ When asked to describe what constitutes a 'good midwife', Dutch student midwives point to the importance of a physiological approach to birth and the avoidance of unnecessary interventions. ${ }^{16}$

While midwifery education may address the importance of midwifery support for physiological childbirth ${ }^{17}$ learning in real-life practice situations is likely to be more relevant to the student midwife than theory-based learning ${ }^{13}$ in the classroom. The discrepancy between theory and practical learning (theory-practice gap) is described by Meyer, Argryis and Schön as the difference between loyalty to a set of beliefs (theory) and loyalty to the actual values reflected in professional practice (theory in use). They also note that gaps between theory and practice are linked to decreases in both professional power and the self-esteem of the learner. ${ }^{18}$

Midwives provide effective, safe maternal and perinatal care which promotes health and well-being. ${ }^{19,} 20$ However, it is important that there is balance between care that is neither 'too much too soon' or 'too little too late'. ${ }^{20}$ It is, therefore, imperative to educate midwives to be competent and confident in employing strategies that support physiological childbirth for the women in their care. Midwifery education should develop strategies that encompass both classroom and practical learning and that develop and support self-efficacious behaviour, principally in clinical settings. Successful development of an educational programme that can do this must include the views of learners themselves, in this case, student midwives. 


\section{| Chapter 3}

\section{Methods}

We conducted a qualitative study in the Netherlands between May and October 2017 exploring Dutch student midwives' attitudes and motives with regard to promoting physiological childbirth and what they feel they need from educational programmes in order to effectively fulfil this role.

\section{Design}

We used focus groups to collect data on student midwives' attitudes toward physiological childbirth, asking them to reflect upon discrepancies between midwifery in the classroom and the realities of practice and to describe their strategies for dealing with 'practice-theory gaps'. In addition, we asked them to consider what must be done in order to promote their competencies as practitioners of physiological childbirth.

\section{Setting and participants}

Following permission from the managers of the three midwifery programmes in the Netherlands, we approached fourth year student midwives by e-mail, with written information about our study and an invitation to participate. We conducted five focus groups: two in Maastricht, and one each in in Rotterdam, Groningen and Amsterdam.

The study was reviewed and approved by the Zuyderland Zuyd ethics committee (17-N-27).

\section{Data collection and analysis}

We used the Attitude, Subjective Norms and (self) Efficacy (ASE) model ${ }^{22}$ to frame questions for the creation of a semi-structured focus group topic list. The ASE model is a useful theoretical framework for exploring how attitudes, norms, and self-efficacy facilitate or inhibit new behaviour. The topic list (table 1) was pilot-tested on a group of fourth year student midwives to confirm both clarity and open-endedness of the questions. The first author, an experienced interviewer, conducted the focus groups, while the second author or another researcher was present to observe and make field notes.

Each focus group lasted between 65 and 90 minutes. The discussions were audio-recorded and transcribed verbatim. Transcripts were checked against audio recordings 
for accuracy. Participants were assigned a pseudonym in order to preserve confidentiality. Informal member checks, in which input was summarized and checked with participants, were conducted at the close of each focus group.

Data collection and analysis were concurrent, allowing for reflection on the viewpoints of the participants. Data were analysed using thematic analysis ${ }^{23}$ supported by NVivo. Transcripts were read and re-read in order to facilitate deep engagement with the data. Following this, the first author attached codes to small segments of the transcripts. Codes were then reviewed by the second author. Themes emerging from the data were identified and these were checked to determine relevance in relation to the data.

This was done visually, utilizing thematic networks. ${ }^{24}$ Candidate themes were refined and reviewed, going back to the data to establish coherent patterns and these were reviewed again by the second author in order to ensure confirmability of findings. Quotes illustrating the themes were identified and given a pseudonym.

\section{Table 1: Topic List}

What does the term 'physiological childbirth mean to you?

A midwifery role that is described nationally and internationally is the support and promotion of physiological childbirth: When you think about this, how do you feel that midwifery education prepares you for this?

Do you see examples of physiological birth practices around you?

What examples are these?

Do you feel that the theory aspects of midwifery training offer enough focus on knowledge and skills for promoting physiological childbirth?

Do you make use of scientific evidence to help you support and promote physiological birth? Is it readily available for you and do you feel able to use it?

How about clinical placements? Which role models are there and what do these role models do to let you see how physiological childbirth can be supported and promoted? 


\section{| Chapter 3}

When you are attached to clinical settings (either community or hospital) how do you promote and support physiological childbirth?

Can you describe situations where you wanted to do more to promote physiological childbirth but were unable to do so?

Can you describe factors that might encourage you to promote physiological childbirth whilst you are in clinical settings?

What can be learning strategies that prepare you for your role in physiological childbirth?

\section{Findings}

E-mails were sent to 160 student midwives in their fourth year of academic study. Thirty-seven student midwives participated in this study (response rate 23\%). All were in their fourth year of academic study. Participants were recruited from each of the three midwifery programmes in the Netherlands. While each programme determines its own study route, the end-competencies are identical, and fourth year students will have had similar educational experiences, in both education in the classroom and in practice. All participants were female, aged between 20 and 25 .

Three major themes emerged from our data: 'Personal power', 'Gaining a voice', and 'Learning by example'.

\section{Personal power}

Students in our study indicated that being able to internalize the midwifery philosophy of care that encompassed a physiological approach to childbirth, and develop a personal approach to realizing this, was associated with feelings of growing personal power as a practitioner of physiological childbirth. This process occurred as a result of experiences during midwifery education. Being allowed the learning opportunity to develop a personal approach and provide midwifery care in accordance with the midwifery philosophy of care was considered important in developing as a midwife.

... if I really want to stand up for something, then I need to be able to do it for myself... (Jeanne). 
The midwifery philosophy of care was apparent in the way students discussed their approaches to the profession of midwifery. While they found it challenging to define physiological childbirth, reverting to 'absence' rather than 'presence' terms such as 'low risk' and 'absence of complications', they described scenarios in which they were able to observe the woman and the progress of labour, as an advocate of physiological childbirth,

... (keeping your) eyes on the woman and not on the things around her. Other things: sitting quietly, observing her...the focus on her. Where you don't do anything, that you 'guard' that it (the birth) is physiological and stays so. That you keep an eye on things. But that you don't have to do anything ... (Anouska).

Student midwives described scenarios in which unnecessary intervention in childbirth should be avoided. In addition to this, working in ways that allowed time to be patient and be 'with women' were seen as essential.

Woman-centred approaches to midwifery care were detailed as central to the midwifery philosophy of care. Student midwives described the importance of supporting the woman to find her own power to give birth. This related to a view in which the student midwives felt that they were able to empower women to have trust in the physiology of childbirth. They considered the fostering of women's trust in their own bodies to be an important part of engendering the woman's personal power. Learning how to do this was seen as important, because they were convinced by their experiences, particularly during clinical placements, that women who experience physiological childbirth are more satisfied.

I think, for the woman that it gives (her) more trust in herself and that she looks back on it (the birth) with more satisfaction if it's physiological

(Debbie).

Students pointed out that another facet of expediting the woman's power to give birth was in careful use of the language around birth. Terms such as 'doing the delivery' were avoided by some students. Wendy told us,

I never say, 'I did a nice delivery'. I always say things like 'I was present at a beautiful birth' or something like that, you know? (Wendy). 


\section{| Chapter 3}

Several of our respondents mentioned the value of shared decision-making for empowering women. Students talked about how the development of a trusting relationship with the woman facilitates personal power for the woman in making choices in childbirth. However, while student midwives felt that the wishes and needs of women should be paramount in physiological childbirth, they experienced tension between advocating the midwifery philosophy of care and their understanding of what woman-centred care constitutes. This was articulated in concerns about imposing midwifery philosophy on the women in their care. Student midwives expressed the desire to maintain neutrality and balance women's choices against evidence-based actions that promote physiological childbirth. Vera explained,

I try to find a balance between her choice to give birth in bed and motivating her to get off the bed... I find this a difficult consideration (Vera).

Student midwives described resources they found helpful in increasing their personal agency as advocates for physiological childbirth. One such resource was using Evidence-Based Practice (EBP) to help develop a critical attitude towards their own, and other professionals', practice. The student midwives in our study described EBP as a resource in which they learned to formulate their own thoughts and questions about practices that they observe,

... without being judgemental, I think it's a good feature to ensure that your own physiological approach - and that of your colleagues - is preserved (Jeannette).

Some students acknowledged that the transition from thought to action can be difficult, notably when their perspective on care differed from that of another professional. While EBP was cited as a useful resource to formulate thoughts or ask questions, it seemed that student midwives saw few examples of preceptors or other professionals using EBP to frame discussions about differing approaches to maternity care. This is also visible in the development of evidence-based practice protocols and directives, where the limited use of both evidence and midwifery involvement may have consequences for the shaping of optimal midwifery care. Danielle gave an example about a lack of discussion or midwifery involvement in the shaping of regional protocols and directives,

... and then it's, like, 'we can't take everyone's opinion on board'. So, the protocol for a whole region is determined by five people ... (Danielle). 


\section{'Gaining a voice'}

Student midwives reported various resources that increased their personal power but noted that using these in clinical settings was challenging. Established hierarchy and feelings of dependency on the preceptor are factors that led to students feeling that they lack the ability to speak out in clinical settings.

Students described the power dynamics of the clinical placement, in terms of a hierarchy where they were on the lowest rung. In the hospital setting being lower in the hierarchy often translated to students feeling that their voices were unheard,

Nine times out of ten, I swallow my words and think "who am I to say anything"? (Saskia).

Students also noted that in the hospital their own midwifery experience was not taken into account by other professionals, an experience they described as demoralizing,

... There's this high-handedness, the way (they) look down at you...no-one sees your experience (Milou).

However, perceived hierarchy was not limited to hospital settings; students also experienced community midwifery practices as hierarchical. In midwifery practices students felt that they had to adhere to the norms and values of the practice as determined by the midwives in 'their' practice. This led to students having to adapt or 'fit in' to the clinical settings to which they were assigned during midwifery training.

This adaptation was primarily driven by feelings of dependency on the preceptor, who is not only a mentor, but also the one who will evaluate the student's work during placements. Mia described this as follows:

You're in a dependent position; you need something from them (the preceptor).

And that's a discrepancy that, um, I think...holds you back... from

challenging their practice or from standing up for your own (approach to midwifery) philosophy (Mia).

Student midwives indicated that they felt that it was expected of them to assume similar ways of practising to that of their preceptor. This presented challenges, especially when students felt that their personal realization of the midwifery philosophy of care was different from that of the preceptor. 


\section{| Chapter 3}

As a student, you can have a physiological approach, but you have to practice according to their (the preceptors') rules ...then you intervene and do vaginal exams every two hours (Joyce).

Having to adapt created conflict for the students in our study. Midwifery programmes expect students to internalize the midwifery philosophy of care and realize this in practice settings during their education. Students set measurable learning goals in order to demonstrate that they are able to do this. However, the reality that students described offers little or no opportunity to practice differently from their preceptors, leading to students setting their personal approach to practice aside to do what is asked of them. An inability to internalize a philosophy for midwifery care in line with (inter) national definitions and to realize this in practice has significant consequences, especially with regard to concerns about increasing medicalisation of childbirth.

However, there were situations in which students felt they could develop their own voices and advocate for physiological childbirth practices. The opportunity to observe, and be involved in, genuine collaborative ways of working between community midwives and obstetricians was viewed as positive. Genuine collaboration fostered an environment in which questions and discussions were encouraged in order to facilitate maternity care based on best practices from various professional backgrounds. The establishment of collaborative relationships with other care providers was viewed as facilitative, with students being more willing to discuss or to challenge practice. This often depended on earlier positive experiences, or hearing positive things about a particular care provider,

For me, it depends a lot on who (i.e., care provider) is opposite me. If it's someone you know - who I've seen more often or have spoken to a couple of times. Or, I've heard good stories about them - then I'm much more willing to say what I think and that I don't agree with them (Alexis).

While positive experiences with other care providers was associated with readiness to challenge practice or discuss differences, the unspoken implication is that, where experiences are less positive, student midwives are less willing to get into discussions with other care providers. Interestingly, one student noted the importance of building collaborative relationships, to ensure that other professionals develop overall confidence in the physiological midwifery approach, 
When you work with them regularly and you can build trust ... once you've achieved trust - they'll be more likely, yes, it sounds a bit strange, but they'll be quicker in having confidence in your approach. I noticed this in a hospital where I'd had an earlier placement, it was, like, 'oh, there's Sophie, we know her', you know?'... it feels much better; you can be open with one another, work together (Sophie).

\section{'Learning by example'}

Students told us that in order to advocate for physiological childbirth, it is essential to have opportunities to observe physiological care practices and see how midwives advocate for physiological childbirth in their interactions with women or with other professionals. Student midwives also looked to their peers from whom they could learn.

\section{Learning from midwives}

The student midwives in our study discussed the importance of being able to learn by example, in both clinical placements and in the classroom. Learning during clinical placements was paramount with students. We heard about both negative and positive examples for learning.

Student midwives highlighted the diversity of placements, principally in the community, observing that while some midwifery practices espoused a physiological approach to maternity care, other practices were less physiology minded. This exposure to differing approaches contributed to the development of the students' personal realization of the midwifery philosophy of care, noting which practices and professional behaviours to incorporate and which not. The diversity experienced by students also raised concerns, particularly if students felt that they were insufficiently exposed to certain practices or behaviours, such as water birth or birth in non-supine positions.

Some students expressed feelings of doubt about implementing aspects of midwifery care that they had not had the opportunity to experiment with during clinical placements. Theory alone seems inadequate if it is not reinforced during clinical placements,

... we had, I think, a lesson about birthing positions and then... if you don't see it (non-supine birthing positions) during placements then it's not something that you feel proficient, and then you try it less quickly

(Marie-Louise). 


\section{| Chapter 3}

Some students reported experiencing freedom to experiment during placements, although how much freedom to practice the student was allowed seemed to be related to preceptor experience. Students described experienced midwives being willing to allow students freedom to experiment, in this example with a birthing stool. Less experienced colleagues appeared uncomfortable with this practice and students felt under surveillance. Anneliese told us,

There was a huge difference... the hospital midwife who said to it, do anything, let me know if you need me. Or the resident who's breathing down your neck. It's difficult to know your place. The midwife says get (the woman) pushing on the birthing stool and the resident is, like, oh, no! No! (Anneliese).

Exposure to physiological birth practices is one aspect of developing core midwifery competencies; attitudinal development is another important aspect. Students cited the attitude that the midwife preceptor has to promoting and supporting physiological childbirth as important for their learning. One student told us that she experienced that,

If the midwives are also physiological, that they give you that (physiological attitude) more than if they are - different - or quickly afraid birth deviating from normal...they take you with them (Carine).

\section{Learning from peers}

Student midwives also discussed the examples they had heard during the classroom portion of their midwifery education, mentioning the value of case histories as a way of learning about clinical situations. Notably, peer-to-peer reflection was mentioned by students as giving them the space to discuss, reflect upon, internalize and develop strategies to incorporate midwifery philosophy of care into their practice. This is a structured activity, in which peer students, usually in groups of 8-12 and facilitated by a lecturer/coach, discuss aspects of learning that the student has experienced during clinical placements. Peer-to-peer reflection is facilitated during clinical placements via a digital platform and as a classroom-based activity. Reflective learning is central to this process. While some students found that there was too much focus on reflection, others saw the value of a structured, reflective activity in which to learn about their own - and others - approaches to promoting and supporting physiological childbirth, 
I didn't think I'd get so much from it (peer-to-peer reflection), we used to laugh a bit about it, but, for me, it was one of the most important parts of my education. Part of it (peer-to-peer reflection) is about asking critical questions without judgement and I think this helps in promoting your own - and your colleagues - physiological approach (Rachel).

Peer-to-peer reflection was seen as a learning activity in which students could effectively explore some of the gaps that exist between midwifery theory and practice and an activity that allowed exploration of the diverse approaches to midwifery care. Student midwives said that in these sessions learning by example was also important. Some of the examples stemmed from practice situations that they or their peers had experienced. However, students were also inspired by the expression of the midwifery philosophy of the facilitating lecturer and the way in which this was used as part of a teachable moment.

We had a lecturer, with a clear and powerful physiological childbirth philosophy. When we discussed cases, she asked critical questions and we discussed cases in detail and what we could do differently next time (Vera).

The students in our study mentioned how the timing of peer-to-peer reflection affected its value. Peer-to-peer reflection in the first two years of education helped them to develop their role as active learners and to work on personal development as individuals. On the other hand, most students viewed peer-to-peer reflection as best meeting their needs as burgeoning professionals during the final two years of midwifery education. In the third and fourth year, where the focus is on clinical placements, students considered peer-to-peer reflection as an important activity in which to explore and reflect upon the way in which they internalized and worked with the midwifery philosophy and how this subsequently contributed to their professional development. In addition, it offered opportunities to learn from their peers who may have had other experiences, and to assimilate new insights into their personal realization of the midwifery philosophy of care in practice.

\section{Discussion}

This qualitative study offers insights into how student midwives in the Netherlands learn to appreciate and to advocate for physiological childbirth. In order to do this, students internalize ${ }^{13,14}$ the midwifery philosophy of care in which the woman is central, supported by strategies such as shared decision-making and evidence-based practice. An internalized midwifery philosophy and the opportunity to realize this in practice gives the student a sense of personal power, which, in turn, is used by 


\section{| Chapter 3}

the student to mitigate some of the challenges faced by student midwives during midwifery practice. The most effective learning students experience is when they are surrounded with positive examples from which to learn.

The student midwives who participated in our study equated an internalized midwifery philosophy with feelings of personal power. Halldorsdottir and Karlsdottir ${ }^{25}$ in their theory of the 'good midwife' refer to the professional wisdom of the midwife, which is developed through an interplay of both theory and practical experience. In exploring the concept of the good midwife' in the Dutch setting, ${ }^{16}$ student midwives discussed a 'midwifery vision', or midwifery philosophy of care, as an aspect of professional wisdom. To develop this, student midwives need to acquire both knowledge and skills and need to internalize the values and norms of the profession. ${ }^{13}, 14,26$ We also found that student midwives experienced conflict between the midwifery philosophy of care and their interpretation of woman-centred care, with students being cautious about advocating physiological approaches to childbirth in an effort to be as neutral as possible when offering information to women. The conflict and dilemmas experienced by these students has been noted elsewhere in the literature ${ }^{27,28}$ and student midwives need support in finding ways to deal with this during midwifery education and in practice. ${ }^{27}$

The word power often has negative connotations, implying the exercise of control by one group with power over a less powerful group. ${ }^{29}$ However, power, in the context described here is better understood in the context of the different expressions of power as described by Veneklasen and Miller. ${ }^{30}$ They distinguish four types of power: 'power with', 'power to', 'power within', and 'power over'. On the one hand, the students in our study describe some of their relationships with preceptors in terms 'power over' - powerlessness and feelings of dependency. This power imbalance is not uncommon in medical settings, having been described elsewhere in the literature. $^{31,32}$ However, the student midwives in our study postulate other expressions of power. Building on 'power within' (the potential power of the individual) and 'power with' (the collective voice), students talked about 'power to' the individual's ability to shape their own world. For student midwives this implies that the creation of a professional identity begins by internalizing and realizing the midwifery philosophy (power within) that guides the individual's practice as a midwife.

Personal power for student midwives also relates to 'power with'. In this expression, power with has to do with working collaboratively in order to build bridges or create equitable relations. Students offered examples of situations in which they learned 
by observing or directly participating in the creation of genuine collaborative ways of working with other professionals involved in midwifery care. In the last few years there has been increasing focus on creating collaborative ways of working between professionals involved in providing maternity care. ${ }^{33}$ It appears that being able to work collaboratively with other care providers is satisfying for midwives. ${ }^{34}$ Helmond et al. ${ }^{35}$ note that one of the most important pre-requisites necessary for good collaboration between professionals is trust. The students in this study confirm this. They found that when they were able to build trusting relationships, good communication with other professionals followed, facilitating their agency in advocating for physiological approaches to childbirth through discussion and communication with other actors in maternity care.

The perception of an established hierarchy within midwifery is not a new phenomenon. ${ }^{36}$ This hierarchy results in the imitation of midwifery preceptor behaviour by student midwives and the inability of student midwives to challenge practice by senior midwives ${ }^{37}$ who are responsible for assessing students' progress during placements. The students in our study corroborated these findings. Relationships with preceptors can either hinder or facilitate learning. ${ }^{38}$ An encouraging, approachable preceptor can be influential in building student midwife confidence to advocate for physiological childbirth and, importantly, the agency to implement care processes that support this.

The students in our study report gaining benefits for their learning from structured reflective practice with their peers, facilitated by midwifery lecturers who are cognisant of the importance of a physiological approach to childbirth and are familiar with practice settings. Schön ${ }^{39}$ describes reflection as an important learning strategy that allows professionals to become aware of their implicit knowledge and able to 'think on their feet'. Reflection, as a means to enhance learning, has been in wide use in midwifery since the 1990 s, although the majority of reflective models stem from nursing, rather than midwifery practice. Collington and Hunt ${ }^{40}$ point out that well-structured reflective discussions may encourage student midwives to develop the critical decision-making skills necessary for autonomous practice. Structured reflection can also support students in navigating some of the conflicts that may arise between realizing a personal expression of the midwifery philosophy in practice, the approach of other professionals to childbirth, and the wishes and needs of women. The students in our study confirmed this viewpoint, highlighting the value of structured reflection as a means of exploring approaches to physiological childbirth, supporting them in developing their own midwifery vision, and in navigating some of the dilemmas that arise in practice. 


\section{| Chapter 3}

The strengths of this study include the choice of focus groups as an appropriate methodology in order to gain a wide variety of views and rich descriptions from student midwives throughout the Netherlands. Data collection and analysis occurred concurrently, and we paid attention to the auditability of our findings. Reflective notes were made by the first author and all key decisions during data collection and analysis were audited by the second author. It is, as far as we are aware, the first study to examine student midwives' educational needs in order to effectively advocate for physiological childbirth. A limitation of this study is the self-selection of the students who participated. It may be that these students felt an affinity with the subject matter, potentially making them less representative of the student midwife population as a whole. Our aim was to ensure a broad representation of students, and we did include students from each midwifery programme in the Netherlands. Another was the choice to focus solely on the views of student midwives. Midwife preceptors are valuable stakeholders and may have views on how student midwives could develop as practitioners of physiological childbirth. This is worthy of further study but was not within the scope of this paper.

\section{Implications for midwifery education}

6o This study contributes new insights into what student midwives require of their educational programmes in order to become self-efficacious advocates of physiological childbirth. Our findings have implications for midwifery education in the Netherlands. While midwifery programmes focus on providing theoretical that supports student midwives in internalizing the midwifery philosophy of care, educators must pay attention to helping students to realize this in practice. This includes teaching students to effectively communicate their philosophy and the advantages that physiological birth may have, in interactions with other maternity care professionals and with women and their families. As the students in our study make clear: all too often, discussion and communication of midwifery philosophy is dependent on external factors. Education should be focused on increasing student agency to discuss, debate and challenge aspects of care where there is evidence that supports physiological childbirth. In addition to this, current education about shared decision-making should place greater emphasis on helping students to navigate the dilemma between advocating the midwifery philosophy of care and the wishes and needs of women and communicating to women the advantages that a physiological approach to childbirth may have.

The role played by the midwife preceptor is essential to student midwife learning, and it is especially important that students have exposure to physiological childbirth practices. Midwifery programmes have the responsibility to ensure that there are 
clinical settings that are able to facilitate these learning experiences.

Dutch midwifery programmes currently offer post-graduate courses intended to help preceptors develop clinical teaching and precepting skills. These focus on the development of didactic skills and the use of feedback and reflection for learning. However, there should be a greater emphasis on ensuring that more midwives are aware of the importance of exposing students to physiological childbirth practices. On-going educational input for midwives to support them in increasing their own self-efficacy in employing strategies that promote physiological birth in particular may in turn, increase student midwife exposure to these practices. Additionally, midwife preceptors should be supported in tolerating discrepancies between their own and a student's approach to physiological childbirth, allowing student midwives freedom to realize and work with the midwifery philosophy of care.

Our findings, together with evidence from other settings, underscore the importance of midwifery role models for effective student midwife learning and for theinternalization and expression of the midwifery philosophy of care. Further research in the Dutch context should focus on the role that midwives must assume in modelling exemplary midwifery behaviours. There is a role for Dutch midwifery programmes to support and develop preceptorship competencies in fulfilling this role.

\section{Acknowledgements}

We would like to thank the student midwives who generously shared their insights with us during this study. We would also like to thank Zuyd University of Applied Sciences for their sponsorship of this project. 


\section{| Chapter 3}

\section{References}

1. Aitink M, Goodarzi B, Martijn L. Beroepsprofiel Verloskundige. 2014.

2. Cronie D, Rijnders M, Buitendijk S. Diversity in the Scope and Practice of Hospital-Based Midwives in the Netherlands. Journal of Midwifery \& Women’s Health. 2012;57(5):469-75.

3. International Confederation of Midwives. ICM Core Document. Philosophy and Model of Midwifery Care. Den Haag: ICM; 2014.

4. Thompson SM, Nieuwenhuijze MJ, Low LK, de Vries R. Exploring Dutch midwives' attitudes to promoting physiological childbirth: A qualitative study. Midwifery. 2016;42:67-73.

5. Offerhaus PM, Otten W, Boxem-Tiemessen JCG, de Jonge A, van der Pal-de Bruin KM, Scheepers PLH, et al. Variation in intrapartum referral rates in primary midwifery care in the Netherlands: A discrete choice experiment. Midwifery. 2015;31(4):e69-e78.

6. Seijmonsbergen-Schermers AE, Geerts CC, Prins M, van Diem MT, Klomp T, Lagro-Janssen ALM, et al. The Use of Episiotomy in a Low-Risk Population in The Netherlands: A Secondary Analysis. Birth. 2013;40(4):247-55.

7. Offerhaus PM, Hukkelhoven CWPM, de Jonge A, van der Pal-de Bruin KM, Scheepers PLH, Lagro-Janssen ALM. Persisting Rise in Referrals During Labor in Primary Midwife-led Care in The Netherlands. Birth. 2013;40(3):192-201.

8. Perdok H, Jans S, Verhoeven C, Henneman L, Wiegers T, Mol BW, et al. Opinions of maternity care professionals and other stakeholders about integration of maternity care: a qualitative study in the Netherlands. BMC pregnancy and childbirth. 2016;16(1):188.

9. Perined. Perinatal Zorg in Nederland 2015. Utrecht: Perined; 2015.

10. Warmelink JC, de Cock TP, Combee Y, Rongen M, Wiegers TA, Hutton EK. Student midwives' perceptions on the organisation of maternity care and alternative maternity care models in the Netherlands - a qualitative study. BMC Pregnancy and Childbirth. 2017;17(1):24.

11. Dahlen HG, Barnett B, Kohlhoff J, Drum ME, Munoz AM, Thornton C. Obstetric and psychosocial risk factors for Australian-born and non-Australian born women and associated pregnancy and birth outcomes: a population based cohort study. BMC pregnancy and childbirth. 2015;15:292.

12. Carolan M, Kruger G. Concerns among first year Midwifery students: Towards addressing attrition rate. Contemporary nurse. 2011;38:139-47.

13. Ulrich S. First Birth Stories of Student Midwives: Keys to Professional Affective Socialization. Journal of midwifery \& women's health. 2004;49:390-7.

14. Weis D, Schank MJ. Professional values: Key to professional development. Journal of Professional Nursing. 2002;18(5):271-5.

15. Jordan R, Farley CL. The Confidence to Practice Midwifery. Preceptor Influence on Student Self-Efficacy. Journal of Midwifery \& Women's Health. 2008;53(5):413-20.

16. Feijen-de Jong EI, Kool L, Peters LL, Jansen DEMC. Perceptions of nearly graduated fourth year midwifery students regarding a 'good midwife' in the Netherlands. Midwifery. 2017;50:157-62. 
17. Mason L. An enquiry-based learning curriculum can help student midwives to explore the promotion of normal birth in the context of current maternity service provision. MIDIRS Midwifery Digest [Internet]. 2017; (October 2017):[424-9 pp.].

18. Argyris C, Schon D. Theory in Practice: Increasing Professional Effectiveness. San Francisco: Jossey-Bass; 1974.

19. ten Hoope-Bender P, de Bernis L, Campbell J, Downe S, Fauveau V, Fogstad H, et al. Improvement of maternal and newborn health through midwifery. The Lancet. 2014;384(9949):1226-35.

20. Sandall J, Soltani H, Gates S, Shennan A, Devane D. Midwife-led continuity models versus other models of care for childbearing women. Cochrane Database of Systematic Reviews. 2016(4).

21. Miller S, Abalos E, Chamillard M, Ciapponi A, Colaci D, Comandé D, et al. Beyond too little, too late and too much, too soon: a pathway towards evidence-based, respectful maternity care worldwide. The Lancet. 2016;388(10056):2176-92.

22. de Vries H, Dijkstra M, Kuhlman P. Self-efficacy. the third factor besides attitude and subjective norm as a predictor of behavioural intentions. Health Education Research. 1988;3(3):273-82.

23. Braun V, Clarke V. Using thematic analysis in psychology. Qualitative Research in Psychology. 2006;3(2):77-101.

24. Attride-Stirling J, Humphrey C, Tennison B, Cornwell J. Gathering data for health care regulation: learning from experience in England and Wales. J Health Serv Res Policy. 2006;11(4):202-10.

25. Halldorsdottir S, Karlsdottir SI. The primacy of the good midwife in midwifery services: an evolving theory of professionalism in midwifery. Scandinavian Journal of Caring Sciences. 2011;25(4):806-17.

26. Carolan M. 'A good midwife stands out': 3rd year midwifery students' views. Midwifery. 2013;29(2):115-21.

27. Sanders J, de Vries R, Besseling S, Nieuwenhuijze M. 'Such a waste': Conflicting communicative roles of Dutch midwifery students in childbirth decision making. Midwifery. 2018;64:115-21.

28. Kuipers Y, Veen H, Klop L, Zondag L. Midwives' conflicting values - dilemmas of loyalty, responsibility and selfhood. 2018.

29. J G. Reflections on the use of the 'Power Cube' approach for analyzing the space, places and dynamics of civil society participation and engagement. MFP Breed Netwerk [Internet]. 2005 1st September 2017.

Available from: https://www.participatorymethods.org/sites/participatorymethods.org/ files/reflections_onuses_powercube.pdf.

30. Veneklasen L MV. A New Weave of Power, People and Politics: Practical Action Publishing; 2002.

31. Crowe S, Clarke N, Brugha R. 'You do not cross them': Hierarchy and emotion in doctors' narratives of power relations in specialist training. Social Science \& Medicine.

2017;186:70-7. 


\section{| Chapter 3}

32. Churchman J, Doherty C. Nurses' views on challenging doctors' practice in an acute hospital. Nursing standard (Royal College of Nursing (Great Britain) : 1987). 2010;24:42-7.

33. Downe S, Finlayson K, Fleming A. Creating a Collaborative Culture in Maternity Care. Journal of Midwifery \& Women’s Health. 2010;55(3):250-4.

34. Warmelink JC, Wiegers TA, de Cock TP, Klomp T, Hutton EK. Collaboration of midwives in primary care midwifery practices with other maternity care providers. Midwifery. 2017;55:45-52.

35. Helmond I, Korstjens I, Mesman J, Nieuwenhuijze M, Horstman K, Scheepers H, et al. What Makes for Good Collaboration and Communication in Maternity Care? A Scoping Study. International Journal of Childbirth. 2015;5:210-23.

36. Begley CM. 'Great fleas have little fleas': Irish student midwives' views of the hierarchy in midwifery. Journal of Advanced Nursing. 2002;38(3):310-7.

37. Begley CM, Glacken M. Irish nursing students' changing levels of assertiveness during their pre-registration programme. Nurse Education Today. 2004;24(7):501-10.

38. Begley CM. 'Knowing your place': student midwives' views of relationships in midwifery in Ireland. Midwifery. 2001;17(3):222-33.

39. Schön DA. The Reflective Practitioner: How Professionals Think in Action. Journal of Continuing Higher Education [Internet]. 1986; 34(3):[29- pp.].

40. Collington V, Hunt S. Reflection in midwifery education and practice: An exploratory analysis. Evidence Based Midwifery. 2006;4. 
"A Powerful Midwifery Vision" | 


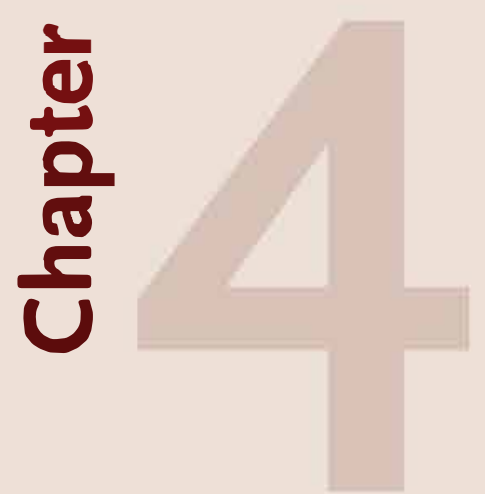

MJ Nieuwenhuijze

SM Thompson

EY Guðmundsdóttir

H Gottfreðsdóttir

Women and Birth 2019, S1871-5192(19)30210-0 


\section{Midwifery students' perspectives on how role models contribute to}

becoming a midwife: A qualitative study 


\section{| Chapter 4}

\section{Abstract}

Background: The dynamics of maternal and newborn care challenge midwifery education programs to keep up-to-date. To prepare for their professional role in a changing world, role models are important agents for student learning.

Objective: To explore the ways in which Dutch and Icelandic midwifery students identify role models in contemporary midwifery education.

Methods: We conducted a descriptive, qualitative study between August 2017 and October 2018. In the Netherlands, 27 students participated in four focus groups and a further eight in individual interviews. In Iceland, five students participated in one focus group and a further four in individual interviews. All students had clinical experience in primary care and hospital. Data were analyzed using inductive content analysis.

Results: During their education, midwifery students identify people with attitudes and behaviors they appreciate. Students assimilate these attitudes and behaviors into a role model that represents their 'ideal midwife', who they can aspire to during their education. Positive role models portrayed woman-centered care, while students identified that negative role models displayed behaviors not fitting with good care. Students emphasized that they learnt not only by doing, they found storytelling and observing important aspects of role modelling. Students acknowledged the impact of positive midwifery role models on their trust in physiological childbirth and future style of practice.

Conclusion: Role models contribute to the development of students' skills, attitudes, behaviors, identity as midwife and trust in physiological childbirth. More explicit and critical attention to how and what students learn from role models can enrich the education program.

Keywords: Midwifery, education, role model, childbirth, qualitative research

\section{Statement of significance}

Greater understanding of the meaning of role models is relevant for improvement of learning strategies in midwifery education. Explicit and critical attention to how and what students learn from role models can improve the education program. 
Midwifery students' perspectives on how role models contribute to becoming a midwife: A qualitative study |

\section{What is already known}

Role models are important agents in preparing students for their professional role.

\section{What this paper adds}

Midwifery students conceptualize a role model from various examples who represents their 'ideal midwife' and guides their education. Positive role models promote woman-centered care and have a significant impact on students trust in physiological childbirth. Students emphasized that they learnt not only by doing, they found storytelling and observing important aspects of role modelling.

\section{Introduction}

Worldwide, the dynamics of maternity care challenge midwifery education programs to keep up-to-date, ensuring that they educate midwifery students who are able to play their part in present and future midwifery. Preparing students for a context in which they often have to balance promoting physiological childbirth and 'being with woman' with modern requirements of interprofessional and technological settings.

In an earlier exploration of the Icelandic and Dutch challenges in training contemporary midwives, key leaders of midwifery education in these countries mentioned the importance of role models as a means to prepare students for their professional role in a changing world. ${ }^{1}$ Role models can show students how to combine ancient and modern competencies, exemplifying the midwifery identity as a guardian of physiological childbirth, and the modern professional in a dynamic, interprofessional environment.

Role models are individuals that others identify with, who possess desirable qualities and exemplify attitudes and behaviors that are considered worth imitating. ${ }^{2}$ Observation and modelling are important means of learning new behaviors. ${ }^{3}$ In education, role models are recognized as important pedagogical agents, who function as an example, providing inspiration for the novice's own future professional performance. ${ }^{4,5}$ They are considered an influential part of informal learning ${ }^{2,6}$ and there are some suggestions for formal use $e^{5,7}$. Role models can be faculty members, preceptors or any professional students come across during their education. .11 $^{91}$ They distinguish from mentors or preceptors who have a formalized relationship with designated roles and responsibilities. ${ }^{12}$ They influence students in developing professional identities, values, attitudes and behaviors, because of the desirable professional image they embody. 2, 4, 7,11,13 


\section{| Chapter 4}

Medical and nursing students report a number of important characteristics and behaviors in role models, including 1) clinical competences like excellent level of knowledge and skills, and a humanistic approach towards patients, 2) teaching skills that create a positive learning environment, and 3) personal qualities like integrity, enthusiasm, respectful interprofessional interaction and passion for their profession. $7{ }^{70}$ Students value exposure to positive role models and see them as beneficial for learning. ${ }^{4,} 10$ Exposure to negative role models appears to contribute to students' reflection on what type of health professional they aspire to become, but may have unwanted consequences, such as negativity towards work, value conflicts, or emulation of undesirable practice. ${ }^{8,10}$ Therefore, a conscious use of role models is advocated, whereby staff and clinicians are aware of their modelling role and make this explicit.7, 10

Most of the evidence about role models stems from medicine or nursing. Little is known about what students and educators (faculty and preceptors) in midwifery education see as significant examples of role models and modelling behavior. One of the few studies we identified in the midwifery domain is dated, and may not be relevant for the changing world of midwifery. ${ }^{11}$ Our study adds new insights on role modelling in the current context of midwifery.

This study is part of a collaborative project in which we explore issues in midwifery education with research data collected in different countries.

\section{Methods}

We conducted a qualitative, descriptive study interviewing Dutch and Icelandic midwifery students to explore their perspective on the meaning of role models in contemporary midwifery education. This design enables a deeper exploration of a topic, when limited information is available.

\section{Settings and participants}

Iceland and the Netherlands have different pathways for midwifery education. These reflect the generic characteristics of midwifery education in high-income countries, as either a direct-entry Bachelor of Science program (the Netherlands) or a postgraduate program after nursing (Iceland)..$^{1}$ By choosing these countries, we aimed for variation in education pathways and scope of midwifery practice, while also retaining sufficient common ground as European high-income countries.

We recruited students from all Dutch and Icelandic midwifery programs by oral 
Midwifery students' perspectives on how role models contribute to becoming a midwife: A qualitative study |

invitation, email and Facebook, offering an information letter explaining the study, confidentiality, anonymity in reporting and secure data management. Students were aware that they could withdraw at any moment during the process of data collection without consequences. They gave informed consent before participating in the study.

\section{Data Collection}

Our research team included investigators from both countries, who were the site investigators for their country. We collected data using face-to-face focus groups and individual interviews. While the focus group allowed for a broader exploration of the topic, the individual interviews enabled us to look deeper and explore the more personal meaning of role models for students. ${ }^{14}$

A semi-structured questionnaire route was created (Table 1 ), ${ }^{15}$ based on studies about role models in health professionals' education. All participants were interviewed in their native language at midwifery institutions, in a room where privacy was guaranteed. Focus groups lasted between 60 and 90 minutes, individual interviews between 30 and 45 minutes. The discussions were audio-recorded and transcribed verbatim. Informal member checks were conducted at the close of each focus group. Data collection continued until saturation was reached.

Table 1: Question route for interviews.

What meaning do role models have for your education as a midwife?

Please describe a person who has been a role model for you.

What makes him/her a role model for you?

Which characteristics does a positive role model have?

What kind of behavior and attitude does a role model show?

What makes a person a negative role model?

What impact did these role models have on your education? 


\section{| Chapter 4}

\section{Ethical considerations}

In the Netherlands, Zuyderland-Zuyd ethics committee approved the study (17-N-27). Ethical approval was not necessary for this type of study in Iceland, as the data collection was part of consulting students for quality improvement and was not invasive into the private sphere of the student. At the beginning of all interviews the interviewer emphasized that students could withdraw or reject answering specific questionswithout explanation or repercussions. All data were anonymized and safely stored in the university data system, only accessible with a password for the researchers.

\section{Data Analysis}

Data collection and analysis were concurrent in each country, allowing for reflection and subsequent discussion on the viewpoints of the participants. We used inductive content analysis to analyze the data. ${ }^{14}$

After each interview and focus group, the primary investigator in that country, added reflective notes, which helped our thinking throughout the analysis process. The primary investigators from each country, met several times (face-to-face and online) during data analysis to discuss the reflections and findings. The first author analyzed the Dutch data. The interviews were re-read and re-listened to facilitate deeper engagement with the data. Codes were attached to small segments of the transcripts using NVivo 11. Emerging themes were identified and checked to determine relevance in relation to the data. Initial themes were refined and divided into subthemes by going back to the data to establish coherent patterns. The last author applied a similar process for analyzing the Icelandic data. Subsequently, the first and last author discussed the themes and subthemes identifying similarities and differences as well as exploring possible new themes that did not come up in the data from the other country. Quotes from both countries illustrate the themes and were given a code.

\section{Rigor and reflectivity}

We used several strategies to ensure methodological rigor. ${ }^{16}$ All investigators were experienced qualitative researchers and had expertise in the fields of midwifery and education in their own country and internationally. They were not education providers to the students' surveyed. Their different national backgrounds encouraged discussion. Field notes were kept from each interview (data triangulation). Use of individual interviews and focus groups contributed to a deeper understanding of the topic (methodological triangulation). Throughout the study, we reflected on the analytic process (investigator triangulation). Research team meetings were organized to discuss the scientific and organizational aspects of the study (peer debriefing). 
Midwifery students' perspectives on how role models contribute to becoming a midwife: A qualitative study |

The forward and backwards translation of the quotes was assisted by a native English speaker. The writing of this article was guided by the consolidated criteria for reporting qualitative research (COREQ).(17)

\section{Findings}

In the Netherlands, 35 students participated in the study. There were four focus groups with 27 students from all midwifery institutions in the Netherlands (Rotterdam ( $n=8)$, Amsterdam ( $n=5)$, Maastricht $(n=5)$, Groningen $(n=9)$ ) plus eight individual interviews with students. All students were female and most were in the third $(\mathrm{n}=6)$ or fourth year $(\mathrm{n}=27)$ of education, one was a first year student and one a second year. All had experience in primary maternity care and hospital placements.

In Iceland, where only one institution exists, nine students participated, four first year students in the individual interviews and five second year students in a focus group. The students all had three to five months experience in primary maternity care and the university hospital.

In exploring students' views about role models and role modelling, four themes emerged: 'opening up the scope of midwifery practice', 'creating an ideal role model', 'learning by observing, listening and doing' and 'becoming a good midwife'. Each theme included several subthemes.

\section{Opening up the scope of midwifery practice}

Students indicated that role models are important for their learning process. Role models are persons they look up to because of their professional accomplishments and who they would like to mirror. The meaning of role models included three aspects. Primarily, they are persons who facilitate the students' learning process. Additionally, role models are important for students' exploration of their philosophy of good midwifery care and they model students' future development as a professional.

\section{Facilitating learning}

Seeing people with whom they can professionally identify do certain things, makes it easier for students to develop new skills, attitudes and try alternative approaches to midwifery care. They associated role models with opportunities to observe skills and procedures they find challenging, learn new approaches or manage new situations. 


\section{| Chapter 4}

A role model already gives shape to something I am still learning. (NL-1)

What will follow me is the importance of quietness, which is what I admire in the case of my clinical mentor. (IS-4)

Our participants also identified certain characteristics in clinicians as role model educators. These role models see the best in students, offer support, encourage responsibility and allow enough space to explore skills and competences in their own way. Significantly, they encourage students by who they are: an inspiring motivator with a passion for midwifery.

That one midwife who could let go and sit in the comer and say nothing. (NL-3)

\section{Exploring the philosophy of midwifery care}

Students often mentioned that having a similar philosophy of midwifery care is requisite to recognizing someone as a role model. They identified role models who can show them how their philosophy of good midwifery care can be applied to practice. Concurrently, sharing the same philosophy allows the student to relax and concentrate on learning how to do things without having to challenge why something is done.

What I am looking for in role models is to explore if my philosophy on midwifery really exists. And that I am not the only one with this philosophy. And that it's doable in practice. (NL-2)

\section{Modelling the future}

Role models encourage students to think beyond their daily activities and initiate views about new developments in midwifery, such as their contribution to the positioning of midwives in the healthcare system. Students value role models' opinions about these issues and tend to listen more carefully to their arguments, allowing students to transcend the here-and-now and to shape their own future professional lives.

A role model helps me to look beyond my graduation, the direction I want to go as a professional in the future. (NL-2)

To be able to follow women throughout pregnancy, birth and post-partum in the program will support me in promoting continuity of care after graduation. This is really a fulfilling experience and should be implemented in the clinical context. (IS-3) 
Midwifery students' perspectives on how role models contribute to becoming a midwife: A qualitative study |

For the students, role models are the inspiration for an ideal. While students sometimes doubt that this ideal is achievable, they consider it worthwhile to strive for this image of ideal practice. However, the students did not idolize role models, remaining critical while seeking examples of ideal midwifery practice.

\section{Creating an ideal role model}

Students said that early on in their education they discover that a role model is not necessarily embodied by one person. They described 'assembling' an ideal role model based on constituent parts of different professionals who they appreciate in practice. This ideal guides their emerging midwifery identity.

\section{Positive role models}

Students mentioned professional characteristics of role models that they saw as important for a 'good' midwife. These characteristics focus on care-giving to women and their partners: empathy, being available for and listening to women and their partners, calmness, patience, confidence and being able to be firm when necessary. Experience is valued, given that the person is also curious about new developments and keeps up-to-date with new insights. Being able to interact with other professionals and daring to question why they are doing things is another characteristic they appreciated.

Well, listen to women ..., being empowered. Working with the direction the woman wants to go. No interfering, when it is not necessary. Uh, being self-confident in such a way that I think: this is how I want to practice midwifery. (NL-4)

She was self-confident, spontaneous and warm with women, as well as very good in communicating with the obstetricians, daring to question and not accepting everything. (NL-5)

Well, I have tried to collect and combine what I perceive as positive in their [models] pursuit ... I feel that there is one main thing of importance that is to build a relationship with the woman and her partner. (IS-1).

\section{Negative examples}

Students from both countries shared examples of professionals' behavior they did not value. Several students indicated that midwifery preceptors are not always aware that they are modelling their profession for the student. One student described 


\section{| Chapter 4}

how a midwife in a hospital setting left all the support of a woman in labor with the student and did not spend time with the woman herself. She felt that this midwife does not realize that she is modelling professional behavior and is

... not showing the specific value midwives have in supporting the physiology of childbirth in a hospital setting. (NL-6)

These negative examples make students acutely aware of the professional they do not aspire to be like.

I would also say that there are some midwives who are not qualified to work as midwives. They try to control your view and also the view of the women ... I mean, they have this opinion and they do not inform the women or offer a discussion about any decision. (IS-1)

\section{Learning by observing, listening and doing}

Our participants clearly saw role models as significant facilitators of their learning process. Some students mentioned that they are actively looking for role models; others just come across someone who they value. All indicated that they think back to situations with positive role modelling often and try to apply to practice what they have seen.

When I see a role model do certain things, I memorize it better. Later on, in a similar situation, I think back and therefore I learn it better. I see the whole situation before me again. (NL-2)

Several students indicated that over time their focus changes in terms of what they need from role models. One student described how, as a first year student, she was impressed by everything and every preceptor, while now, as a third year student,

You look at what fits for me and then you take little pieces from others that you think are valuable, particularly in the interaction with women but also in the personality of the midwife. (NL-5)

\section{Learning new things and pushing boundaries}

The students liked professionals who allow them to experience things they, as students, feel insecure about because they do not exactly know how to do them. They mentioned examples such as vaginal examination in an upright position or discussing pain relief options. They remembered being taught these things in a theoretical context, but specific suggestions were easily lost if not followed up with practice-based assimilation. 
Midwifery students' perspectives on how role models contribute to becoming a midwife: A qualitative study |

And when you do a vaginal exam on a woman in vertical position for the first time - I am glad I came across that during my placement ... (NL-7) Last week I was working on the labor ward and there I was attending a woman having her third child in a spontaneous labor. She wanted to stay in the water but I was afraid and insecure ... I mean I was insecure because I did not have the monitor, etc. The midwife was however very supportive and encouraged me .... (IS-3)

Role models also inspire students to push their professional boundaries, in particular in assuming new responsibilities where earlier, midwives would have referred to an obstetrician. For example, applying additional diagnostics for suspected gestational diabetes or using fetal monitoring for decreased fetal movements in primary care.

Much of the role modelling focused on interactions with women and around promoting physiological childbirth. Students also appreciate watching midwives or obstetricians manage pathology and witnessing the communication between professionals and with the woman and her partner in such situations.

Students value role models (midwives and obstetricians) who show confidence in the birth process and are not directed by fear. They described professionals who were alert, present and patient with the physiology of birth. This behavior was seen as highly important for students in developing their own professional identity. These role models also showed confidence in the student, allowing her to do things herself and not constantly directing her.

In the hospital, supervised by the obstetrician, I experienced that low-risk is possible. Especially, the older ones who have seen everything. They stand with their arms crossed, just watching. (NL-8)

Role modelling is not only inspired by the situations students are exposed to. Midwifery storytelling, about how midwives dealt with earlier cases models how students may perform or behave in certain circumstances. Students love to hear these stories.

I would like to hear more stories of midwives experiences in the clinic. That they would discuss more with students what they have done in specific situations. (IS-4)

Students also mentioned their midwifery lecturers as role models. Students are helped by lecturers that model attitudes that demand a critical view on midwifery, 


\section{| Chapter 4}

in particular with regard to evidence-based. However, some students sometimes missed links with current practice, as lecturers are viewed as supervisory and do not always share their former experiences with students.

... the lecturers, spirited academics who really challenge you occasionally. However, that gets us where we are now. It is not an easy program, if you are not giving it $110 \%$, you will not make it. (NL-9)

I said to my midwife; well I've been reading about this and it says that this is a completely useless intervention ... it makes me feel good to be able to say that and be sure that this is based on evidence. (IS-5)

\section{Barriers}

Students identified certain barriers to learning from role models. They mentioned that they could not always gain further experience in the modelled behavior, as they are dependent on positive assessments from others during their clinical placements. Also, exposure to different professionals in a placement contributes to the overriding concern with what others expect of them, rather than singling out a professional who is a positive role model and mirroring what she/he is doing.

People always say, you pick up something from every midwife and that way you become the midwife you want to be. That is true, but to get a positive assessment you have to do what they expect of you. (NL-3)

Contradictory information is also a barrier. It confuses students and makes it harder to follow the desired behavior of a role model. Strict protocols limit possibilities to experiment with different approaches to care that they value in a role model.

Then it is hard to protect your own role. Where do I stand in this, how can I protect this (physiological childbirth) or not? And the midwife says: go ahead and use the birth stool, and the residents says: O, no! No! (NL-10)

Students are acutely aware that the precepting midwives are often overburdened and not always able to give them time, opportunities to practice, or be the role model the student seeks.

The labor ward is very busy. The other day there was this first time mother who came in active labor and the midwife just said to her - well perhaps it is best for you to have an epidural ... You know she wasn't going to even try to support her to give birth without an epidural. (IS-6) 
Midwifery students' perspectives on how role models contribute to becoming a midwife: A qualitative study |

Students felt that value could be found in being encouraged to observe, rather than do things, in order to learn. They also suggested using role models, both positive and negative, in reflections on their learning. In this way, students felt that they could better develop their own view on midwifery and being a good midwife.

\section{Becoming a good midwife}

Positive role models endure, providing reminders for the student of the sort of midwife she aspires to be, sometimes long after contact with the particular professional has ended.

That is what I try - to take it (physiological approach) with me to every clinical placement, every time I quickly think of that one midwife, yes, no, yes! This is how you can do it as well. (NL-11)

\section{Bildung - achieving full potential as a midwife}

The term Bildung used in higher education is based on an original idea of Humboldt's Bildung, which translates as 'formation' but which is contextualized as learning that allows students to cultivate their full potential. ${ }^{18}$

Students talked about role models who influence them in their style of practice. As one student said, these are "... essential for becoming a good midwife, something you cannot learn in theory." (NL-12). They often mentioned midwives with a physiological approach to childbirth, and their impact on the student's development as a professional. This is linked to not only what these midwives do, but also the questions they ask and the stories they tell - these contribute to student reflection on their own motives and reasons. These midwives are patient and teach students patience.

I have a couple of midwives in mind of whom I think: they really safeguard physiology. For me, as a student, if my actions are becoming too pathological, she calls me back ... - we'll wait and see a little longer. (NL-11)

Students expressed that experiences with role models shape how they will advocate for physiological childbirth or women's choice in their own practice; "How much, in the end, I will stand up for physiological childbirth" (NL-13). Practicing midwives are a big influence on how they perceive that physiological childbirth is central to midwifery.

Some students mentioned that they, as students, are also a role model. By gaining confidence in their skills and professionalism, they want to inspire others and share new ways of working. 


\section{| Chapter 4}

We were doing a hands-off birth. And the nurse had her hands like this (student positions her hands) ... I thought I will show you, this is how you can do it as well. (NL-4)

\section{Developing a personal philosophy on midwifery care}

Students built their own professional ideal based on the models they see in practice and are more likely to believe and value arguments expressed by their role models. Most of their ideas of a good midwife and midwifery care revolve around being in touch with the woman, putting her at the center of care, connecting with her and her partner, and trusting in childbirth.

Not always immediately thinking about possible problems. They are in the back of your mind, I mean, you have to consider them, but not put them first. (NL-11)

In antenatal care, I have been following an excellent midwife and what is important is that she has worked on all levels of the childbirth process, antenatal care, labor care and post-partum. She has a holistic perspective ... (IS-3).

\section{Discussion}

Based on interviews with 44 students from the Netherlands and Iceland, we found that early on in their education, midwifery students identify professionals in maternity care who demonstrate attitudes and behaviors they appreciate.

Students assimilate these attitudes and behaviors into a desirable role model that is representative of the 'ideal midwife', who they can aspire to during their education. Positive role models portrayed woman-centered care, while negative models displayed behaviors students identified as not fitting with good care. Students emphasized that they learnt not only by doing, but that observation and storytelling were viewed as valuable aspects of learning from role models. Moreover, students acknowledged the significant impact of midwifery role models on their own trust in physiological childbirth and future style of practice.

While background and educational context differs between Dutch and Icelandic students, we found no contradictory findings with regard to role models. All students saw role models as a means of picturing aspirational midwives providing high quality care to women and babies. 
Midwifery students' perspectives on how role models contribute to becoming a midwife: A qualitative study |

Similar to studies in midwifery ${ }^{11}$ and other disciplines, the students in our study underlined the importance of role models in their education. New is that the midwifery students also highlighted storytelling as part of role modelling. They appreciated midwives who talked about former cases and how they had managed those. Storytelling has been a part of midwifery education for centuries ${ }^{19}$ and archetypal stories have been passed on, based on the messages they contain. ${ }^{20}$ While storytelling seems a long way from evidence-based practice, stories offer important situational knowledge that, together with midwifery evidence, can be combined to deepen understanding. This makes storytelling a rich and valuable didactic method.

The students remarked that they liked observing their role models, in particular, interactions in challenging situations. In midwifery education, practice is seen as a stimulating and powerful way of learning. ${ }^{21}$ Our participants described how they learnt by observing, comparing and contrasting different role models. This active observation can enrich students with a broader range of professional behavior. Several studies on role models have advocated integrating role modelling into formal midwifery curricula as an essential learning strategy. ${ }^{6,8,10}$ This requires preceptors who are aware of their role modelling at the time it is occurring and intentionally state what they are modelling. ${ }^{4}, 5$ It also includes enhancing students' reflective assessments of the behavior they observe in their preceptors. ${ }^{5}$ However, expectations of constant positive modelling of behavior may not be realistic. ${ }^{10}$

Reflective meetings, where this is purposely addressed, will be valuable for understanding what is desirable and to get a realistic understanding of what is possible, moving away from right/wrong dualism. ${ }^{5}$

Students connected their ideal role models with requisites for becoming a good midwife. The characteristics students identified as desirable for role models and good midwives overlap with the findings of a Dutch study among student midwives on the conceptualization of a 'good' midwife. ${ }^{22}$ This study is based on a theory of professionalism in midwifery. ${ }^{23}$ Our participants mentioned characteristics conditional for woman-centered care, such as empathy, patience, building a relationship with the woman, listening to the woman, involving the partner, firmness when necessary, and promoting physiological childbirth. Additionally, they indicate that a midwife is a professional, who is skilled and experienced, self-confident, critical, restrained with interventions, open to new developments, a skilled communicator with other professionals, and contributes to the positioning of midwifery. These characteristics fit into the eight themes of being a good midwife described by Halldorsdottir \& Karlsdottir's theory of professionalism ${ }^{23}$ and elaborated by Feijen et al. ${ }^{22}$. An aspect in one of the themes that our participants did 


\section{| Chapter 4}

not mention, was the aspect of the midwife nurturing herself to prevent burnout. This is an important aspect in the theme personal and professional development. It is possible that this lack of awareness may be attributed to the students still being novice. However, the demands of the professional context and stressful events make midwives vulnerable for burnout. ${ }^{24}$ This is something that deserves specific attention in education.

In role modelling, the focus of the students was on mastering childbirth from a woman-centered and physiological perspective. Studies in other health disciplines showed that students highly rank patient-centered care 7, 8 However, the emphasis on promoting physiology is midwifery specific and reflects the philosophy of midwifery care. ${ }^{25}$ Findings from a systematic qualitative review, including 35 articles on what matters to women during childbirth, ${ }^{26}$ illustrate that most women want a physiological childbirth, in combination with attentive and safe care. These findings justify the desire of the students in our study to seek role models who can demonstrate this approach to care. This is important, as interventions are widely increasing in maternity care ${ }^{27}$ and the opportunity to observe 'hallmark' midwifery, such as non-intervention in birth, is significantly associated with student self-efficacy in assuming such behaviors themselves ${ }^{28}$ Students need to gain experience, which is not always accessible for them in busy wards. Implementing midwifery models of woman-centered care in hospitals will give students opportunities to actually see and practice woman-centered care..$^{29}$ As educators, we have to ascertain these physiological births more consciously, so students are aware of the learning opportunities when they are present.

\section{Strength and limitations}

Using data from two countries with different pathways to midwifery allowed us to achieve a deeper exploration of role models in midwifery education.

Our cross-sectional qualitative exploration of midwifery students' perspectives on role models does not permit establishing how students' views on role models changes over time, as some participants indicated in this study. Our study also lacks the perspectives of midwives (preceptors and educators) who can give a further understanding of modelling in education. These issues should be a focus of subsequent research.

As students, our participants might have been inclined to give socially desirable answers that match the philosophy of their educational program, even though confidentiality was emphasized. Students self-selected to participate in this study, and it is possible that more successful and apparently confident students 
Midwifery students' perspectives on how role models contribute to becoming a midwife: A qualitative study |

volunteered. To learn more about the meaning and impact of role models,

it is necessary to explore the views of less successful students.

The students said little about the use of technology, and their experiences with this. Although monitors and epidurals came up, the institutional routine to use them made it hard to balance it with their wish for promoting physiological childbirth. Positive role models seemed to help them gain confidence and find balance.

\section{Conclusion}

The students in this study indicated that role models play an important part in their education as a midwife. Role models contribute to the development of their skills, attitudes, behaviors and their identity as a midwife. For this, students create their own 'ideal' role model with attitudes and behaviors they value in a good midwife and to which they can aspire to during their education.

More explicit and critical attention to how and what students learn from role models can enrich the education program. This can support the development of students' philosophy of midwifery and their practice in real life.

\section{Acknowledgements}

We thank the midwifery students who were willing to participate in our study.

\section{Funding}

This research received no specific grant from any funding agency in the public, commercial, or not-for-profit sectors.

\section{Conflict of interest}

No conflict of interest has been declared by the authors. 


\section{| Chapter 4}

\section{References}

1. Gottfreðsdóttir H, Nieuwenhuijze MJ. Midwifery education: Challenges for the future in a dynamic environment. Midwifery. 2018;59:78-80.

2. Beth Perry RN. Role modeling excellence in clinical nursing practice. Nurse Education in Practice. 2009;9(1):36-44.

3. Bandura A. Social Learning Theory. Englewood Cliffs: Prentice Hall; 1977.

4. Cruess SR, Cruess RL, Steinert Y. Role modelling - making the most of a powerful teaching strategy. BMJ. 2008;336(7646):718-21

5. Benbassat J. Role modeling in medical education: the importance of a reflective imitation. Acad Med. 2014;89(4):550-4.

6. Passi V, Johnson N. The hidden process of positive doctor role modelling. Medical Teacher. 2016;38(7):700-7.

7. Passi V, Johnson S, Peile e, Wright S, Hafferty F, Johnson N. Doctor role modeling in medical education: BEME Guide No.27. Medical teacher. 2013;35.

8. Tagawa M. Effects of undergraduate medical students' individual attributes on perceptions of encounters with positive and negative role models. BMC Medical Education. 2016;16(1):164.

9. Baldwin A, Mills J, Birks M, Budden L. Reconciling professional identity: A grounded theory of nurse academics' role modelling for undergraduate students. Nurse Education Today. 2017;59:1-5.

10. Jack K, Hamshire C, Chambers A. The influence of role models in undergraduate nurse education. Journal of Clinical Nursing. 2017;26(23-24):4707-15.

11. Bluff R, Holloway I. The efficacy of midwifery role models. Midwifery. 2008;24(3):301-9.

12. Omer T, Suliman W, Moola S. Roles and responsibilities of nurse preceptors: Perception of preceptors and preceptees. Nurse education in practice. 2016;16:54-9.

13. Burgess A, Oates K, Goulston K. Role modelling in medical education: the importance of teaching skills. The Clinical Teacher. 2016;13(2):134-7.

14. Moser A, Korstjens I. Series: Practical guidance to qualitative research. Part 3: Sampling, data collection and analysis. European Journal of General Practice. 2018;24(1):9-18.

15. Polit D, Beck C. Nursing Research: generating and assessing evidence for nursing practice. Philadelphia: Wolters Kluwer Health; 2012.

16. Korstiens I, Moser A. Series: Practical guidance to qualitative research. Part 4: Trustworthiness and publishing. The European journal of general practice. 2017;24:1-5.

17. Tong A, Sainsbury P, Craig J. Consolidated criteria for reporting qualitative research (COREQ): a 32-item checklist for interviews and focus groups. International Journal for Quality in Health Care. 2007;19(6):349-57.

18. Bohlin H. Bildung and moral self-cultivation in higher education: what does it mean and how can it be achieved? Forum for Public Policy [Internet]. 2008 25th June 2019:[1-10 pp.]. Available from: hppt://www.eric.ed.gov/?id=EJ1099530.

19. Schrader C. Mother and Child were Saved: The memoirs (1693-1740) of the Fresian midwife. Amsterdam: Rodopi; 1987.

20. Olafsdottir O, Kirkham M. Narrative time: Stories, childbirth and midwifery. Childbirth, 
Midwifery students' perspectives on how role models contribute to becoming a midwife: A qualitative study |

Midwifery and Concepts of Time. 2009;17:167-83.

21. Ulrich S. First Birth Stories of Student Midwives: Keys to Professional Affective Socialization. Journal of midwifery \& women's health. 2004;49:390-7.

22. Feijen-de Jong EI, Kool L, Peters LL, Jansen DEMC. Perceptions of nearly graduated fourth year midwifery students regarding a \&\#x2018;good midwife\&\#x2019; in the Netherlands. Midwifery. 2017;50:157-62.

23. Halldorsdottir S, Karlsdottir SI. The primacy of the good midwife in midwifery services: an evolving theory of professionalism in midwifery. Scandinavian Journal of Caring Sciences. 2011;25(4):806-17.

24. Pezaro S, Clyne W, Turner A, Fulton EA, Gerada C. 'Midwives Overboard!' Inside their hearts are breaking, their makeup may be flaking but their smile still stays on. Women and Birth. 2016;29(3):e59-e66.

25. International Confederation of Midwives. ICM Core Document. Philosophy and Model of Midwifery Care. Den Haag: ICM; 2014.

26. Downe S, Finlayson K, Oladapo OT, Bonet M, Gülmezoglu AM. What matters to women during childbirth: A systematic qualitative review. PLoS One. 2018;13(4):e0194906-e.

27. Euro-Peristat Project. European Perinatal Health Report. Core indicators of the health and care of pregnant women and babies in Europe in 2015. 2018.

28. Jordan R, Farley CL. The Confidence to Practice Midwifery. Preceptor Influence on Student Self-Efficacy. Journal of Midwifery \& Women's Health. 2008;53(5):413-20.

29. Lundgren I, Berg M, Nilsson C, Olafsdottir OA. Health professionals' perceptions of a midwifery model of woman-centred care implemented on a hospital labour ward. Women and Birth. 2019. 


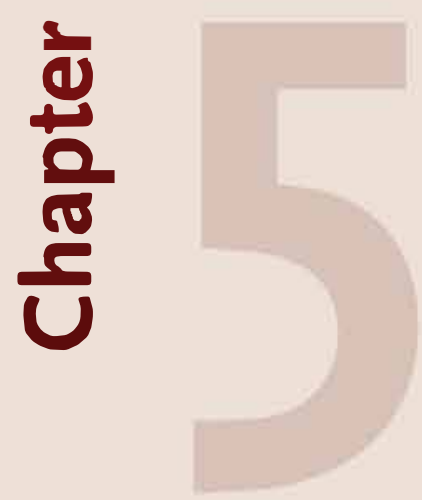

SM Thompson

MJ Nieuwenhuijze

L Budé

$\mathrm{R}$ de Vries

L Kane Low

BMC Pregnancy and Childbirth. 2018; 18:100 


\section{Creating an Optimality Index - Netherlands: a validation study}

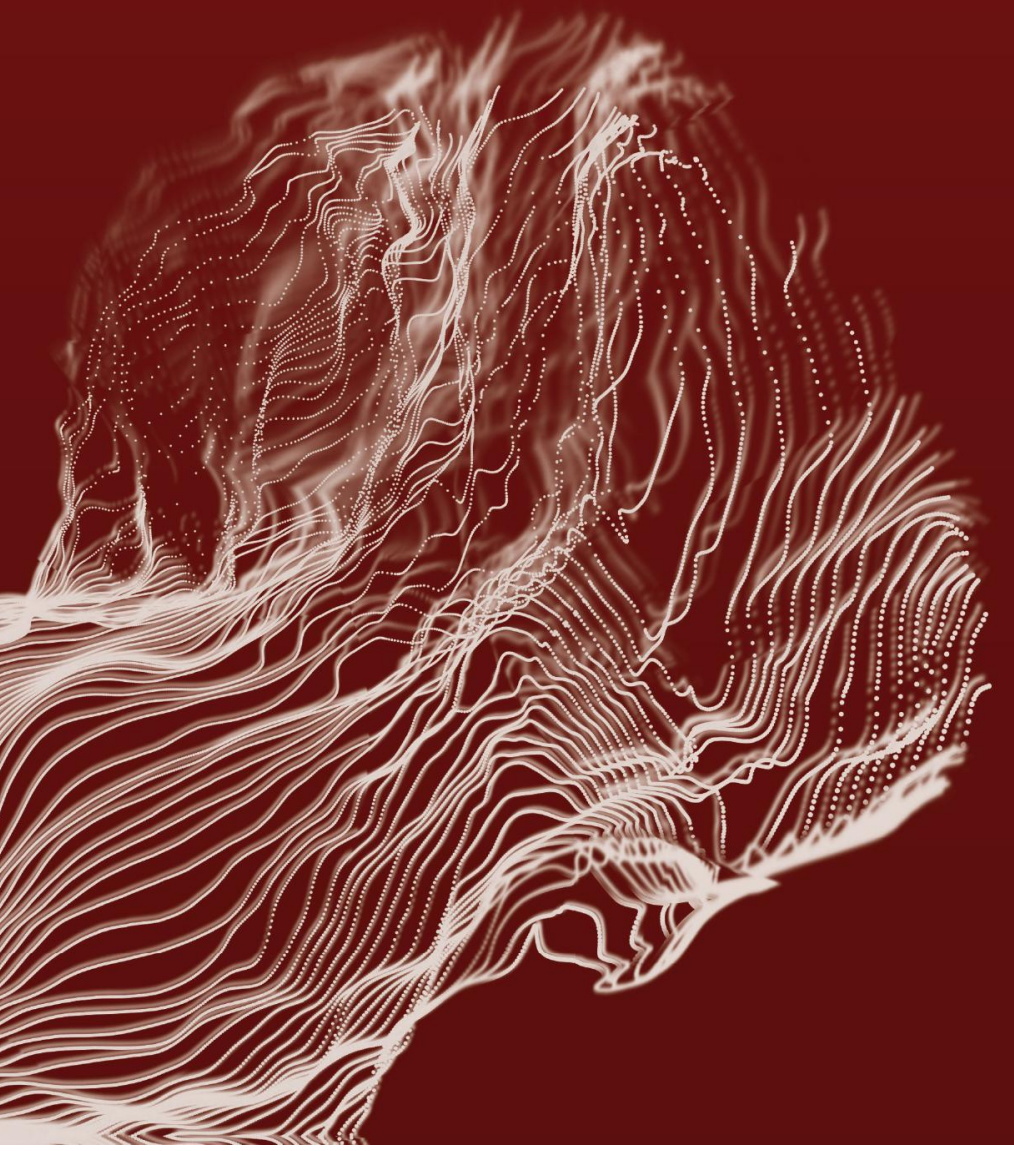




\section{| Chapter 5}

\section{Abstract}

\section{Background}

At present, the maternity care system in the Netherlands is being reorganized into an integrated model of care, shifting the focus of midwives to include increasing numbers of births in hospital settings and clients with medium risk profiles. In light of these changes, it is useful for midwives to have a tool which may help them in reflecting upon care practices that promote physiological childbirth practices.

The Optimality Index-US is an evidence based tool, designed to measure optimal perinatal care processes and outcomes. It has been validated for use in the United States (OI-US), United Kingdom (OI-UK) and Turkey (OI-TR). The objective of this study was to adapt the OI-US for the Dutch maternity care setting (OI-NL).

\section{Methods}

Translation and back translation were applied to create the OI-NL. A panel of maternity care experts $(n=10)$ provided input for face validation items in the OI-NL. Assessment of inter-rater reliability and ease of use was also conducted. Following this, the OI-NL was used prospectively to collect data on 266 women who commenced intrapartum care under the responsibility of a midwife. Twice groups were compared, based on parity and on care-setting at birth.

Mean scores between these groups, corrected for perinatal background factors were assessed for discriminant validity.

\section{Results}

Face validity was established for OI-NL on the basis of expert input. Discriminant validity was confirmed by conducting multiple regressions analyses for parity $(\beta=6.21$, $\mathrm{P}=0.00)$ and for care-setting $(\beta=12.1, \mathrm{p}=0.00)$. Inter-rater reliability was $98 \%$, with one item (Apgar score) sensitive to scoring differences. Qualitative information from midwives demonstrated ease of use as a tool.

\section{Conclusion}

OI-NL is a valid and reliable tool for use in the Dutch maternity care setting. In addition to its value for assessing evidence-based maternity care processes and outcomes, there is potential for use for learning and reflection. Against the backdrop of a changing maternity care system, and due to the specificity of its items OI-NL may be of value as a tool for detecting subtle changes indicative of escalating medicalisation of childbirth in the Netherlands. 
Key words: The Netherlands, physiological childbirth, Optimality, validation, Optimality Index-Netherlands

\section{Background}

In the Netherlands, midwives in primary care are responsible for care provision to healthy women with uncomplicated pregnancies. Women are referred to obstetrician-led care (secondary care) by midwives when there are complications or an increased risk of complications. Increasingly, midwives are also working in hospitals under the supervision of obstetricians, where they care for the majority of women who have been referred because of complications in pregnancy or birth.1, 2

A physiological approach to childbirth is considered a core midwifery competency ${ }^{3}$ and Dutch midwives report viewing the promotion and support of physiological childbirth as fundamental to their role. ${ }^{4}$ However, this viewpoint appears at odds with quantitative studies from the Netherlands that demonstrate increasingnumbers of non-urgent referrals to obstetric-led care in the intrapartum period and a broad diversity in referral rates between midwifery practices, varying between 9.7 and $63.7 \% .^{5}$ It is unlikely that these differences are caused by risk of complications because of different population characteristics alone, but could also be related to differences in the ways midwives practice or to midwife perceptions of the likelihood of adverse events in birth.6,7 Moreover, variations in specific areas of midwifery practice have been noted, including a high variation in the incidence of episiotomy between Dutch primary care midwifery practices. ${ }^{8}$ Another example of a less physiological approach to childbirth is the limited use of non-supine birthing positions in hospital and, notably, primary care settings. ${ }^{?}$

These examples suggest that Dutch midwives sometimes find it challenging to promote and support physiological childbirth. Hospital settings may negatively impact on the ways in which midwives facilitate physiological childbirth. ${ }^{10}$ Other challenges to physiological childbirth practice may include environmental factors such as medical hierarchy or nursing staff. Hospital midwives may feel inhibited in their role as promoters and supporters of physiological childbirth in the hospital setting, which is oriented towards a biomedical, rather than a holistic approach to childbirth. This is of concern as physiological childbirth, a complex biological and hormonal process ${ }^{11}$ which unfolds naturally when undisturbed, ${ }^{12}$ can be empowering ${ }^{13}$ and salutogenic. ${ }^{14}$ While obstetric interventions are beneficial in certain situations, the over-use of these can result in unintended consequences, including iatrogenic harm ${ }^{15}$ to individual women and their babies and unsustainable economic costs for the wider society. ${ }^{16}$ 


\section{| Chapter 5}

At present, the Dutch midwifery system is evolving towards an integrated model of care, and increasing numbers of births take place in hospital settings. Integrated care includes an extended remit for midwives to provide care both medium risk and low risk women. Rates of obstetric interventions in the Netherlands remain still low compared to other industrialized countries, ${ }^{17}$ however, there is concern among midwives and others that the change to an integrated model of care may lead to more interventions. ${ }^{18,19}$

Against the backdrop of significant changes to the Dutch model of midwifery, it is helpful to have a tool that can be used to investigate developments in the intrapartum use of interventions and promote reflection on the evidence-based use of these interventions, and thereby prevent the escalation towards unnecessary disruption of physiological childbirth. One such tool is the Optimality Index (OI).

\section{Optimality and the Optimality Index}

Optimality as a concept in perinatal health care, based on work done by Precht1, ${ }^{20}$ can be defined as the maximal perinatal outcome, with minimal intervention, placed within the context of the woman's social, medical, and obstetric history. In 1996, the Optimality concept was used as the basis for a tool developed to measure the quality of midwifery care in the Netherlands. ${ }^{21}$ This work, in turn, was used as the foundation for the Optimality Index-United States (OI-US). ${ }^{22}$ The OI-US has two components: 1) a Perinatal Background index (PBI) - 14 items on pre-existing maternal risk characteristics, such as age, partner status, lifestyle and previous obstetric history and, 2) the Optimality Index (OI) with 42 items on the prenatal, birth and postnatal domains. Optimal care practices are scored with a 1; non-optimal practices are scored as 0 . This allows a care professional to calculate a percentage score for both perinatal background factors (PBI) and current pregnancy, birth and postpartum and neonatal items (OI). The OI assumes that a risk free status without medical intervention is the most optimal and scores $100 \%{ }^{23}$ The OI-US has been described as a tool in which professionals involved in the provision of maternity care can appraise both processes and outcomes of maternity care for low- and medium risk women. ${ }^{24}$ In addition, it may also have potential as an educational tool. A small study $(n=9)$ from the United States examined the OI-US specifically as a tool for learning. ${ }^{25}$ The OI-US was used as the basis for a number of educational activities with student midwives. Most students considered it a useful tool for assessing and reflecting on care given during childbirth and for supporting the awareness for evidence-based use of interventions. While these findings are from a small qualitative study and, as such, should be interpreted cautiously, they are of interest to 
midwifery educators when considering how (future) midwives can best be supported in their role as facilitators of physiological childbirth.

The OI has been validated for use in the United States (OI-US) ${ }^{23}$ and, following tailoring to the specific care setting, it has also been validated for use in the United Kingdom ${ }^{24}$ and Turkey. ${ }^{26}$

Recently, the OI has also been adapted to fit recorded data in a large perinatal database in the Netherlands ${ }^{27}$ - this 'lean' version of the OI (OI-NL2015) was developed specifically for use in the Dutch Birth Centre Study, ${ }^{28}$ in which data were used from the Dutch Perinatal Registry (PRN database). The tailoring of the Optimality Index to variables in the PRN database deviates from pre-existing versions of the Optimality Index (OI-US, OI-UK and OI-TR) by including only items available in that database $(\mathrm{n}=31)$. While this may be a pragmatic choice aimed at ensuring availability of data, this approach is less robust than a complete adaptation and validation of the Optimality Index specific to a country's maternity care context, as demonstrated in the United Kingdom and Turkey. ${ }^{24,}{ }^{26}$ Importantly, as Hermus et al. also note, the OI-NL2015 has not been validated for use in the Netherlands. ${ }^{27}$

Optimality as a concept is in line with the Dutch perspective of childbirth as a fundamentally physiological process. ${ }^{21}$ The evidence-based care practices reflected in its items support non-intervention to enhance physiological childbirth in combination with maximal perinatal outcomes. However, the OI-US is not tailored to care in the Netherlands and has not been validated for use there.

Our study details the development and validation of the OI for the Dutch maternity care setting, creating an Optimality Index-Netherlands (OI-NL) that has face and discriminant validity and is a reliable instrument for measuring application of evidence based care to support healthy physiological childbirth and identifying the care practices that support and promote this physiology.

\section{Methods}

This study was conducted in two phases (a visual overview of these can be found in Appendix 1). In the first phase, back and forth translation and input for an expert panel (face validity) were used to create a Dutch language version. Subsequently, discriminant validity and inter-rater reliability of the Optimality Index-Netherlands (OI-NL) were assessed. The study was approved by the ethics committee, Zuyderland Zuyd (16-N-69). 


\section{| Chapter 5}

\section{Development of the OI-NL}

Following the steps for cross-cultural validation, ${ }^{29}$ the OI-US was translated from English to Dutch by two of the authors (ST and MN) both of whom have midwifery expertise in the Dutch setting and are fluent in both languages. Some small discrepancies in translation were resolved by discussion before synthesis into one document. The document was then translated back into English by two linguistic experts and this translation was reviewed for faithfulness to the OI-US version by two of the authors (LKL and RdV), both of whom are familiar with the content and context of the OI-US. Appendix 2 contains an overview of the items contained in both the OI-US and the OI-NL.

\section{Face validation}

A Dutch language translation was then presented to a panel of 10 experts in Dutch maternity care, consisting of community midwives $(n=2)$, hospital midwives $(n=2)$, obstetricians $(n=2)$, midwifery lecturers $(n=2)$ and midwife researchers $(n=2)$. They were requested to review all the items within the OI-NL to determine the relevance and accuracy of the items in relationship to care within the Netherlands. They were also invited to identify items that were not part of the OI-US but were relevant to the Dutch context. The feedback on the PBI (this comprises the first 15 items of the OI$\mathrm{NL}$ ) focused on the item pertaining to ethnicity, this was adapted to reflect ethnicity in the Netherlands and simplified for use. Both midwives and obstetricians pointed out the possibility of Body Mass Index (BMI) values being incorrectly scored and suggested collating values for height and weight and calculating the BMI once data was collected in order to reduce errors. The further feedback concerned a number of items which we adapted, it was decided to group previous birth by caesarean section into an item specifying 'intrapartum complications', adding 'instrumental birth' to the item 'intrapartum complications' as they considered these relevant to the obstetric history of multiparous women. They also suggested separating previous fetal death after 16 weeks gestation from previous antenatal complications, as detailed in the OI-US. We also opted to include the item 'domestic/intimate partner violence' as a perinatal background factor, adding detail to clarify that this item pertains to both social history and current pregnancy.

For the OI items, the experts suggested the removal of the item 'non-stress test in pregnancy' as it is not part of midwife-led antenatal care in the Netherlands. Clarification was requested on the item 'liquor' as, without colour classification (clear/ meconium stained) it was considered ambiguous. The item 'delayed cord clamping' was added, as this is recommended practice in physiological births..$^{30}$ We adapted the quantity of blood loss (item postpartum haemorrhage) from $500 \mathrm{ml}$ to $1000 \mathrm{ml}$, 
reflecting the Dutch definition of $\mathrm{PPH} .{ }^{31} \mathrm{~A}$ similar adaptation was made for the item on placenta retention, again bringing the duration of time for defining retention in line with Dutch definitions. ${ }^{31}$ In addition to gestation at birth, our experts suggested that the index should reflect the certainty of gestation, as first trimester (dating) ultrasonography is a routine part of care in the Netherlands. ${ }^{32}$ Following World Health Organization's (WHO) recommendations for early infant feeding, ${ }^{33}$ we added early breastfeeding as an item and used the WHO guidelines to define the measure. Further to these suggestions, some minor linguistic feedback was given in order to ensure clarity of wording in the Dutch translation of the OI.

\section{Pilot test}

The OI-NL was then pilot tested in a primary midwifery practice in order to determine its feasibility as a data collection instrument in this environment. Three primary care midwives in one midwifery practice used the OINL on 15 occasions. They reported both clarity of items and ease of use. An English or Dutch language version of the OI-NL is available from the authors.

\section{Discriminant validity}

\section{Settings and participants}

Between September 2016 and January 2017, 161 Dutch midwifery practices linked to the department of midwifery education at Zuyd University of Applied Sciences were sent written information about this study. They were invited to participate in this study and collect data on the women that started their birth under their care.

\section{Data Collection}

In the midwifery practices that agreed to participate, women were approached for consent either during pregnancy or shortly after birth. Once consent was given, the midwife completed the OI-NL data form in a de-identified manner using information about the pregnancy, labour and birth and early postpartum period recorded in the case notes of each individual client, shortly after each birth. Primiparous and multiparous women who were in midwifery care at the start of labour were included. 


\section{| Chapter 5}

\section{Power calculation and data analysis}

For assessing discriminant validity of the OI-NL, we conducted our data analysis using completed OI-NL forms.

A sample size calculation indicated that 28 completed OI-NLs per defined group ( $\mathrm{n}=56$ in total) would be adequate to demonstrate an effect size of $0.5(\boldsymbol{\alpha}=<0.05$, $80 \%$ power) using an independent t-test to compare mean OI scores between two independent groups: primiparous and multiparous women.

For each participant, percentages scores were calculated for the total OI-NL and the PBI and OI part of the OI-NL. These were used for analysis. A priori, we established that forms with more than $10 \%$ missing would be excluded. When less than $10 \%$ of the items were missing the dominator would be reduced, in accordance with the instructions provided by the OI-US. ${ }^{22}$

We assessed discriminant validity by testing two hypotheses. We hypothesized that primiparous women in our data set will demonstrate a lower OI score than multiparous women. This assumption is based on national data, which show that primiparous women have more interventions during birth than multiparous women. ${ }^{17}$ This finding will demonstrate that the OI is sensitive to these intervention differences between primiparous and multiparous women. Furthermore, we examined the association between birth-setting and the Optimality Index Score, hypothesizing that women cared for in either a home or out-patient (polyclinic) midwife-led setting will demonstrate significantly higher OI scores than women requiring intrapartum transfer to obstetric-led care. ${ }^{34}$

Using SPSS version 24, we conducted multiple linear regressions analysis, using the OI percentage score as dependent variable and parity, PBI score and midwifeled births as independent variables. Parity was a dichotomous variable, coded as 0 for primiparous women and 1 for multiparous women, generating results that indicate the effect of parity, corrected for perinatal background factors. Midwife-led care was a dichotomous variable, coded as 0 for obstetric-led care and 1 for midwife-led care. Significance was set at $5 \%$ (two-tailed test).

\section{Inter-rater reliability}

Percentage agreement was measured in order to determine inter-rater reliability between two raters. The first author of this study (ST) and a midwife working with the OI-NL scored a data set from 25 clients in one midwifery practice to examine reliability of the OI-NL as a whole and at item level. Agreement of more than $80 \%$ was considered evidence of reliability. ${ }^{35}$ 
Creating an Optimality Index - Netherlands: a validation study |

\section{Results}

The Optimality Index-Netherlands consisted of a PBI (15 items) and OI (42 items). Discriminant validity and inter-rater reliability were assessed.

\section{Pilot test}

The three midwives, based in a primary care midwifery practice, who tested the OINL, reported that the items were clear and easy to interpret. They estimated the time needed to complete the OI-NL at around 10 minutes and reported that completing the OI-NL in the early postpartum period was the most effective while they were still able to clearly remember details about the client, the care that had been given and while they still had easy access to the medical documentation of each client.

\section{Confirmation of Validity}

The 15 midwifery practices that participated in the study were of mixed size, including solo and group practices. The practices were situated throughout the Netherlands covering both urban and rural areas. We sent 505 OI-NL forms to these midwifery practices; of these, 272 completed forms were returned (53.8\%). Seventy-six forms were returned with missing items. In 72 cases, missing items constituted no more than $10 \%$. Four forms were excluded as there was greater than $10 \%$ of data missing and another two forms were excluded, as these had been completed for women who received obstetric care during pregnancy so were not under the care of the midwife at the start of labour. This left 266 completed forms, more than the a priori 56 forms required for sufficient power sample to assess discriminant validity and sufficient in number to detect differences between the groups, based on the power calculation.

The main characteristics of the participants are presented in Table 1. 


\section{| Chapter 5}

Table 1: Characteristics of women included in the sample

\begin{tabular}{|l|c|}
\hline Age & Participants No. \\
\hline Mean age & $(\%)$
\end{tabular}

\section{Discriminant Validity}

The mean PBI percentage scores for primiparous and multiparous women in our study were $92.61 \%$ and $91.44 \%$ respectively, the mean OI percentage scores for primiparous and multiparous women in our study were $82.98 \%$ and $89.00 \%$ respectively (Table 2). For women who had midwife-led care, mean PBI scores were 92.66\%. For the obstetric-led care, these were $90.02 \%$. Mean OI percentage scores were $90.61 \%$ (midwife-led) and $78.54 \%$ (obstetric-led) respectively (table 3 ). 
Creating an Optimality Index - Netherlands: a validation study |

Table 2: Descriptive statistics for parity of the women in our study

\begin{tabular}{|c|c|c|c|c|c|}
\hline & $\mathbf{N}$ & $\begin{array}{l}\text { Min. } \\
\text { \% score }\end{array}$ & $\begin{array}{c}\text { Max. } \\
\% \text { score }\end{array}$ & $\begin{array}{l}\text { Mean } \\
\text { \% score }\end{array}$ & $\begin{array}{c}\text { Std. } \\
\text { Deviation }\end{array}$ \\
\hline \multirow{4}{*}{$\begin{array}{l}\text { PBI percentage } \\
\text { - Total group } \\
\text { - Primiparous women } \\
\text { - Multiparous }\end{array}$} & & & & & \\
\hline & 266 & 64.29 & 100.00 & 91.88 & 8.26 \\
\hline & 97 & 65.29 & 100.00 & 92.64 & 9.39 \\
\hline & 169 & 66.67 & 100.00 & 91.44 & 7.53 \\
\hline \multirow{4}{*}{$\begin{array}{l}\text { OI percentage } \\
\text { - Total group } \\
\text { - Primiparous women } \\
\text { - Multiparous }\end{array}$} & & & & & \\
\hline & 266 & 58.97 & 100.00 & 86.81 & 8.38 \\
\hline & 97 & 58.97 & 100.00 & 82.98 & 9.80 \\
\hline & 169 & & & 89.00 & 6.53 \\
\hline
\end{tabular}

Table 3: Descriptive statistics for care setting of the women in our study

\begin{tabular}{|c|c|c|c|c|c|c|}
\hline & $\mathrm{N}$ & $\begin{array}{l}\text { Min. } \\
\% \text { score }\end{array}$ & $\begin{array}{l}\text { Max. } \\
\% \text { score }\end{array}$ & $\begin{array}{l}\text { Mean } \\
\% \text { score }\end{array}$ & $\begin{array}{c}\text { Std. } \\
\text { Deviation }\end{array}$ & 97 \\
\hline \multicolumn{7}{|l|}{ PBI percentage } \\
\hline - Total group & 196 & 65.73 & 100.00 & 91.57 & 8.85 & \\
\hline - Midwife-led & 115 & 65.73 & 100.00 & 92.66 & 8.38 & \\
\hline - Obstetric-led & 81 & 66.67 & 100.00 & 90.02 & 9.31 & \\
\hline \multicolumn{7}{|l|}{ OI percentage } \\
\hline - Total group & 196 & 60.20 & 97.62 & 85.62 & 8.42 & \\
\hline - Midwife-led & 115 & 76.19 & 97.62 & 90.61 & 4.62 & \\
\hline - Obstetric-led & 81 & 60.20 & 92.86 & 78.54 & 7.48 & \\
\hline
\end{tabular}

In testing our hypotheses, the multiple linear regressions analysis demonstrates that parity is a significant predictor of the OI percentage score, also when corrected for perinatal factors (PBI score) with a $\beta=6.21(\mathrm{p}=.00)$ (Table 4). 
| Chapter 5

Table 4: Multiple linear regressions: Parity

\begin{tabular}{|c|c|c|c|c|c|c|c|}
\hline \multirow[b]{2}{*}{ Model } & \multicolumn{2}{|c|}{$\begin{array}{l}\text { Unstandardized } \\
\text { Coefficients }\end{array}$} & \multirow{2}{*}{$\begin{array}{l}\text { Standardi- } \\
\text { zed Coef- } \\
\text { ficients } \\
\text { Beta }\end{array}$} & \multirow[b]{2}{*}{$\mathbf{t}$} & \multirow[b]{2}{*}{$\mathbf{p}$} & \multicolumn{2}{|c|}{$\begin{array}{c}95.0 \% \\
\text { Confidence } \\
\text { Interval for B }\end{array}$} \\
\hline & B & $\begin{array}{l}\text { Std. } \\
\text { Error }\end{array}$ & & & & Lower & Upper \\
\hline (Constant) & 68.38 & 5.43 & & 12.59 & 0.0 & 57.51 & 79.24 \\
\hline Parity & 6.21 & 0.99 & 0.36 & 6.25 & 0.0 & 4.23 & 8.20 \\
\hline PBI percentage & 0.16 & 0.06 & 0.16 & 2.72 & 0.01 & 0.04 & 0.27 \\
\hline
\end{tabular}

Furthermore, the professional providing care is a significant factor, with midwife-led care (either at home or out-patient (polyclinic) demonstrating significantly higher OI scores than obstetric-led births $(\beta=12.1, \mathrm{p}=.00)$, when corrected for perinatal factors (Table 5).

Table 5: Multiple linear regressions: Care-setting

\begin{tabular}{|c|c|c|c|c|c|c|c|}
\hline \multirow[b]{2}{*}{ Model } & \multicolumn{2}{|c|}{$\begin{array}{l}\text { Unstandardized } \\
\text { Coefficients }\end{array}$} & \multirow{2}{*}{$\begin{array}{c}\text { Standardi- } \\
\text { zed Coef- } \\
\text { ficients } \\
\text { Beta }\end{array}$} & \multirow[b]{2}{*}{$\mathbf{t}$} & \multirow[b]{2}{*}{ p } & \multicolumn{2}{|c|}{$\begin{array}{c}95.0 \% \\
\text { Confidence } \\
\text { Interval for B }\end{array}$} \\
\hline & B & $\begin{array}{l}\text { Std. } \\
\text { Error }\end{array}$ & & & & Lower & Upper \\
\hline (Constant) & 79.24 & 4.46 & & 17.78 & 0.0 & 70.33 & 88.15 \\
\hline Care setting & 12.09 & 0.88 & 0.71 & 13.78 & 0.0 & 10.34 & 13.84 \\
\hline PBI percentage & -0.01 & 0.05 & -0.01 & -0.16 & 0.88 & -0.11 & 0.09 \\
\hline
\end{tabular}

\section{Inter-rater reliability}

Overall rater agreement was calculated to be $98 \%$. We also examined rater agreement per item. For the PBI, rater agreement ranged from $96 \%$ to $100 \%$, with just two of the fifteen items showing a difference in scoring. Of the 42 items comprising the 
OI, there were differences in scoring in 16 items, with agreement ranging from $88 \%$ to $100 \%$. One item, Apgar score at 5 minutes, was outside this range, with an agreement rate of $76 \%$. This result suggests that the item Apgar score is sensitive for incorrect scoring when using the OI-NL.

\section{Discussion}

Our study confirms that the OI-NL is a valid and reliable tool for use in the Dutch low risk maternity care setting. We tested the discriminant validity of the instrument by comparing the scores of primiparous and multiparous women and found that the OI-NL was sensitive to differences in obstetric interventions during birth.

Primiparous women had significantly lower OI-NL percentage scores than multiparous women, also when corrected for perinatal background factors. Our sample also showed that midwife-led care is associated with lower levels of obstetric intervention. This is line with our hypothesis as in the Dutch primary care settings midwives give care to healthy women with physiological pregnancies and refer women with complications or pathologies for obstetric-led care.

As we noted above, the OI-NL includes one item that is particularly susceptible to rater error. The 'Apgar Score' item was the only one with less than $80 \%$ rater agreement, ${ }^{35}$ - perhaps because the clinical record has scores for three different points in time (1, 5, and 10 minutes). It is likely that this issue can be addressed by emphasizing the use of the five minute Apgar score in the OI-NL instructions and not the score at one or ten minutes.

The OI-US has been described as a tool in which professionals involved in the provision of maternity care can appraise both processes and outcomes of maternity care for low- and medium risk women. ${ }^{24}$ We consider that the OI-NL could be a useful tool for experienced midwives who may have more routinized care practices or who may be less 'at home' with evidence-based ways of working. Many care practices are deeply entrenched in midwifery practice and, as such, it may be difficult for professionals to recognize these - Wagner described this phenomenon metaphorically, using the phrase 'fish do not know that water exists', meaning that professional socialization, particularly where birth is medicalized, can lead to difficulty in pinpointing a 'normal' birth. ${ }^{36}$ The OI-NL is a tool that may help professionals to 'see water', recognize routinized care practices and re-examine and reflect upon these. Evidence-based guidelines that support physiological approaches to childbirth can empower midwives, particularly in medicalized care settings. ${ }^{4}$ However, midwives appear to be influenced by factors other than Evidence Based Medicine (EBM), including personal attitudes towards physiological childbirth and 


\section{| Chapter 5}

inter-professional collaboration with others with similar and differing perceptions of obstetric risk. ${ }^{37}$ Midwives also report that in hospital settings, they feel they must 'account' for decisions regarding physiological childbirth and experience limitations in the way they can 'experiment' with e.g. birthing positions. ${ }^{4}$ Providing a validated, evidence-based tool can support midwives in identifying interventions that are evidence based compared to those that are debatable and not evidence-based. While recognizing non-evidence based care is important, other skills, such as the ability to challenge non-evidence based practice and advocate practices that support and promote physiology, irrespective of care setting, will also be relevant. While the evidence is limited to one small study, the OI-NL has potential as an education tool, promoting reflection and discussion ${ }^{25}$ about the diversity of midwifery practice that student midwives may experience in midwifery practices in the Netherlands and because it is a valid instrument that captures evidence-based physiological childbirth practices, specific to the Dutch context.

It is perhaps reflective of the dynamism of Dutch midwifery that two studies relating to the Optimality Index in the Netherlands have emerged at the same time. ${ }^{27}$ While both of these studies focus on the concept of optimality within the Netherlands, they are fundamentally different, with different purposes. OI-NL2015 was developed for use as a research tool to use within a specific, larger study of birth centres. It is linked to the PRN, a large perinatal database, which has both advantages and disadvantages. The link to the PRN allows immediate access to a large amount of data, but it also makes the OI-NL2015 a 'lean' instrument, capturing only 31 variables included in the database. The OI-NL is a broader tool with 57 variables, comparable with OI-US, ${ }^{23} \mathrm{OI}-\mathrm{UK}^{24}$ and OI-TR, ${ }^{26}$ capturing evidence-based physiological childbirth practices, tailored to the specific Dutch setting. It is valid and offers maternity care providers the opportunity to reflect on both care processes and outcomes from prospective, current data, while data from the PRN database are already one to two years old at publication. The OI-NL has the additional advantage of being a tool that could be used to evaluate different models of maternity care. The OI-NL2015 was designed to examine maternity care within birth centres. The OI-NL validated here, with the specificity of its 42 items and its attention to variables not available in existing registries, could allow for the assessment and comparison of aspects of the delivery and outcomes of care in a variety of settings. However, an assessment of the effectiveness of the Dutch midwifery care model or comparisons between midwifery and obstetric led models of care were not the focus of this study. 


\section{Strength and weakness of the study}

This study has a number of strengths, notably which, as far as we are aware, it is the first validation study of the OI that uses prospective data from midwives offering care for women with physiological pregnancies, rather than pre-existing data sets or clients with mixed risk profiles. ${ }^{26}$ While a data set would have offered larger amounts of data for validation, an earlier validation study ${ }^{24}$ indicated that the OI indicated potential as a prospective tool but was not tested as such. Our study operationalized this approach, with sufficient prospective data to meet the sample size calculation. This study offers a broad overview of the items relevant for reflection on the physiology of childbirth within the Dutch midwifery care setting, including an assessment of validity.

This study has some weaknesses, namely a large amount of missing data $(n=70)$ for the actual place of birth. The OI-US includes an item on the intended place of birth at the start of the intrapartum period but does not include an item detailing the actual place of birth. In our original translation, we followed the OI-US lead. Reflection and discussion between the authors once data collection had commenced led to a decision, one month into data collection, to request that midwives document the care setting (midwife-led home or out-patient (polyclinic) or transfer to obstetric care. While it was useful for us to collate information about the place of birth, it does not affect the assessment of validity of the items contained within the OI-NL.

\section{Conclusion}

Our study confirms that the OI-NL is a valid and reliable instrument that captures the relevant, evidence-based items that support physiological childbirth, tailored to the Dutch maternity care system. Importantly, in a time in which there are concerns about the medicalisation of childbirth - in the Netherlands and elsewhere - it brings an evidence-based, physiological approach to childbirth into sharp focus and offers potential as an instrument measuring detailed care processes and outcomes of physiological maternity care in the Dutch System. 


\section{| Chapter 5}

\section{References}

1. Amelink-Verburg MP, Buitendijk SE. Pregnancy and labour in the Dutch maternity care system: what is normal? The role division between midwives and obstetricians. J Midwifery Womens Health. 2010;55(3):216-25.

2. Cronie D, Rijnders M, Buitendiik S. Diversity in the Scope and Practice of Hospital-Based Midwives in the Netherlands. Journal of Midwifery \& Women's Health. 2012;57(5):469-75.

3. International Confederation of Midwives. International Definition of the Midwife. Core Document. The Hague.2017.

4. Thompson SM, Nieuwenhuijze MJ, Low LK, de Vries R. Exploring Dutch midwives attitudes to promoting physiological childbirth: A qualitative study. Midwifery. 2016;42:67-73.

5. Offerhaus PM, Geerts C, de Jonge A, Hukkelhoven CWPM, Twisk JWR, Lagro-Janssen ALM. Variation in referrals to secondary obstetrician-led care among primary midwifery care practices in the Netherlands: a nationwide cohort study. BMC Pregnancy and Childbirth. 2015;15(1):42.

6. Offerhaus PM, Hukkelhoven CWPM, de Jonge A, van der Pal-de Bruin KM, Scheepers PLH, Lagro-Janssen ALM. Persisting Rise in Referrals During Labor in Primary Midwife-led Care in The Netherlands. Birth. 2013;40(3):192-201.

7. Scamell M, Alaszewski A. Fateful moments and the categorisation of risk: Midwifery practice and the ever-narrowing window of normality during childbirth. Health, Risk \& Society. 2012;14(2):207-21.

8. Seijmonsbergen-Schermers AE, Geerts CC, Prins M, van Diem MT, Klomp T, Lagro-Janssen ALM, et al. The Use of Episiotomy in a Low-Risk Population in The Netherlands: A Secondary Analysis. Birth. 2013;40(4):247-55.

9. Nieuwenhuijze M, De Jonge A, Korstiens I, Lagro-Janssen T. Factors influencing the fulfillment of women's preferences for birthing positions during second stage of labor. Journal of Psychosomatic Obstetrics \& Gynecology. 2012;33(1):25-31.

10. Priddis H, Dahlen H, Schmied V. Juggling Instinct and Fear: An Ethnographic Study of Facilitators and Inhibitors of Physiological Birth Positioning in Two Different Birth Settings. International Journal of Childbirth. 2011;1(4):227-41.

11. Buckley SJ. Executive Summary of Hormonal Physiology of Childbearing: Evidence and Implications for Women, Babies, and Maternity Care. J Perinat Educ. 2015;24(3):145-53.

12. Romano AM, Lothian JA. Promoting, Protecting, and Supporting Normal Birth: A Look at the Evidence. Journal of Obstetric, Gynecologic \& Neonatal Nursing. 2008;37(1):94-105.

13. Humenick SS. The Life-Changing Significance of Normal Birth. J Perinat Educ. 2006;15(4):1-3.

14. Downe S. Towards salutogenic birth in the 21st century. In: Walsh D, editor. Essential Midwifery Practice: Intrapartum Care: Wiley Blackwell; 2010.

15. Requejo J, Victora C, Bryce J. Data Resource Profile: Countdown to 2015: Maternal, Newborn and Child Survival. International Journal of Epidemiology. 2014;43(2):586-96.

16. Gibbons L, Belizán J, Lauer J, Betrán A, Merialdi M, Althabe F. The Global Numbers and Costs of Additionally Needed and Unnecessary Caesarean Sections Performed per Year: Overuse as a Barrier to Universal Coverage health systems financing. World Health Report 2010. 2010;30. 
Creating an Optimality Index - Netherlands: a validation study |

17. Perined. Perinatal Zorg in Nederland 2015. Utrecht: Perined; 2015.

18. Perdok H, Jans S, Verhoeven C, Henneman L, Wiegers T, Mol BW, et al. Opinions of maternity care professionals and other stakeholders about integration of maternity care: a qualitative study in the Netherlands. BMC pregnancy and childbirth. 2016;16(1):188-.

19. Warmelink JC, de Cock TP, Combee Y, Rongen M, Wiegers TA, Hutton EK. Student midwives' perceptions on the organisation of maternity care and alternative maternity care models in the Netherlands - a qualitative study. BMC Pregnancy and Childbirth. 2017;17(1):24.

20. Prechtl H. The Optimality Concept. Early Human Development [Internet]. 1980; (4):[201-5 pp.].

21. Wiegers TA, Keirse MJNC, Berghs GAH, van der Zee J. An approach to measuring quality

of midwifery care. Journal of Clinical Epidemiology. 1996;49(3):319-25.

22. Murphy PA, Fullerton JT. Measuring Outcomes of Midwifery Care: Development of An Instrument To Assess Optimality. Journal of Midwifery \& Women’s Health. 2001;46(5):274-81.

23. Low LK, Miller J. A Clinical Evaluation of Evidence-Based Maternity Care Using the Optimality Index. Journal of Obstetric, Gynecologic \& Neonatal Nursing. 2006;35(6):786-93.

24. Sheridan M, Sandall J. Measuring the best outcome for the least intervention: can the Optimality Index-US be applied in the UK? Midwifery. 2010;26(6):e9-e15.

25. van Olphen Fehr J. Using the Optimality Index-US to Teach Midwifery Students to Recognize and Implement Evidence-Based Practices That Promote Optimal Outcomes in Perinatal Health. Journal of Midwifery \& Women’s Health. 2013;58(5):531-7.

26. Yucel C, Taskin L, Low LK. Validity and reliability of the Turkish version of the Optimality Index-US (OI-US) to assess maternity care outcomes. Midwifery. 2015;31(12):1135-42.

27. Hermus M, Boesveld I, van der Pal-de Bruin K, Wiegers T. Development of the Optimality Index-NL2015, an Instrument to Measure Outcomes of Maternity Care. Journal of Midwifery \& Women’s Health. 2017;62(5):580-8.

28. Hermus M, Wiegers T, Hitzert M, Boesveld I, Van den Akker E, Akkermans H, et al. The Dutch Birth Centre Study. Study design of a programmatic evaluation of the effect of birth centre care in the Netherlands. BMC pregnancy and childbirth. 2015;15:148.

29. Sousa VD, Rojjanasrirat W. Translation, adaptation and validation of instruments or scales for use in cross-cultural health care research: a clear and user-friendly guideline. Journal of Evaluation in Clinical Practice. 2011;17(2):268-74.

30. WHO. Delayed umbilical cord clamping for improved maternal and infant health and nutrition outcomes. Geneva: World Health Organization 2014.

31. Verloskundige Vademecum. Eindrapport van de commissie Verloskunde van het college voor zorgverzekeringen. Diemen: CVZ; 2003.

32. NVOG. Modelprotocol 'Datering voor de zwangerschap'. 2011. Accessed:21st October 2017. Available from: https://www.nvog.nl/wp-content/uploads/2018/09/Datering-van-dezwangerschap-2.0-update-aug-2018.pdf.

33. UNICEF W. Global Strategy for Infant and Young Child Feeding. Geneva: World Health Organization; 20032003.

34. Sandall J, Soltani H, Gates S, Shennan A, Devane D. Midwife-led continuity models versus other models of care for childbearing women. Cochrane Database of Systematic Reviews. 2016(4). 


\section{| Chapter 5}

35. McHugh M. Interrater reliability. The kappa statistic. Biochemia medica : časopis Hrvatskoga društva medicinskih biokemičara / HDMB. 2012;22:276-82.

36. Wagner M. Fish can't see water: the need to humanize birth. International Journal of Gynecology \& Obstetrics. 2001;75(S1):S25-S37.

37. Daemers D, Van Limbeek-Reinaerts E, Wijnen H, Nieuwenhuijze M, De Vries R. Factors influencing the clinical decision-making of midwives: a qualitative study. BMC Pregnancy and Childbirth. 2017;17.

\section{Appendix 1}

\section{Steps in the validation process}

Cross-cultural and face validation

January - June 2016

- Back and forth translation by linguistic experts and midwifery professionals

- Synthesis into Dutch language document

- Input from an expert panel - does the instrument appear to capture the relevant, evidence-based items that support physiological childbirth in the Netherlands

- Pilot test

Assessment of discriminant validity and inter-rater reliability September 2016 - March 2017

- Collect data in primary midwifery practices using the OI-NL instrument

- OI-NL forms returned from primary care midwives $(n=266)$

- Assessment of discriminant validity

- Differences in OI-NL percentage score between primiparous and multiparous women

- Differences in OI-NL percentage score between midwife-led care births and births referred to obstetric care

- Inter-rater reliability 
Creating an Optimality Index - Netherlands: a validation study |

\section{Appendix 2}

The Optimality Index-US and the Optimality Index-NL.

The cross-cultural and face validation process is described in the method and results section of this paper. Areas that were adjusted to the Dutch situation have been highlighted.

The NL-OI adapted some sequential changes in order to make the index as easy to use as possible.

\section{Additional file}

The OI-US and the OI-NL instruments are presented together so that the reader is able to compare the similarities and differences following the creation of the OI-NL. This is available via: www.bmcpregnancychildbirth.biomedicalcentral.com/track/ $\mathrm{pdf} / 10.1186 / \mathrm{s} 12884-018-1735-\mathrm{z}$ 


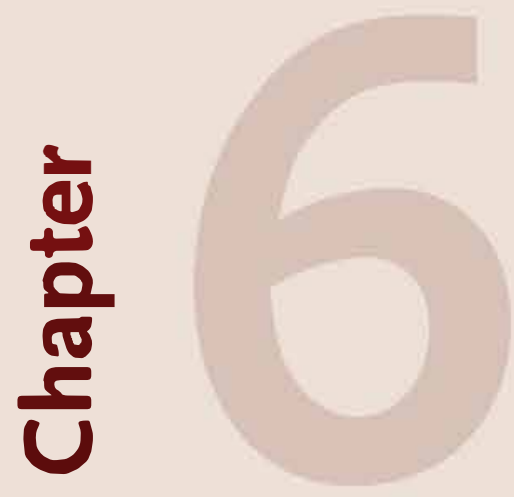

SM Thompson

MJ Nieuwenhuijze

L Kane Low

$\mathrm{R}$ de Vries

Journal of Midwifery and Women's Health. 2019; 64 (5): 641-648 


\section{Creating guardians of physiological}

birth: The development of an educational initiative for student midwives in the Netherlands

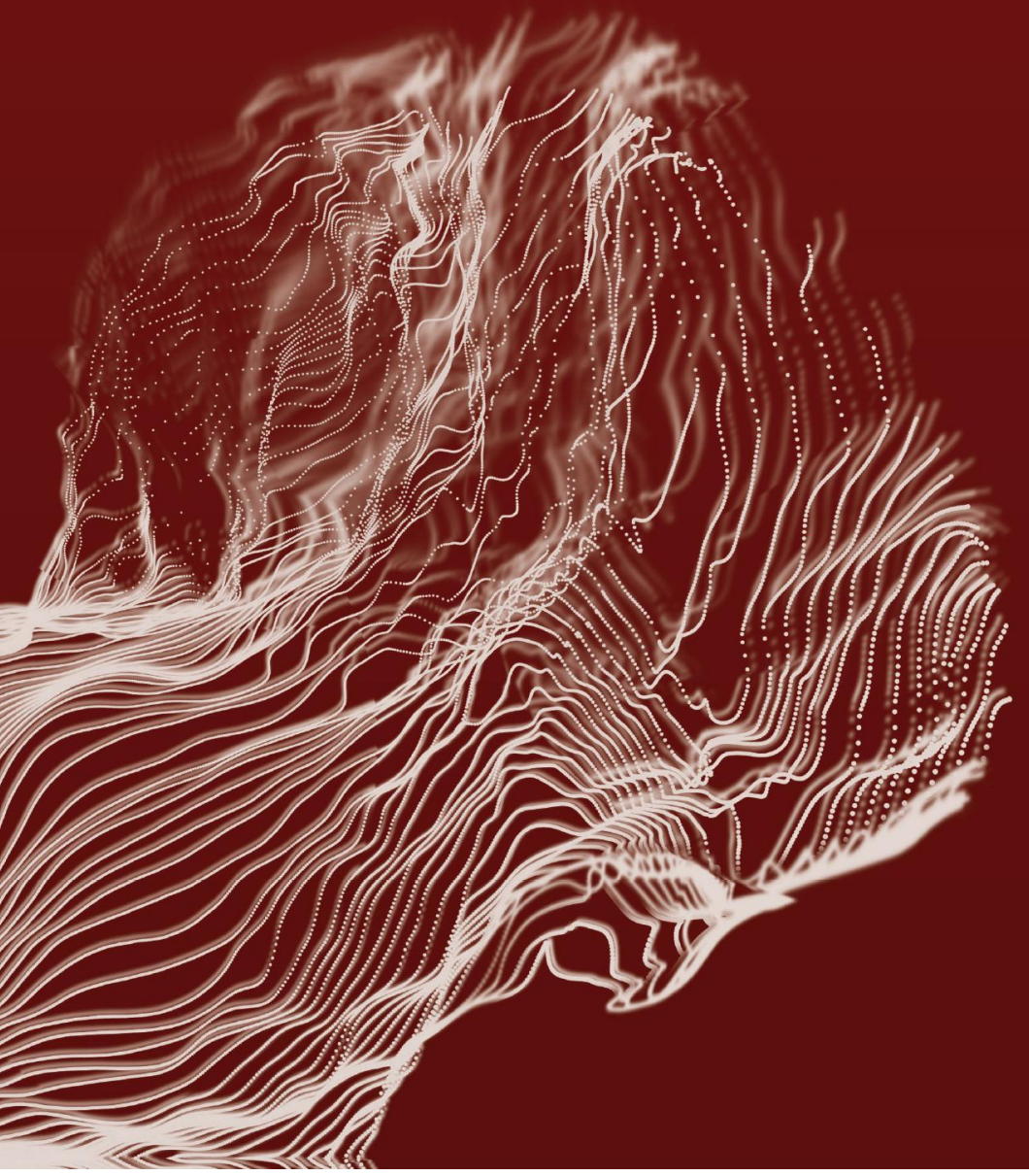




\section{| Chapter 6}

\section{Precis}

Debate and discussion skills that help student midwives engage with other professionals and women about physiologic childbirth are key to increasing agency in promoting physiology.

\section{Abstract}

Women want positive birth experiences with high quality maternity that is neither 'too much too soon' nor 'too little too late'. Research confirms the effectiveness of midwifery care, and the midwifery approach to birth as physiologic may counter the upward trend for the unnecessary medicalisation of birth. The role of guardian of physiologic birth is seen as central to midwifery practice, however, medical hegemony has led to the subordination of midwives which inhibits them in fulfilling the role as guardian of physiologic birth. Learning to become powerful advocates of physiologic birth creates midwives able to speak up for effective, evidence-based maternity care and challenge the unnecessary use of obstetric intervention. Midwifery education has a role to fulfil in molding midwives who are able to assume this role.

This brief report describes the development of an educational prototype aimed at increasing student midwife agency as an advocate of physiologic birth. This was done using Rapid Prototyping (RP) methodology, in which important stakeholders gave input and feedback during the educational design and development process.

Input from stakeholders led to the inclusion of persuasive communication strategies and discussion and debate as teaching methodologies, in order to increase student midwife agency to argue for physiologic birth. Reflective evidence-based practice, using the Optimality Index-NL allowed students to reflect on their practice while providing a framework for discussion.

Working with the RP methodology allowed for the development of a prototype, which reflected the needs of midwifery stakeholders and was mindful of material and human resources. 
Creating guardians of physiological birth: The development of an educational initiative for student midwives in the Netherlands |

Key words: Student midwives, physiologic birth, Rapid Prototyping, midwifery Education, stakeholders, communication skills, reflective practice, optimality.

Quick points: Increasing student midwife agency as advocates of physiologic birth is an important component of midwifery education.

Specific educational initiatives can be designed using Rapid Prototyping methodology, which includes the views and feedback of important stakeholders.

A focus on communication skills such as discussion and debate may increase student midwife agency as guardians of physiologic birth.

The Optimality Index is a useful tool that can be used to structure evidence-based reflection by student midwives on their own care processes.

\section{Introduction}

Physiologic birth can be a transformative and empowering experience for women. ${ }^{1}$ Because physiologic birth is considered as a health producing, rather than a riskproducing event, it is the cornerstone of international midwifery policy. ${ }^{2}$ In high income countries, research confirms the effectiveness of midwifery care ${ }^{3}$ and in low and middle income countries, midwives have played a critical role in reducing maternal and perinatal mortality and morbidity. ${ }^{4}$ Investigators have documented women's desire for a positive birth experience that includes birthing a healthy baby in an environment that is both clinically and psychologically safe, supported by competent and kind professionals. ${ }^{5}$ These findings are in line with recent guidance from the World Health Organization (WHO) ${ }^{6}$ that notes that, for many women, birth is about more than mere survival. ${ }^{7}$

Central to midwifery care is a philosophy that emphasizes supporting healthy physiology, including the biological, social, and psychological processes of childbirth, and focuses on tailoring interventions to the minimum required for optimal, safe care. ${ }^{8}$ Medical hegemony is embedded in the maternity care systems of many high income countries. ${ }^{9}$ Obstetric dominance in maternity care in the second half of the twentieth century saw an expansion of a technocratic approach to birth, resulting in a sharp increase in the use of interventions during birth, despite evidence that routine, often unnecessary, interference in the birth process leads to iatrogenic harm and significantly increases the cost of health care. ${ }^{10}$ Correspondingly, in medical settings, midwives are challenged by gender inequality and unequal power relations with 


\section{| Chapter 6}

other professionals, diminishing their power and influence. ${ }^{11}$ Dutch midwives and student midwives view guardianship of physiologic birth as central to their role. ${ }^{12,13}$ However, like midwives elsewhere, ${ }^{11}$ they also describe being influenced by medical hierarchy and experience feelings of powerlessness. These inhibit their agency and hence their power to ${ }^{14}$ promote physiologic birth.

Midwifery education can, and should, provide expertise and leadership to meet these challenges. Essentially, midwifery education is responsible for molding students into professionals who meet the needs of women for positive birth experiences which are as physiologic as possible ${ }^{5}$ while navigating the challenges presented by medicalisation. This requires the development and internalization of an attitude that reflects the midwifery ethos of physiologic birth. ${ }^{2}$ Dutch midwifery curricula provide a sound theoretical basis in the physiologic approach to birth ${ }^{15}$ and gives student midwives opportunities to participate in physiologic births. However, some studies from the Netherlands suggests that a perceived lack of agency may be the root cause of some of the challenges that Dutch midwives ${ }^{12}$ and student midwives ${ }^{13}$ face, inhibiting their ability to advocate for physiologic birth.

This brief report describes the steps taken, using a Rapid Prototyping methodology ${ }^{16}$ to design an educational initiative aimed at increasing the agency of student midwives to advocate for physiologic birth. In it, the finalized prototype is presented together with reflections on the design process and the resulting educational initiative.

\section{Process}

\section{Rapid Prototyping}

In a fast-paced and knowledge-based world, developing interventions must be efficient in both time and human resources. Rapid Prototyping (RP) has its origins in software design, where expeditious design solutions (prototypes) for a rapidly changing environment were of key importance. ${ }^{16}$ It is now gaining traction as a method for designing and developing educational programs and courses. ${ }^{17}$

$\mathrm{RP}$ is characterized by an iterative approach with overlapping steps including a needs assessment, and input from key stakeholders (such as future users and experts) on each iteration in order to design an initial prototype. This initial prototype is a representation of how the designer thinks the output (end product) should look based on the input of the stakeholders. This is then presented to stakeholders 
for them to offer feedback in as many iterations as is necessary to achieve a final prototype. The final prototype can then be implemented and evaluated (Figure 1). RP shares some similarities with participatory action research methodologies, in particular, stakeholder involvement. It differs from other consensus methodologies in that it does not seek to evaluate or improve upon an existing product or generate preliminary findings for further investigation. ${ }^{18}$

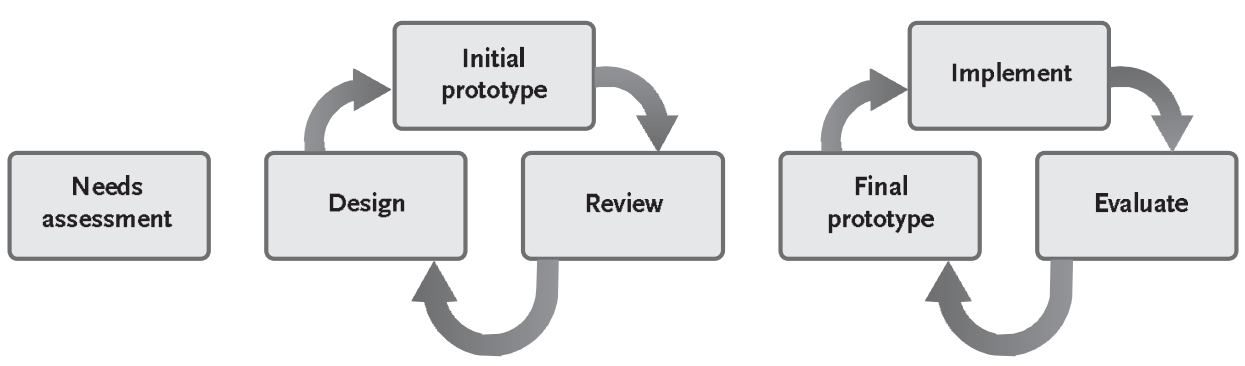

Figure 1: RP design methodology as used in the development of an educational prototype aimed at increasing student midwife self-efficacy for physiologic birth

\section{Needs assessment}

The first step in RP process is a comprehensive needs assessment via analysis of the issue that the prototype aims to address and the setting of objectives. A needs analysis should include research in order to uncover the complexities of the problem that a prototype aims to address. ${ }^{16}$

The needs assessment began with earlier work around this topic with midwives and students in the Netherlands. One such study explored midwives' attitudes towards promoting physiologic birth and identified factors that facilitate or inhibit midwives in this role. ${ }^{12}$ Another looked at what student midwives need from midwifery education in order to advocate for physiologic birth. ${ }^{13}$ Using the findings from these studies (Table 1), ideas were generated for inclusion in an initial prototype.

Table 1: Earlier research findings used to inform prototype development 


\section{| Chapter 6}

\section{Community and Hospital midwives in the Netherlandsa)}

Feelings of confidence and clinical competence important for feeling able to promote physiologic birth

Need to learn how to effectively challenge routinized care processes with evidence

A need to teach strategies for empowerment

The importance of role models among midwife colleagues

\section{Student midwives in the Netherlands ${ }^{\text {b) }}$}

Being able to develop, internalize and express midwifery philosophy of care important for confidence and competence

Reflection, in particular with regard to learning to use evidence to challenge

Feelings of personal power mitigates some of the challenges faced by students in hierarchical practice settings

The importance of role models - in particular those with a clearly expressed midwifery vision

Sources: ${ }^{a)}$ Thompson et al, $2016^{12}$; $^{\text {b) }}$ Thompson et al, $2019^{1}$

Another important aspect of the needs assessment was ascertaining organizational needs, in this case, the needs of the midwifery bachelor program for which the finalized prototype was intended.

Midwifery program managers $(\mathrm{n}=2)$ and curriculum leaders $(\mathrm{n}=4)$ from a Dutch midwifery academy were consulted, in order to establish organizational needs that the prototype initiative would need to fulfil. The midwifery program managers stressed the importance of a lean design, mindful of human and material resources. Additionally, they requested an end product (an educational initiative) that would be attractive and relevant for students by creating an innovative prototype that would enrich the existing education about physiologic birth and not simply repeat material already covered.

In order to meet these conditions, the existing program was screened for its content 
Creating guardians of physiological birth: The development of an educational initiative

for student midwives in the Netherlands |

relating to physiologic birth, ensuring that the likelihood of repetition of material was reduced or eliminated. This also allowed the determination of which point in the bachelor program the prototype should be included. The bachelor is based on a number of central pillars of which physiologic birth is one. Educational content related to physiologic birth is integrated within the program, including theory blocks and the acquisition of skills during clinical placements in the hospital and community settings. It was decided to offer the prototype in the second semester of the third year of the four-year program. This is a point at which student midwives have covered the majority of theoretical components and have had a range of clinical placements, both in the hospital and community settings. In addition to this, the second semester includes both theory and clinical placements, allowing for application of theory to practice, increasing the educational value.

\section{Stakeholder input}

Stakeholder participation in RP offers the possibility of rapid feedback ${ }^{16}$ and close involvement of stakeholders to contribute to an initial and final prototype which addresses their needs. Stakeholder inclusion also allows for the generation of the input (such as conditions, requirements and ideas) needed to create a prototype. ${ }^{17}$ Additionally, including stakeholders increases the intrinsic motivation ofthese groups ${ }^{19}$ and creates feelings of ownership ${ }^{20}$ for eventual use of the finalized prototype. Importantly, the iterative nature of stakeholder feedback replaces linear and time-consuming sequence approaches such as Analyse-DesignDevelop-Implement-Evaluate (ADDIE), ${ }^{21}$ a common approach in curriculum design, reducing both development time and costs. ${ }^{22}$

Given the involvement of stakeholders in this project, the university ethics committee (Zuyderland Zuyd) reviewed and approved this study.

Important midwifery stakeholders with a vested interest in midwifery education were recruited. These included student midwives, midwifery lecturers from the bachelor program, and midwife preceptors in practice settings (community and hospital).

Group interviews with student midwives $(n=4)$, midwifery lecturers $(n=4)$ and individual interviews with community and hospital midwife preceptors $(n=2+2)$ were held, in order to generate content for the prototype. Groups of 4 - 8 stakeholders are appropriate for the generation of input within RP methodology. ${ }^{23}$

The midwives and student midwives were self-selected, having received information 


\section{| Chapter 6}

about the study and an invitation to participate that was sent to all 35 fourth-year students in their final placement and to the midwives precepting these students $(n=35)$. The midwifery lecturers were approached based on their areas of expertise, in order to gain broad input, reflective of important areas of the bachelor program. Each session lasted between 60 and 90 minutes and was audio recorded. The interviews were conducted by the first author, an experienced interviewer. Field notes were taken by the second author. Each interview commenced with a short presentation of the information generated by the needs assessment. Following this, a topic list was used to guide discussion which focused mainly on the generation of material or content for inclusion in the prototype.

\section{Input generated by the stakeholders}

The data from all group and individual interviews (the field notes and recordings) were analysed using deductive content analysis. ${ }^{24}$ The choice for a deductive approach was made as it seemed an appropriate choice to incorporate earlier published findings ${ }^{12,13}$ and to further develop those findings into an initial prototype. Input from each session was organized into a content framework, offering an overview of suggested educational content and didactic form. These were then synthesized into one document and examined in relation to the bachelor program content already on offer.

\section{Student input}

The student midwife participants offered a number of suggestions for the prototype. These focused primarily on creating opportunities for students to learn from each other in both face to face and in online settings. In particular, students indicated the value of peer to peer reflective learning activities, particularly during clinical placements, as an activity in which students could reflect on their own practice and share and learn from each other's experiences. Student midwives also highlighted the importance of structured discussion or debates as a part of the prototype. Learning to discuss and debate was linked to physiologic midwifery content and developing the necessary communication skills to discuss and debate effectively. Lastly, student midwives requested the inclusion of designated, explicit theme days relating to physiologic birth, rather than implicit educational activities that are woven into to the bachelor program. Other suggestions included using case histories, skills trainings, and assignments during clinical placements, all of which are already included in the bachelor program.

\section{Lecturer input}


Input generated from the lecturers concentrated on supporting students in the development of a midwifery philosophy of care, including activities in which students consider themselves in relation to the type of professional they wish to become. This included creating space in the prototype for students to develop interest in an area of physiologic birth care, through either written or discussion work. Lecturers also indicated that discussion and debating the evidence that underpins physiologic birth in a persuasive or convincing manner would be a valuable activity.

In addition to this, the lecturers emphasized the importance of developing clear Intended Learning Outcomes (ILOs) for the prototype as a first step. Discussion focused around the importance of ILOs focusing on student behaviour rather than purely cognitive processes. Miller's Pyramid of Clinical Competences ${ }^{25}$ and Bloom's Taxonomy ${ }^{26}$ were used to shape the development of ILO's. Four over-arching ILO's were devised, and these were reviewed and provided with written feedback by the lecturers (included in Table 2).

Table 2: Prototype Educational Initiative

\begin{tabular}{|c|c|c|c|}
\hline $\begin{array}{l}\text { Intended learning } \\
\text { outcomes: The } \\
\text { student midwife } \\
\text { can... }\end{array}$ & THEORETICAL & $\begin{array}{l}\text { CLINICAL PLACE- } \\
\text { MENTS }\end{array}$ & $\begin{array}{l}\text { DIDACTIC } \\
\text { METHODOLOGY }\end{array}$ \\
\hline $\begin{array}{l}\text { use the Optimality } \\
\text { Index-Netherlands } \\
\text { and can interpret } \\
\text { findings in relation } \\
\text { to optimal care } \\
\text { processes }\end{array}$ & $\begin{array}{l}\text { Concepts of optima- } \\
\text { lity in maternity care } \\
\text { Introduction to the } \\
\text { Optimality Index } \\
\text { Advantages to use } \\
\text { during clinical } \\
\text { placements } \\
\text { Instructions for use }\end{array}$ & $\begin{array}{l}\text { The student mid- } \\
\text { wife completes } 5 \\
\text { Optimality Index } \\
\text { Netherlands forms } \\
\text { in either primary or } \\
\text { hospital care setting }\end{array}$ & $\begin{array}{l}\text { Face to face } \\
\text { Presentation and } \\
\text { workshop } \\
\text { Recording of session } \\
\text { for use online }\end{array}$ \\
\hline
\end{tabular}




\section{| Chapter 6}

\begin{tabular}{|c|c|c|c|}
\hline $\begin{array}{l}\text { distinguish between } \\
\text { the diverse approach- } \\
\text { es to maternity } \\
\text { care (physiologic, } \\
\text { biomedical) and can } \\
\text { question when each } \\
\text { approach might be } \\
\text { appropriate }\end{array}$ & $\begin{array}{l}\text { Communication } \\
\text { training: } \\
\text { Communicating the } \\
\text { evidence } \\
\text { Synthesizing midwi- } \\
\text { fery evidence from } \\
\text { different sources } \\
\text { Integrating } \\
\text { knowledge plus } \\
\text { own experience to } \\
\text { underpin argument } \\
\text { and discussion }\end{array}$ & $\begin{array}{l}\text { Peer to peer reflective } \\
\text { activity } \\
\text { Reflection on own } \\
\text { care using Optimality } \\
\text { Index Netherlands } \\
\text { Awareness of care } \\
\text { processes to increase } \\
\text { optimality in all birth } \\
\text { settings }\end{array}$ & $\begin{array}{l}\text { Face to face } \\
\text { Workshop } \\
\text { Online session }\end{array}$ \\
\hline $\begin{array}{l}\text { Select and critique } \\
\text { the evidence that } \\
\text { underpins physiolog- } \\
\text { ic childbirth }\end{array}$ & $\begin{array}{l}\text { Debating physiologic } \\
\text { childbirth practices } \\
\text { Reading assignment } \\
\text { as preparation } \\
\text { Debate with motions } \\
\text { to defend or rebut }\end{array}$ & $\begin{array}{l}\text { Experiment with } \\
\text { learned techniques } \\
\text { during clinical } \\
\text { placements }\end{array}$ & $\begin{array}{l}\text { Independent reading } \\
\text { and study } \\
\text { Debate }\end{array}$ \\
\hline $\begin{array}{l}\text { Argue and justify } \\
\text { actions and care } \\
\text { processes that } \\
\text { support physiologic } \\
\text { childbirth }\end{array}$ & $\begin{array}{l}\text { Communication } \\
\text { training: } \\
\text { Communicating with } \\
\text { conviction } \\
\text { Persuasive commu- } \\
\text { nications techniques } \\
\text { Presentation skills }\end{array}$ & $\begin{array}{l}\text { Experiment with } \\
\text { learned techniques } \\
\text { during clinical } \\
\text { placements }\end{array}$ & $\begin{array}{l}\text { Face to face } \\
\text { workshop }\end{array}$ \\
\hline
\end{tabular}

\section{Input from practicing midwives}

Input from the individual interviews with midwives emphasized two areas in particular: the use of evidence supporting physiologic birth to underpin clinical decision making and the further development of skills to speak up for physiology 
Creating guardians of physiological birth: The development of an educational initiative for student midwives in the Netherlands |

and communicate or discuss this with other professionals involved in maternity care and with women. To achieve this, a greater emphasis on debate and discussion strategies needed to be included. Midwives also highlighted reflective practice as an important learning activity for discussion and learning about various strategies that support healthy physiology. All of the midwives interviewed talked about ways in which they try to share their enthusiasm and passion for midwifery with the students that they precept. It was felt that a plenary activity, perhaps in round table discussion form, could be an activity in which students could be inspired and enthused. Other input included use of role play and skills training, both of which are already included in the bachelor program.

Overall, the stakeholder groups generated a significant amount of input for the prototype, including the formulation of intended learning outcomes, educational activities about physiologic birth to support students in developing a personal expression of the midwifery philosophy of care, discussion and debating skills in order to better communicate evidence based practice, and peer to peer reflective learning activities. This input was then used to craft an initial prototype.

\section{The Prototype}

In synthesizing the input from participating stakeholders, two main areas for inclusion in the initial prototype emerged: the application of reflective evidence based practice (EBP) and the skills needed to communicate the evidence with conviction, including discussion and debating skills.

A framework was identified which was considered would best support reflective evidence based practice. The Optimality Index ${ }^{27}$ is validated for use in the US ${ }^{28}$ and the Netherlands. ${ }^{29}$ The Optimality Index has been described as an evidence based tool maternity care professionals can use to appraise both processes and outcomes of maternity care for low and medium risk women. Additionally, the Optimality Index is useful for experienced midwives with routinized care practices who may be less confident with evidence based ways of working, ${ }^{28}$ allowing for reflection on care practices and creating awareness of adaptations to practice that facilitate optimal birth. Moreover, the concept of optimality complements a physiologic approach to midwifery. Optimality is defined as the maximal perinatal outcome with minimal intervention, placed within the context of the woman's social, medical, and obstetric history. ${ }^{30}$ Not least, the Optimality Index has also shown potential as an educational tool for student midwives. ${ }^{31}$ Reflection allows professionals to become aware of their implicit knowledge and develop the ability to think on their feet. ${ }^{32}$ Structured reflective discussions encourage student midwives to develop the critical 


\section{| Chapter 6}

decision making skills necessary for autonomous practice in the Netherlands, a core professional skill. ${ }^{33}$ Structured peer to peer reflective sessions contribute towards increased self-awareness and the development of personal skills and as a means of linking theory to midwifery practice. ${ }^{34}$

Debate and discussion are effective skills for settings in which complex discussion and decision making inform clinical practice. ${ }^{35}$ Student midwives must develop the ability, and the agency, to debate and engage in dialogue with other professionals in the maternity care domain, as well as with pregnant women and their families, about the likely benefits of physiologic childbirth. Debate and discussion are active learning activities that allow for the development of critical discourse. ${ }^{36}$ A pedagogy that develops the ability to challenge practice through discussion and debate is an appropriate choice for the realities of contemporary healthcare and the promotion of professional (midwifery) practice. ${ }^{37}$ These two aspects were central to the design of the initial prototype, along with some of the other input generated by the stakeholder interviews.

\section{From initial to final prototype: review and iteration}

In this step in the RP process, the initial prototype is presented to stakeholders so that they can review it and provide further input. The prototype is then modified in as many iterative cycles as is necessary, involving the stakeholders, in order to create a final product that is ready for real world testing. ${ }^{16}$

The initial prototype was presented to stakeholders and they were asked to consider whether the initial prototype met their needs. A group interview was organized for the lecturers to review the initial prototype. For practical reasons relating to clinical placements (student midwives) and professional commitments (midwives) written input, rather than interviews was requested and obtained.

Lecturers were positive about the prototype but pointed out that activities that contribute to achieving increased agency as an objective must be paramount. It was felt that using the Netherlands version of the Optimality Index (OI-NL) ${ }^{29}$ in combination with reflective practice would be innovative, as it would encourage discussion and reflection on the evidence base for physiologic birth practices.

Student and practicing midwife stakeholders welcomed the idea of activities in which enthusiasm and passion for midwifery could be shared and considered such an activity within the context of a theme day. Lecturers were slightly less enthusiastic about explicit theme days but saw value in a plenary kick-off to the prototype which would be inspiring for student midwives to attend. Other significant feedback related 
to the prototype's size. It was felt, in particular by the lecturers, that some activities were already extant in the sure that further development time be used efficiently and that a final prototype be mindful of available human and material resources.

Three iterations were needed in order to arrive at a finalized prototype, ready for testing in the bachelor program.

\section{The Finalized Prototype}

The finalized prototype reflected the input delivered during each iteration. Care was taken to ensure that the prototype maintained a focus on educational activities aimed at developing and supporting student agency and advocacy of physiologic birth. Attention was also paid to selecting the most relevant activities, linked to the ILO's, in order to streamline the finalized prototype (Table 2).

\section{From Finalised Prototype to the ESSENTIAL Program}

Educational content was then developed, in order to be able to implement the finalized prototype early in 2019 as a pilot within the bachelor program (Table 3). The finalized prototype initiative was named the ESSENTIAL program (ESSENTIAL being an acronym for the working title of the project: Increasing Self-Efficacy in Student Midwives for Physiological Childbirth).

A number of didactic approaches were considered. In order to achieve the ILO's (Table 2), content needed to be directed towards learning in the higher echelons of Miller's Pyramid 25 (shows/does). These echelons go beyond knowing about a task but require a student to show how a task is performed and being able to perform it. This justifies the significant number of activities offered as workshops, communication skills trainings, role play and discussion in which students are encouraged to participate. Communication skills trainings in particular were directed towards content in which convincing or persuasive communication is central to learning how to increase influence. ${ }^{38}$ Being in a position, either through formal or grassroots means, to influence others is associated with feelings of well-being ${ }^{39}$ and may increase self-efficacy as a result. 38,39

Educational content was organized into three half-day sessions; these are scheduled at times in which students on clinical placements were expected to be present for link days (teaching sessions offered during clinical placements to link theory and practice). Each session contains a plenary session, either as inspiration (session one) or as a short introduction to theory (sessions two and three). In session one, the concept of optimality is introduced and in the second and third sessions, reflec- 


\section{| Chapter 6}

tive activities allow students to reflect on the optimality of their own cases, based on OI-NL data sheets that they have been tasked to complete during on-going clinical placements. Communication training content is themed, allowing students to develop convince agency skills as a convincing communicator (session 1), develop skills to persuade or convince another person (session 2) and an assimilation (session 3) in which learned communication skills are applied to a formal debate setting.

An evaluation is planned to assess the effect of the ESSENTIAL program on the agency of third year student midwives. Using a mixed methods approach, agency outcome measures such as self-efficacy and perceived empowerment will be assessed and compared with a cohort of student midwives who were not offered this initiative as part of their bachelor program. These findings will be reported in a separate publication.

Table 3: ESSENTIAL ${ }^{\text {a) }}$ program content

\begin{tabular}{|c|c|}
\hline EDUCATIONAL CONTENT & SHORT DESCRIPTION \\
\hline INSPIRATION AND MOTIVATION & $\begin{array}{l}\text { Program kick-off in plenary form, led by } \\
\text { high profile midwives. Highlighted the im- } \\
\text { portance of midwifery leadership, midwives } \\
\text { with power and influence being at the table, } \\
\text { involved in decision-making and policy at all } \\
\text { levels. Power in the midwifery context was } \\
\text { discussed, in particular the link between } \\
\text { power and personal agency. }\end{array}$ \\
\hline $\begin{array}{l}\text { DEVELOPING PERSONAL AGENCY } \\
\text { SKILLS }\end{array}$ & $\begin{array}{l}\text { Communication skills training in groups } \\
\text { of } 12 \text { students led by a midwifery lecturer } \\
\text { and a communication skills trainer. Focus } \\
\text { on developing agency, including insights in } \\
\text { personal power or powerlessness; } \\
\text { developing credibility and using structure } \\
\text { to build argumentation }\end{array}$ \\
\hline $\begin{array}{l}\text { DEVELOPING PERSUASIVE AND CON- } \\
\text { VINCING COMMUNICATION SKILLS }\end{array}$ & $\begin{array}{l}\text { Communication skills training in groups of } \\
12 \text { students led by a midwifery lecturer and } \\
\text { communication skills trainer and actress. } \\
\text { Recognizing and applying strategies linked } \\
\text { to persuasive and convincing communica- } \\
\text { tion. Focus on both verbal and non-verbal } \\
\text { techniques. }\end{array}$ \\
\hline
\end{tabular}


Creating guardians of physiological birth: The development of an educational initiative for student midwives in the Netherlands |

\begin{tabular}{|l|l|} 
DISCUSSION AND DEBATING SKILLS & $\begin{array}{l}\text { Developing skills to construct adequate } \\
\text { argument, including the ability to assert } \\
\text { claims in a convincing manner, select } \\
\text { appropriate data to be able to support claims. } \\
\text { Ability to anticipating counter argument and } \\
\text { have rebuttals prepared. }\end{array}$ \\
\hline REFLECTIVE PRACTICE & $\begin{array}{l}\text { Reflective discussion facilitated by } \\
\text { midwifery lecturer. Using the Optimality } \\
\text { Index Netherlands during placement and } \\
\text { reflecting upon optimality index scores; } \\
\text { discussing care processes that may increase } \\
\text { likelihood of optimal outcomes }\end{array}$ \\
\hline
\end{tabular}

a) Description of the educational content of an educational initiative aimed at Increasing Self-Efficacy in Student Midwives for Physiological Childbirth (acronym ESSENTIAL)

\section{Reflections on this process: Lessons learned}

Using RP methodology, a finalized prototype for an educational initiative was created, addressing the need to strengthen student midwife agency as advocates of healthy physiologic birth. The finalized prototype was effectively linked to existing educational activities on physiologic birth within the current midwifery program ensuring that content was added or innovated, rather than repeated. Additionally, organizational demands in terms of producing a prototype that was mindful of human and material resources were met. By listening to program managers, lecturers, student midwives and preceptors, it was possible to ensure a prototype design and content that met their needs.

Reflecting on the development process, RP methodology ${ }^{16}$ was an appropriate choice for creating and refining a finalized prototype. While there is a precedent for RP use in the design of adult educational programs in the maternity care domain, ${ }^{40}$ this is, as far as is known, the first time it has been used in an undergraduate midwifery program. Three iterative cycles were needed, over a period of four months, in order to finalize the prototype, which met the needs of the bachelor program with regard to resource efficiency while also meeting program goals for midwifery students.

Engaging and working with various stakeholders was important for a number of reasons. One success factor was early consultation with the management team responsible for the bachelor program. Ensuring their support for the necessity of the initiative and obtaining and maintaining on-going commitment for both 


\section{| Chapter 6}

development and implementation of the initiative was central to its acceptance and success. Another success factor was the inclusion of lecturer and student midwife stakeholders. Aside from their importance in generating content, including lecturer and student stakeholders created a degree of ownership that is important for the acceptability of new initiatives. ${ }^{20}$

Sensitivity towards the stakeholders as a human resource was paramount. Dutch midwives perceive their workloads to be high. ${ }^{41}$ This resulted in a choice to use individual interviews and written feedback, rather than organizing group interviews for the midwife and student midwife stakeholders. It was not an aim of this process to seek data saturation, as in traditional qualitative methodologies. The group and individual interviews were aimed at confirming the findings of earlier studies ${ }^{12,13}$ that were used to inform the prototype development. Ensuring relevant stakeholder involvement in the generation of ideas for an educational initiative, its content and pedagogy was considered essential. Larger group interviews may have generated greater amounts of input and more confirmed consensus. However, this was mitigated this by incorporating significant amounts of qualitative data generated in earlier studies, ${ }^{12,}{ }^{13}$ ensuring an evidence base for the development of the initial prototype and subsequently reducing any possible impact on the workload of Dutch midwives who precept student midwives.

The choice was made to focus the finalized prototype initiative solely on student midwives. Increasing student agency for physiologic birth may produce a ripple effect among precepting midwives as preceptors come into contact with students who are aware of their personal power as agents of physiologic birth. While student midwives are influenced by the attitudes of the midwives who serve as clinical preceptors ${ }^{13}$ midwives may also benefit from role models in developing their own feelings of competency for physiologic birth. However, reflecting on this approach, the development of a parallel intervention for midwife preceptors is something that should be the focus of further research.

\section{Conclusion}

For midwives to fulfil their role as guardians of physiologic birth in settings that are increasingly technocratic, midwifery education must focus on developing midwifery education that prepares professionals for this role. The stakeholder input generated in this Rapid Prototyping design methodology suggests a focus on reflective practice and debate and discussion skills linked specifically to optimality in birth as central to efforts to develop professionals who are strong advocates for healthy physiologic birth. 


\section{References}

1. Olza Fernandez I, Leahy-Warren P, Benyamini Y, Kaźmierczak M, Karlsdóttir S, Spyridou A, et al. Women's psychological experiences of physiological childbirth: a metasynthesis. BMJ Open. 2018:20347.

2. International Confederation of Midwives. ICM Core Document. Philosophy and Model of Midwifery Care. Den Haag: ICM. 2014.

3. ten Hoope-Bender P, de Bernis L, Campbell J, Downe S, Fauveau V, Fogstad H, et al. Improvement of maternal and newborn health through midwifery. The Lancet. 2014;384(9949):1226-35.

4. Lori JR, Stalls S, Rominski SD. Strengthening Midwifery to End Preventable Maternal, Child, and Newborn Deaths. Journal of Midwifery \& Women’s Health. 2015;60(4):343-7.

5. Downe S, Finlayson K, Oladapo OT, Bonet M, Gülmezoglu AM. What matters to women during childbirth: A systematic qualitative review. PLoS One. 2018;13(4):e0194906-e.

6. World Health Organization. WHO recommendations: intrapartum care for a positive childbirth experience. 2018.

7. World Health Organization. WHO recommendations on antenatal care for a positive pregnancy experience. 2016.

8. Horton R, Astudillo O. The power of midwifery. Lancet. 2014;384.

9. Benoit C, Zadoroznyj M, Hallgrimsdottir H, Treloar A, Taylor K. Medical dominance and neoliberalisation in maternal care provision: The evidence from Canada and Australia. Social Science \& Medicine. 2010;71(3):475-81.

10. McIntyre MJ, Chapman Y, Francis K. Hidden costs associated with the universal application of risk management in maternity care. Australian Health Review. 2011;35(2):211-5.

11. World Health Organization. Midwives voices, midwives realities. Findings from a global consultation on providing quality midwifery care Geneva: World Health Organization; 2016.

12. Thompson SM, Nieuwenhuijze MJ, Low LK, de Vries R. Exploring Dutch midwives' attitudes to promoting physiological childbirth: A qualitative study. Midwifery. 2016;42:67-73.

13. Thompson SM, Nieuwenhuijze MJ, Low LK, De Vries R. "A powerful midwifery vision": Dutch student midwives' educational needs as advocates of physiological childbirth. Women and Birth. 2019.

14. Veneklasen L, Miller V. A New Weave of Power, People and Politics: Practical Action Publishing; 2002.

15. van Son N. Het nieuwe landelijke opleidingsprofiel verloskunde. Tijdschrijft voor Verloskunde [Internet]. 2016; 2016(3).

16. Tripp SD, Bichelmeyer B. Rapid prototyping: An alternative instructional design strategy. Educational Technology Research and Development. 1990;38(1):31-44.

17. Hillen S, Landis M. Two Perspectives on E-Learning Design: A Synopsis of a U. S. and a Eu-ropean Analysis. International Review of Research in Open and Distance Learning. 2014;15:199-225.

18. List D. The consensus group technique i social research. Field Methods [Internet]. 2001; 13(3):[277-90 pp.].

19. Gross-Davis. B. Tools for Teaching. 2nd ed. San Francisco Jossey-Bass; 2009. 


\section{| Chapter 6}

20. Ginter PM DW. Strategic Management for Health Care Organizations. 8th ed. Hoboken NJ: Wiley; 2018.

21. Dick W CL. The Systematic Design of Instruction. 4th ed. New York: Harper Collins College Publishers; 1996.

22. Desrosier J. Rapid Prototyping Reconsidered. The Journal of Continuing Higher Education. 2011;59:135-45.

23. Jones TS, Richey RC. Rapid prototyping methodology in action: A developmental study. Educational Technology Research and Development. 2000;48(2):63-80.

24. Elo S, Kyngäs $H$. The qualitative content analysis process. Journal of Advanced Nursing. 2008;62(1):107-15.

25. Miller GE. The assessment of clinical skills/competence/performance. Academic Medicine. 1990;65(9):S63-7.

26. Krathwohl DR. A Revision of Bloom's Taxonomy: An Overview. Theory Into Practice. 2002;41(4):212-8.

27. Murphy PA, Fullerton JT. Measuring Outcomes of Midwifery Care: Development of An Instrument To Assess Optimality. Journal of Midwifery \& Women’s Health. 2001;46(5):274-81.

28. Low LK, Seng JS, Miller JM. Use of the Optimality Index-United States in Perinatal Clinical Research: A Validation Study. Journal of Midwifery \& Women’s Health. 2008;53(4):302-9.

29. Thompson SM, Nieuwenhuijze MJ, Budé L, de Vries R, Kane Low L. Creating an Optimality Index - Netherlands: a validation study. BMC Pregnancy and Childbirth. 2018;18(1):100.

30. H P. The Optimality Concept. Early HUman Development [Internet]. 1980; (4):[201-5 pp.].

31. van Olphen Fehr J. Using the Optimality Index-US to Teach Midwifery Students to Recognize and Implement Evidence-Based Practices That Promote Optimal Outcomes in Perinatal Health. Journal of Midwifery \& Women's Health. 2013;58(5):531-7.

32. Schon D. The Reflective Practitioner: How Professionals Think in Action. London New York: Routledge Taylor and Francis; 1983.

33. Kool L, Feijen-de Jong EI, Schellevis FG, Jaarsma DADC. Perceived job demands and resources of newly qualified midwives working in primary care settings in The Netherlands. Midwifery. 2019;69:52-8.

34. Collington V, Hunt S. Reflection in midwifery education and practice: An exploratory analysis. Evidence Based Midwifery. 2006;4.

35. Hartin P, Birks M, Bodak M, Woods C, Hitchins M. A debate about the merits of debate in nurse education. Nurse Education in Practice. 2017;26:118-20.

36. Keynejad RC, Creed S, Fernando M, Bell D, Codling D, Crowther G, et al. Docbate: A National Medical Student Debate. Academic Psychiatry. 2017;41(6):839-41.

37. Hall D. Debate: Innovative teaching ro enhance critical thinking and communication skills in healthcare professionals. The Internet Journal of Allied Health Sciences and Practice [Internet]. 2011; 9(3):[1-8 pp.].

38. Gass RH SJ. Persuasion: Social Influence and Compliance Gaining. 6th ed. New York NY: Routledge; 2018. 
Creating guardians of physiological birth: The development of an educational initiative for student midwives in the Netherlands |

39. Sommer KL, Bourgeois MJ. Linking the perceived ability to influence others to subjective well-being: A need-based approach. Social Influence. 2010;5(3):220-44.

40. Molenaar J, Korstiens I, Hendrix M, de Vries R, Nieuwenhuijze M. Needs of parents and professionals to improve shared decision-making in interprofessional maternity care practice: A qualitative study. Birth. 2018;45(3):245-54.

41. Warmelink JC, Hoijtink K, Noppers M, Wiegers TA, de Cock TP, Klomp T, et al. An explorative study of factors contributing to the job satisfaction of primary care midwives. Midwifery. 2015;31(4):482-8. 


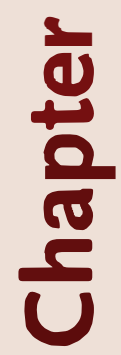

SM Thompson

L Kane Low

L Budé

$\mathrm{R}$ de Vries

MJ Nieuwenhuijze

Submitted 


\section{Evaluating the effect of an}

educational intervention on student midwife self-efficacy for their role as physiological childbirth advocates

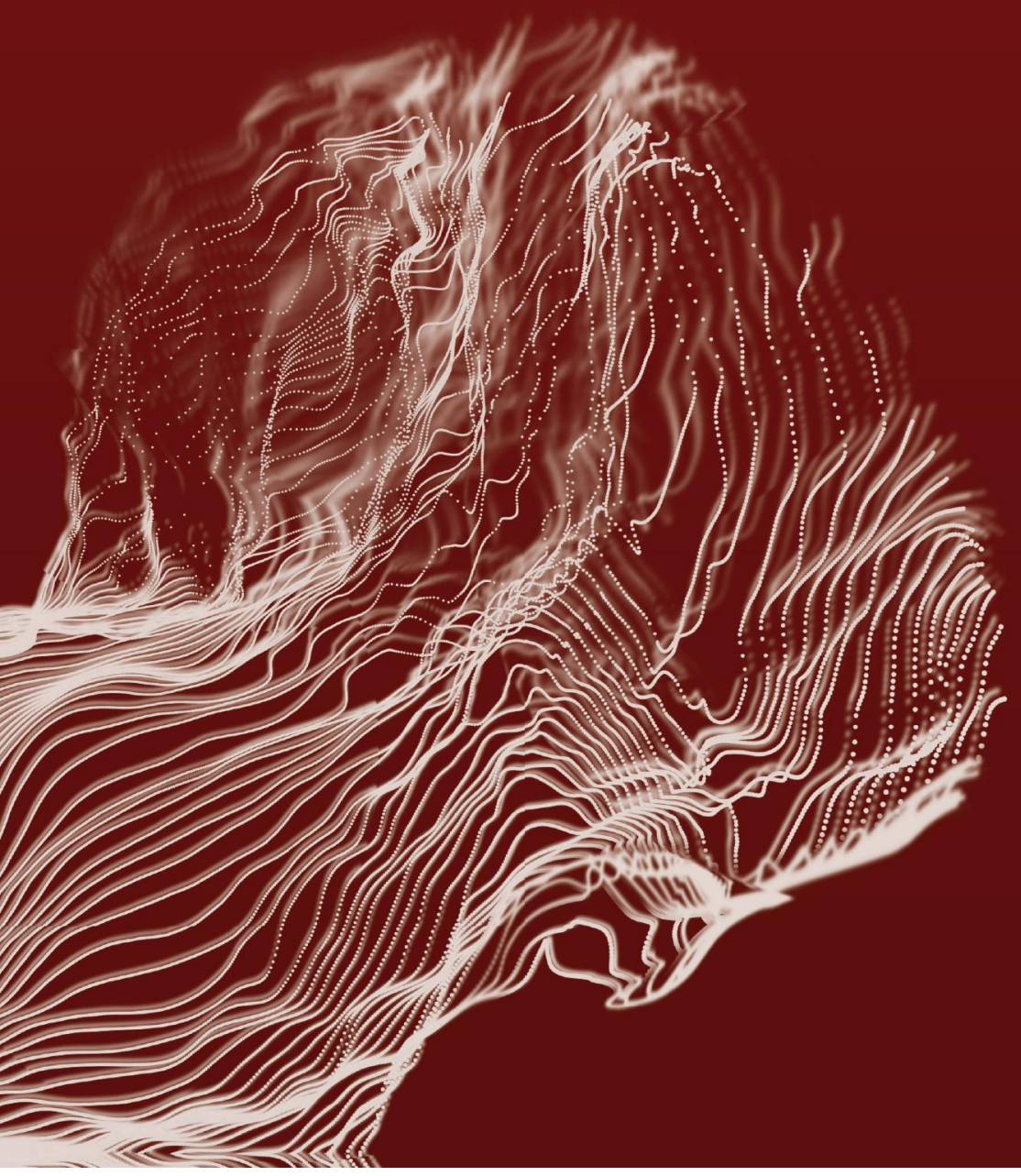




\section{| Chapter 7}

\section{Abstract}

Introduction: Midwifery education that strengthens self-efficacy can support student midwives in their role as advocates for a physiological approach to childbirth

Methods: To assess the effect of an educational intervention on self-efficacy, a pre- and post-intervention survey was administered to a control group and an intervention group of third year student midwives. The General Self-Efficacy Scale (GSES) was supplemented with midwifery-related self-efficacy questions related to behaviour in home and hospital settings, the communication of evidence, and ability to challenge practice.

Results: Student midwives exposed to midwifery education designed to strengthen self-efficacy demonstrated significantly higher levels of general self-efficacy $(p=.001)$ when contrasted to a control cohort. These students also showed significantly higher levels of self-efficacy in advocating for physiological childbirth $(\mathrm{p}=.029)$. There was a non-significant increase in self-efficacy in the hospital setting in the intervention group, a finding that suggests that education may ameliorate the effect of hospital settings on midwifery practice.

Discussion: In spite of the small size of the study population, education that focuses on strengthening student midwife self-efficacy shows promise.

\section{Introduction}

The Lancet Series on Midwifery ${ }^{1}$ emphasized the value and effectiveness of maternity care that begins with a focus on the needs of women and their families, rather than on identifying and responding to pathology. The philosophy that drives high quality care for childbearing women and their families is one in which biological, psychological, and social processes are optimized, a woman's capacity for childbirth and her subsequent role as a mother is strengthened, and obstetric interventions are used only when indicated. When asked, women indicate that positive childbirth experiences are those in which they can give birth without unnecessary medical intervention, in a location that they consider to be safe, supported by compassionate caregivers. ${ }^{2}$ The support and facilitation of physiological childbirth is a core value of midwifery practice. ${ }^{3-6}$ This is reflected in midwifery education, which places a strong emphasis on the internalization of the midwifery philosophy of physiological childbirth, together with acquisition of competencies (knowledge, skills and attitudes) as part of professional socialization., 8 
At the same time, however, midwives - and student midwives are faced with the reality of theory-practice gaps ${ }^{9}$ in which the professional ideals learned as a student do not always align with the realities of practice.

One such theory-practice gap is the promotion of physiological childbirth. Difficulties experienced by midwives include conflicts between authoritative knowledge and evidence-based practice, ${ }^{10}$ an unwillingness to challenge routinized care practices, and a dominant medical hierarchy ${ }^{11,12}$ which limits midwifery influence. ${ }^{13}$

Incorporating evidence-based knowledge about pregnancy and birth against the backdrop of the cultural and organizational hegemony of medical practice can be challenging. To address this, educators should pay attention to developing other characteristics in students ${ }^{14}$ that may supplement midwifery knowledge. One such characteristic is self-efficacy.

Social cognitive theory ${ }^{15}$ posits that self-efficacy - an individual's belief in their ability to carry out a course of action necessary to accomplish a desired goal - is an important factor for achieving professional goals. This characteristic is of particular importance in the education of health care professionals because students need to overcome the self-doubt associated with the intellectual, motivational, and social challenges of medical or health professions education. ${ }^{16}$ Midwifery education provides a sound fundament in the theoretical and practical skills needed to promote physiological childbirth. ${ }^{17}, 18$ Education that strengthens self-efficacy for applying knowledge and skills to practice may be an important area for midwifery educators to consider in designing education that educates midwives to be advocates for physiological childbirth.

In a recent curriculum innovation in the Bachelor of Midwifery at a Dutch University of Applied Sciences, it was decided to supplement existing education about physiological childbirth with an initiative aimed at strengthening student midwife agency for physiological childbirth. ${ }^{19}$ Using Rapid Prototyping (RP) design methodology ${ }^{19}$, we developed an educational programme with input from midwifery stakeholders (student midwives, midwifery preceptors and educators). This goal-oriented programme (Increasing Self-Efficacy in Student Midwives for Physiological Childbirth - known as the 'ESSENTIAL' programme) consisted of three half-day sessions during the third year of midwifery education with intended learning outcomes (ILO's) and educational content that focused on effectively and convincingly communicating the evidence for physiological approaches to childbirth. The Dutch Optimality Index 21 (OI-NL) was used as a reflective tool to support student engagement in assessing outcomes of care. Students were trained in persuasive communication strategies, 


\section{| Chapter 7}

including rhetorical discussion and debating skills. The design and development of the ESSENTIAL programme has been described in detail in a separate publication. ${ }^{19}$

In this paper, we report the results of a study that explores the effect of the ESSENTIAL programme on student midwife self-efficacy for their role as promotors of physiological childbirth.

\section{Methods}

We used a quasi-experimental design to explore the effects of the ESSENTIAL programme, an educational intervention offered to third year student midwives intended to promote self-efficacy in the advocacy of physiological childbirth.

Both qualitative and quantitative data were collected from student midwives evaluating the educational initiative in order to explore the reception to, and acceptability of, the intervention.

\section{Participants and data collection}

We recruited from two cohorts of undergraduate student midwives who were in a four year, direct entry Bachelor of Midwifery programme in the Netherlands. Members of the first group, recruited in 2018, were controls; the experimental group, recruited in the subsequent year was exposed to an educational intervention (the ESSENTIAL programme). Participants received an e-mail inviting them to participate in the study with two reminders being sent approximately one week and three weeks later. After giving informed consent, participants were then invited to fill in a questionnaire at two points in time during their third year of midwifery education.

Students in both cohorts were in their third year of study and had followed an identical programme comprised of theory and clinical placements up to the moment of recruitment. The 2018 cohort (from which a control group was recruited) consisted of a total of 65 potential participants; the 2019 cohort who were invited to participate in the educational intervention consisted of 47 potential participants.

Data were collected using an online questionnaire. We administered the questionnaire for both groups at two time points: February and June 2018 for the control group and February and June 2019 for the intervention group. The first measurement for each cohort (February 2018 or February 2019) we labeled T1; the second measurement for each cohort was correspondingly labeled T2. During this time frame, the control group followed the regular curriculum, which consists of theoret- 
ical study (tutorials, lectures and workshops) and an internship in either a primary care midwifery practice or hospital setting. The intervention group followed an identical curriculum and additionally, were invited to participate in the ESSENTIAL programme.

The study was reviewed and approved by the university ethics committee, Zuyderland Zuyd (METCZ20180038). Students' participation in both the study and intervention was voluntary, and confidentiality and anonymity were guaranteed.

\section{Measures}

We used a series of measures that included quantitative and qualitative assessment options to evaluate self-efficacy and self-efficacy related to midwifery care as our primary outcomes of interest.

\section{General self-efficacy}

In order to assess general self-efficacy, we used the 10-item general self-efficacy scale $^{22}$ (GSES), which is validated for use in the Netherlands ${ }^{23}$ in the field of health and health psychology. The GSES was designed to assess optimistic self-belief, in how far individuals believe they are competent to fulfill tasks and function in a broad range of challenging circumstances. ${ }^{24}$ The GSES differs from other measures of optimism in that it focuses on personal agency - defined here as power to effect successful outcomes. ${ }^{25,} 26$ The 10 item scale is scored on a four-point Likert scale ranging from 1 (not at all true) to four (exactly true). Responses are then summed to give a composite score ranging between 10 and 40, with higher scores representing higher self-efficacy. In their work, Schwarzer and Jerusalem ${ }^{22}$ recommend the addition of specific items to assess self-efficacy relating to more specific constructs. Following their recommendation, we constructed items to assess the agency of student midwives in promoting and facilitating physiological childbirth (Midwifery related self-efficacy).

\section{Midwifery related self-efficacy}

Using Bandura's guide for constructing self-efficacy scales, ${ }^{27}$ we devised a scale in order to assess self-efficacy within the specific domain of physiological midwifery practice. In order to capture the construct of physiological midwifery practice, we generated seven aspects of physiological childbirth care processes from the recently validated Dutch Optimality Index ${ }^{21}$ (OI-NL). This ensured that the items were an appropriate 'fit' with contemporary physiological midwifery care processes in the Netherlands. We differentiated between feeling able to promote a physiological 


\section{| Chapter 7}

approach in primary care (home) and hospital settings, creating two subscales, consisting of seven questions per sub-scale. Participants were asked to score each item on a 10-point scale, ranging from $0=$ "cannot do at all" to $10=$ "highly certain can do". Responses are then summed to give a score ranging between 0 and 70 per sub-scale.

Also included were six aspects which focused on personal agency for challenging practice and persuading others of the value of physiological childbirth in the maternity care domain. An example of these questions included perceived self-efficacy in discussing differing approaches to childbirth with an obstetrician, a midwife preceptor, or with a woman. This sub-scale consisted of eight items. Participants were asked to score each item on a 10-point scale, ranging from $0=$ "cannot do at all" to $10=$ "highly certain can do". Responses are then summed to give a score ranging between 0 and 80 .

Examples of the questions we formulated can be found in Tables 1 and 2.

\section{Table 1: Midwifery related self-efficacy}

At home / in hospital, I trust in my ability to...

leave the membranes until they rupture spontaneously.

provide support with various coping strategies in order to support women with labour pain.

provide supportive, one-to-one continuous support during labour and birth.

motivate women to be physically active during labour.

auscultate foetal heart tones intermittently.

provide space for a woman to push without verbal direction from me.

support a woman to birth her baby using different, non-supine birthing positions. 
Evaluating the effect of an educational intervention on student midwife self-efficacy for their role as physiological childbirth advocates |

Table 2: Self-efficacy in advocating for physiological childbirth

I trust in my ability to...

challenge areas of practice or (midwifery) management in areas where there is good quality evidence for a different approach.

discuss areas of practice where there is contradictory evidence with

- obstetric

- nursing or

- midwifery colleagues

challenge my preceptor if I see aspects of midwifery practice or management that are not evidence-based.

discuss areas of practice that promote and support physiology with a woman.

engage in a dialogue with a woman when she requests interventions that are not evidence-based.

use the evidence that supports physiological childbirth to support my discussions with other midwives.

\section{Beliefs about Birth and about evidence-based practice}

Previous studies illustrate that both student midwives and practicing midwives view the promotion of physiological childbirth as a core aspect of their professional identity. ${ }^{11,12}$ Moreover, they value evidence-based practice as a means of shaping their interactions with other stakeholders in maternity care. To this end, beliefs about birth and evidence-based practice were considered important secondary outcome measures as they appear to contribute to midwifery agency.

\section{Birth Beliefs Scale (BBS)}

We used the Basic Beliefs about Birth scale ${ }^{28}$ (BBS) to assess student midwives' beliefs about birth. Validated in Israel, the measure consists of two sub-scales (natural birth and medical birth beliefs), consisting of eleven statements reflecting basic beliefs about birth. The items are scored using a 5-point Likert scale, with scores 


\section{| Chapter 7}

ranging from $1=$ "completely disagree" to $5=$ "completely agree". Scores for each sub-scale are derived by calculating a mean of the responses, with resulting scores between 1 and 5 .

\section{Evidence-based practice beliefs scale}

The EBP belief scale ${ }^{29}$ was used to assess student midwives' beliefs about evidence-based practice. The validated EBP beliefs scale consists of 16 items measured using a 5-point Likert scale with scores ranging from 1="completely disagree" to $5=$ "completely agree". Items are scored (including two reverse scores for negatively phrased items) and are summed to achieve a score ranging between 16 and 80, with higher scores reflecting strength of beliefs about the use of evidence-based practice.

The questionnaire included the scales mentioned above and demographic information on the participants' age, their highest educational attainment prior to starting midwifery education and the number of weeks spent in community and hospital clinical practice. We pilot-tested the questionnaire with a group of fourth year student midwives $(n=5)$ asking them to provide feedback in terms of clarity of questions and the length of time needed to complete the questionnaire. Some small linguistic adjustments were made on the basis of student feedback.

In addition to these measures, we collected quantitative and qualitative data pertaining to how participants evaluated and experienced the ESSENTIAL programme. We used a short questionnaire consisting of 2 open and 9 closed questions evaluating the content of each component of the ESSENTIAL programme. We also asked participants to rate the quality of each of the sessions on a 10 point scale. Higher scores (5.5 and above) were considered representative of satisfaction with the session and scores lower than 5 representative of dissatisfaction.

Additional, qualitative data were collected during an informal feedback session, in which we had a structured conversation with students. This conversation was based around 5 open-ended questions relating to student experiences and motivation to participate in the ESSENTIAL programme. A written record was made of this session.

\section{Data analysis}

Our primary outcome was general and midwifery-related self-efficacy. We used an independent samples t-test to compare mean scores between the control group and intervention group. A p-value $<.05$ was considered statistically significant. 
Missing items were imputated using maximum likelihoods methods(30) in cases where not more than $10 \%$ of the total data from each measurement scale were missing. Questionnaires with more than $10 \%$ of data missing were excluded.

Data entry and analysis was performed using SPSS version 25.0.

\section{Results}

\section{Participation in the questionnaire}

A flow diagram (figure 1) demonstrates the recruitment and participation of student midwives in filling out the questionnaire, both in the control group and the intervention group.

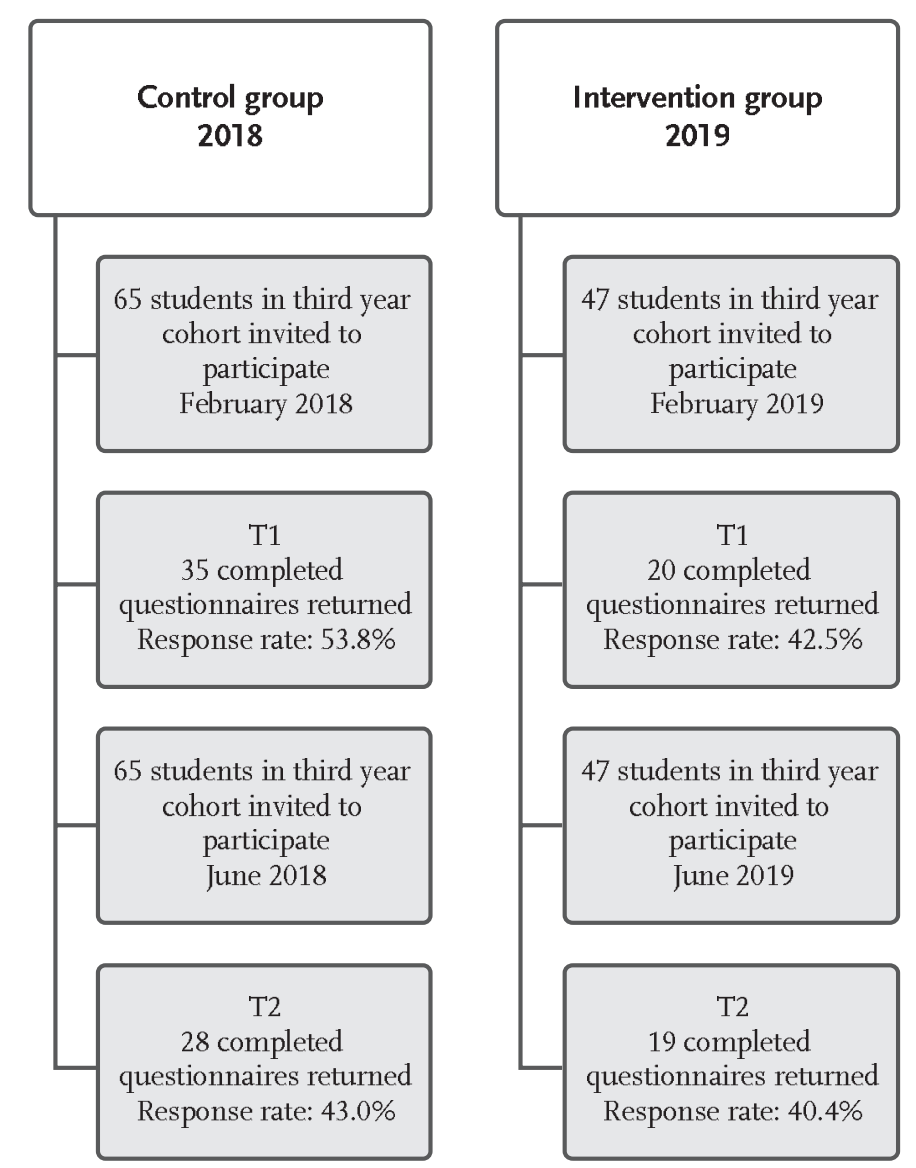

Figure 1: Flow chart: recruitment, participation and response rates for participation in the questionnaire 


\section{| Chapter 7}

The control and intervention groups were similar in terms of mean age and educational attainment prior to entering midwifery education. All were female and their age ranged between 19 and 38 years with a mean age of 22. For an overwhelming majority, the on-going Bachelor of Science was the highest academic achievement. One student had completed a Bachelor and Master in another subject area before starting the present Bachelor of Science. Participants also had similar exposure to theoretical education and internships during the midwifery programme.

In total, 102 questionnaires were returned. Of these, one questionnaire in the control group (February 2018) contained more than $10 \%$ of missing data. This questionnaire was removed, leaving 101 questionnaires for analysis. In line with a priori decision-making, missing data (less than 10\%) in 27 questionnaires were imputed using maximum likelihoods methods.

\section{Participation in the ESSENTIAL programme}

All of the students in the intervention group $(n=47)$ were invited to participate in the ESSENTIAL programme. Of these, 40 students participated in session 1 (85.1\%), 35 students participated in session $2(74.4 \%)$ and 24 students participation session 3 I36 (51\%).

\section{Effect of the ESSENTIAL programme \\ General self-efficacy}

The effect of the ESSENTIAL programme on general self-efficacy is reported in Table 3. Student midwives in both groups reported similar levels of general self-efficacy at T1. At T2, students in the intervention group reported significantly higher levels of general self-efficacy $(\mathrm{p}=.001)$, in contrast to the control group.

Table 3: General Self-efficacy [range $=10-40$ ]

\begin{tabular}{|l|l|l|l|l|l|l|l|}
\hline & T1 & \multicolumn{5}{c|}{} & T2 \\
\hline & N & Mean & $\begin{array}{l}\text { Std. } \\
\text { deviation }\end{array}$ & N & Mean & $\begin{array}{l}\text { Std. } \\
\text { deviation }\end{array}$ \\
\hline Control group & 34 & 30.41 & 3.34 & 28 & 30.60 & 3.24 \\
\hline Intervention group & 20 & 30.50 & 2.85 & 19 & 32.89 & 0.45 \\
\hline
\end{tabular}




\section{Midwifery self-efficacy}

The results of midwifery self-efficacy are presented in Table 4 .

In home settings: At T1, the control group had a higher level of midwifery selfefficacy compared to the intervention group. This difference was not significant. At T2, both groups demonstrated similar mean sum scores. Both groups showed an increase in self-efficacy between T1 and T2; however, when compared to the increase in the mean sum score in the control group, the increase in the intervention group was statistically significant $(p=.017)$.

In hospital settings: At T2, the control group mean score was decreased by several points. This decrease was not statistically significant. In the intervention group, there was a slight increase in levels of self-efficacy in hospital settings at T2. While not a statistically significant change, the increase may be relevant as a clinical/ educational finding.

Table 4: Midwifery care self-efficacy in home and hospital settings [range $=0-70$ ]

\begin{tabular}{|l|l|l|l|l|l|l|l|}
\hline & N & Home & N & Hospital \\
\hline & T1 & T2 & & T & T2 \\
\hline Control group & 34 & 56.64 & 58.39 & 28 & 51.02 & 47.32 \\
\hline Intervention group & 20 & 53.50 & 58.36 & 19 & 47.90 & 49.84 \\
\hline
\end{tabular}

Student midwife self-efficacy for challenging practice and debating aspects of midwifery practice with women, midwifery preceptors and other professionals in the maternity care domain is illustrated in Table 5 . The intervention group demonstrated significantly higher self-efficacy at T2 when compared to the control group ( $\mathrm{p}=.029)$. 


\section{| Chapter 7}

Table 5: Self-efficacy in communication [range $=0-80$ ]

\begin{tabular}{|l|l|l|l|l|l|l|}
\hline & $\mathrm{N}$ & $\mathrm{T} 1$ & $\begin{array}{l}\text { Std. } \\
\text { deviation }\end{array}$ & $\mathrm{N}$ & $\mathrm{T} 2$ & $\begin{array}{l}\text { Std. } \\
\text { deviation }\end{array}$ \\
\hline Control group & 34 & 54.29 & 7.74 & 29 & 57.03 & 7.93 \\
\hline Intervention group & 20 & 53.40 & 9.29 & 19 & 61.78 & 6.45 \\
\hline
\end{tabular}

\section{Birth beliefs}

Student midwives showed high scores of belief in birth as a natural event and lower scores for belief in birth as a medical event (Table 6). In the intervention group, we observed a decrease in belief in birth as a medical event at T2, compared with the mean sum scores for this group at T1. This decrease was significant ( $p=.015)$. This is in contrast to the control group where the mean sum scores for birth as a medical event increased over time, although this increase was not statistically significant.

Table 6: Birth Beliefs [range $=1-5$ ]

\begin{tabular}{|c|c|c|c|c|c|c|}
\hline & $\mathrm{N}$ & \multicolumn{2}{|c|}{$\begin{array}{l}\text { Birth as a } \\
\text { natural event }\end{array}$} & $\mathrm{N}$ & \multicolumn{2}{|c|}{$\begin{array}{l}\text { Birth as a } \\
\text { medical event }\end{array}$} \\
\hline & & $\mathrm{T} 1$ & $\mathrm{~T} 2$ & & $\mathrm{~T}$ & $\mathrm{~T} 2$ \\
\hline Control group & 34 & 4.41 & 4.48 & 28 & 2.43 & 2.55 \\
\hline Intervention group & 20 & 4.32 & 4.38 & 19 & 2.77 & 2.42 \\
\hline
\end{tabular}

\section{Evidence-based practice beliefs}

There were no significant differences in EBP beliefs between the control group and the intervention group (data not presented). 


\section{Evaluation of the ESSENTIAL programme by student participants}

Nineteen students participated in the evaluation and were positive in their assessment of the quality of each of the sessions (Table 7). Students were asked to rate each aspect of the ESSENTIAL programme on a 10 point scale, with scores above 6.0 indicating satisfaction with the programme.

Table 7: Evaluation of the ESSENTIAL programme [range $=0-10]$

\begin{tabular}{|c|c|c|c|c|}
\hline & Session 1 & Session 2 & Session 3 & $\begin{array}{l}\text { ESSENTIAL } \\
\text { Programme } \\
\text { as a whole }\end{array}$ \\
\hline Mean score & 7.5 & 7.6 & 8.2 & 8.2 \\
\hline
\end{tabular}

Students were asked to answer some questions about which aspects of the programme were most or least useful. Students indicated that honing their skills for debate were valuable, as one participant told us, "it showed me the importance of using my own personal power".

The Dutch Optimality Index (OI-NL) was noted to be of value for students, being viewed as 'something new' and 'a useful tool for discussing how we do things, but especially, why we do the things we do'.

Students also gave verbal feedback in an informal setting following the final educational activity of the ESSENTIAL programme. As participation was voluntary and sessions were offered at moments when students were on clinical placements, sometimes far away from the university, they were asked what encouraged them to participate. Students indicated that they were curious about the content of the programme; one student said, "it looked like I might be able to get something (from ESSENTIAL) about leadership. I didn't want to miss out". Students also indicated that choices to continue attending were made on the basis of having enjoyed participating in the initial session.

Students described feeling inspired by a "fantastic guest speaker who I felt I could really learn something from. She is a role model for me". Another highlighted feeling inspired by realizing that she could learn how to appear more self-assured. 


\section{| Chapter 7}

Improvements suggested by students included providing more information ahead of time, attention to which day the programme was scheduled for (scheduling issues meant that one session was planned on a Tuesday). One student told us that she would have liked the programme to have continued to 'the next level - beyond. I would like it (the ESSENTIAL programme) to go further'.

\section{Discussion}

We evaluated the effect of the ESSENTIAL programme on the self-efficacy for promoting physiologic childbirth with a group of student midwives and compared this to a cohort of student midwives who were not exposed to this programme. Our findings show that the ESSENTIAL programme has promise as an educational intervention that strengthens student midwife self-efficacy for promoting physiological childbirth. This is an important first step in establishing credible and effective midwifery education that supports student midwives in their development as guardians of the physiological childbirth domain.

The importance of the role of the midwife as a professional who is able to promote and facilitate physiological childbirth is well documented.2, 31 Contemporary midwifery education focuses on the competences of physiological childbirth - the 'what. There is, perhaps, too little focus on the 'how' - the skills needed to promote physiological childbirth. Midwives sometimes feel inhibited in this role and experience professional dissonance as a result. ${ }^{11,32}$ In the field of midwifery education there is very little evidence about the development of self-efficacious behaviour with regard to the promotion and support of physiological childbirth. This lack of evidence inspired us to use the construct of self-efficacy to evaluate our programme, rather than a construct such as confidence. Bandura ${ }^{33}$ notes that self-efficacy has qualities that confidence does not, in particular, self-efficacy includes agentic qualities - an affirmation of capability combined with the strength of the belief.

The value of developing self-efficacy is gaining traction in medical education. ${ }^{34}$ The development of self-efficacious behavior is seen as an important aspect of learning, in particular, motivation to learn ${ }^{35}$, task selection, task persistence and cognitive strategies that support the task at hand. ${ }^{34}$ Increasingly, educational researchers are exploring the importance of self-efficacy in healthcare students. ${ }^{16,36}$

In terms of clinical performance, it is noted that practical experiences, also termed 'enactive mastery' is the most powerful means of influencing self-efficacy. ${ }^{34}$ Ideally, practical experience is gained in authentic learning situations in which students 
Evaluating the effect of an educational intervention on student midwife self-efficacy

for their role as physiological childbirth advocates |

are exposed to role models to whom they can look to in order to develop their own professional identity. $8,37,38$ There are, however, gaps between ideal and real practice, ${ }^{9}$ particularly in medicalized settings. In these settings, the likelihood of professional dissonance, resulting from practicing in accordance with the norms and values of the biomedical approach to childbirth, is significant. ${ }^{11,32}$

Moreover, repeated exposure to negative practical experiences is likely to reduce self-efficacious behaviours. ${ }^{34}$ Given these realities, the need to support student midwives in developing the tools to bridge the theory-practice gap is a priority for educators. The evidence notes the importance of communication and collaborative skills in bridging theory-practice gaps. $.^{39}, 40$ Our work confirms this, in particular, in relation to skills for discussion, debate and convincing communication about the evidence for physiological childbirth with other professionals. This justifies the choice made, when developing ESSENTIAL to provide educational content with a focus on developing self-efficacy in convincing communication through active participation in workshops, reflective discussions and debate.

We noted some results that, while not statistically significant, are of interest from an educational perspective. In particular, midwifery self-efficacy in home birth settings increased in both the control and intervention groups, with the intervention group demonstrating a significant increase between their T1 and T2 scores. This may suggest that, for these students, exposure to ESSENTIAL increased their self-efficacy for physiological childbirth in the home setting. For self-efficacious behaviour in hospital settings, the self-efficacy of the control group decreased between $\mathrm{T} 1$ and T2. The intervention group, on the other hand, showed an increase in self-efficacy for promoting physiological childbirth in hospital settings between T1 and T2. This

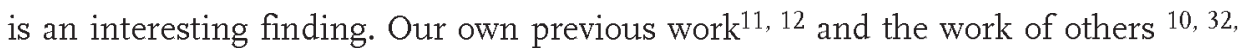
${ }^{41}$ highlight the impact of medicalized childbirth setting on midwives in terms of their practices and their willingness to challenge the practice of others. Our findings suggest that focusing on strengthening self-efficacy prepares student midwives for the clinical setting, ameliorating the forces that make it difficult to advocate for physiological approaches to birth.

It should be noted that we measured self-efficacy among our groups of midwifery students at two points during their third year of education. A period of four months elapsed between the measurements at T1 and those at T2. During that time, the student had periods of theoretical and clinical education, both of which may also increase self-efficacy. ${ }^{35,} 36$ This exposure to an authentic learning setting, for the group exposed to ESSENTIAL, may have provided the opportunity for 'enactive mastery ${ }^{34}$ allowing this group to apply what they had practiced in a simulated setting (workshops, reflection and discussion) to the authentic practice setting. 


\section{| Chapter 7}

By comparing the two cohorts - which are broadly homogeneous - we were able to take possible changes to self-efficacy caused by maturation into account. While there were small increases in self-efficacy in the control group, the significant increase in self-efficacy in the intervention group cannot be explained by maturation alone and is a likely effect of the intervention.

\section{Strengths and Limitations}

As far as we know, this is the first study to evaluate the effect of midwifery education aimed at strengthening self-efficacy of student midwives in their role as advocates of physiological childbirth. It was paramount to be able to test the ESSENTIAL programme in a real-world setting ${ }^{42}$ This, plus the small numbers of participants available in the third year of our Bachelor of Science programme contributed to our choice for a quasi-experimental study design. ${ }^{43}$ Testing and evaluating the effect of the ESSENTIAL programme indicates its promise in producing strengthened self-efficacy for physiological childbirth with significant effect observed in general self-efficacy and in self-efficacy when advocating for physiological childbirth.

A limitation was our choice not to use a repeated measures design. This was due to the limited participation of students from one university. Their participation was both voluntary and anonymous and we prioritized the guarantee of anonymity out of sensitivity for the student participants. Because of this guarantee, we were unable to ascertain whether students who participated in T1 also participated in T2. This means that while we can interpret effect over each cohort, without a pairwise comparison we cannot detect individual effects. While this is a methodological limitation, the observation of a statistically significant effect in general self-efficacy and self-efficacy related to discussion skills provides a foundation from which to implement the ESSENTIAL programme and collect more data in a larger study in order to confirm these findings and gain new insights.

In assessing midwifery self-efficacy, we used the work of Teeuw, Jerusalem and Schwarzer, ${ }^{23}$ and, as recommended, added a domain-specific self-efficacy scale to supplement the GSES. We were, however, unable to identify a domain specific, validated midwifery self-efficacy scale. To this end, we relied on creating a scale that captured the construct of physiological childbirth care in the Netherlands ${ }^{21}$, in combination with skills that midwives and student midwives themselves highlight as pre-requisite skills for physiological childbirth advocacy. ${ }^{11,12}$ While both the constructs of physiological childbirth care processes and the necessary advocacy skills were derived from recent literature from the Netherlands, it was outside 
of the scope of this study to validate this measure. This study highlights the need for a specific midwifery self-efficacy scale and developing and validating such a scale should be a focus for further research.

\section{Conclusion}

Our results create the foundation for building future interventions within midwifery education. We believe that our study offers promising new insights on the effect and value of midwifery education that focuses on strengthening self-efficacy. Midwifery education should ensure that student midwives develop the necessary competencies to be able to practice midwifery, including the competency to function as a guardian of physiological childbirth. ${ }^{18}$ Other research has confirmed the importance of self-efficacy for the development of professional identity. ${ }^{16,} 36$ Our study shows how increasing student midwife self-efficacy can help midwives to maintain their unique and important professional identity ${ }^{32}$ as champions of physiological birth.

\section{References}

1. Horton R, Astudillo O. The power of midwifery. Lancet. 2014;384.

2. Downe S, Finlayson K, Oladapo OT, Bonet M, Gülmezoglu AM. What matters to women during childbirth: A systematic qualitative review. PLoS One. 2018;13(4):e0194906-e.

3. International Confederation of MIdwives. International Definition of the Midwife. CoreDocument. The Hague. 2017.

4. International Confederation of Midwives. Essential Competencies for Midwifery Practice. 2018 Update. The Hague. 2019

5. Aitink M, Goodarzi B, Martijn L. Beroepsprofiel Verloskundige. 2014.

6. American College of Nurse-Midwives. Supporting healthy and safe physiologic birth: A consensus statement by ACNM, MANA and NAPCM. Journal of Midwifery and Women's Health [Internet]. 2012; 57:[529-32 pp.].

7. Weis D, Schank MJ. Professional values: Key to professional development. Journal of Professional Nursing. 2002;18(5):271-5.

8. Ulrich S. First Birth Stories of Student Midwives: Keys to Professional Affective Socialization. Journal of midwifery \& women’s health. 2004;49:390-7.

9. Argyris C, Schon D. Theory in Practice: Increasing Professional Effectiveness. San Francisco: Jossey-Bass; 1974.

10. Keating A, Fleming VEM. Midwives experiences of facilitating normal birth in an obstetric-led unit: a feminist perspective. Midwifery. 2009;25(5):518-27.

11. Thompson SM, Nieuwenhuijze MJ, Low LK, de Vries R. Exploring Dutch midwives' attitudes to promoting physiological childbirth: A qualitative study. Midwifery. 2016;42:67-73. 


\section{| Chapter 7}

12. Thompson SM, Nieuwenhuijze MJ, Low LK, De Vries R. "A powerful midwifery vision": Dutch student midwives' educational needs as advocates of physiological childbirth. Women and Birth. 2019.

13. Nilsson C, Olafsdottir O, Lundgren I, Berg M, Dellenborg L. Midwives' care on a labour ward prior to the introduction of a midwifery model of care: a field of tension. International Journal of Qualitative Studies on Health and Well-being. 2019;14.

14. Pajares F. Self-Efficacy Beliefs, Motivation,and Achievement in writing: A Review of the Literature. Reading and Writing Quarterly. 2003;19:139-58.

15. Bandura A. On the Functional Properties of Perceived Self-Efficacy Revisited. Journal of Management. 2011;38(1):9-44.

16. Klassen RM, Klassen JRL. Self-efficacy beliefs of medical students: a critical review. Perspect Med Educ. 2018;7(2):76-82.

17. Renfrew MJ, McFadden A, Bastos MH, Campbell J, Channon AA, Cheung NF, et al. Midwifery and quality care: findings from a new evidence-informed framework for maternal and newborn care. The Lancet. 2014;384(9948):1129-45.

18. ICM, UNfPA. Strengthening quality midwifery education for Universal Health Coverage 2030: framework for action.2019.

19. Thompson SM, Nieuwenhuijze MJ, Low LK, De Vries R. Creating Guardians of Physiologic Birth: The Development of an Educational Initiative for Student Midwives in the Netherlands. Journal of Midwifery \& Women's Health. 2019;64(5):641-8.

20. Tripp SD, Bichelmeyer B. Rapid prototyping: An alternative instructional design strategy. Educational Technology Research and Development. 1990;38(1):31-44.

21. Thompson SM, Nieuwenhuijze MJ, Budé L, de Vries R, Kane Low L. Creating an Optimality Index - Netherlands: a validation study. BMC Pregnancy and Childbirth. 2018;18(1):100.

22. Jerusalem M, Schwarzer, R. Self-efficacy as a resource factor in stress appraisal processes. 1992. In: Self-efficacy. Thought control of action [Internet]. Washington DC: Hemisphere.

23. Teeuw B, Jerusalem, M, Schwarzer, R. Dutch General SElf-Efficacy Scale 1994 [Available from: https://www.meetinstrumentenzorg.nl/Home/SearchPost?meetinstrument=211.

24. Luszczynska A, Gutierrez-Dona, B. General self-efficacy in various domains of human functioning: Evidence from five countries. International Journal of Psychology. 2005;40(2):80-9.

25. Gaventa J. Reflections on the use of the 'Power Cube' approach for analyzing the space, places and dynamics of civil society participation and engagement. MFP Breed Netwerk [Internet]. 2005 1st September 2017. Available from: https://www.participatorymethods.org/sites/ participatorymethods.org/files/reflections_on_uses_powercube.pdf.

26. Veneklasen L, Miller V. A New Weave of Power, People and Politics: Practical Action Publishing; 2002.

27. Bandura A. Guide for Constructing Self-Efficacy Scales (Revised). Self-efficacy beliefs of adolescents. 2006;5:307-37.

28. Preis H, Benyamini Y. The birth beliefs scale - a new measure to assess basic beliefs about birth. Journal of Psychosomatic Obstetrics \& Gynecology. 2017;38(1):73-80.

29. Melnyk BM, Fineout-Overholt E, Mays MZ. The Evidence-Based Practice Beliefs and Implementation Scales: Psychometric Properties of Two New Instruments. Worldviews on 
Evaluating the effect of an educational intervention on student midwife self-efficacy for their role as physiological childbirth advocates |

Evidence-Based Nursing. 2008;5(4):208-16.

30. Field A. Discovering Statistics Using SPSS. Los Angeles London New Delhi Singapore Washington: Sage; 2009.

31. World Health Organization. WHO recommendations: intrapartum care for a positive childbirth experience2018 1st November 2019.

32. McFarland A, Jones J, Luchsinger J, Kissler K, Smith DC. The experiences of midwives in integrated maternity care: A qualitative metasynthesis. Midwifery. 2020;80:102544.

33. Bandura A. Self-efficacy : the exercise of control1997.

34. Dinther M, Dochy F, R.Segers M. Factors affecting students' self-efficacy in higher education. Educational Research Review. 2011;6:95-108.

35. Artino AR. Academic self-efficacy: from educational theory to instructional practice. Perspect Med Educ. 2012;1(2):76-85.

36. Alavi N. Self-Efficacy in Nursing Students. Nursing and midwifery studies. 2014;3:e25881.

37. Byrom S, Downe S. She sort of shines: midwives accounts of good midwifery and good leadership. Midwifery. 2010;26(1):126-37.

38. Nieuwenhuijze MJ, Thompson SM, Gudmundsdottir EY, Gottfreðsdóttir H. Midwifery students' perspectives on how role models contribute to becoming a midwife: A qualitative study. Women and Birth. 2019.

39. Huston CL, Phillips B, Jeffries P, Todero C, Rich J, Knecht P, et al. The academic-practice gap: Strategies for an enduring problem. Nursing Forum. 2018;53(1):27-34.

40. Leach MJ, Tucker B. Current understandings of the research-practice gap in nursing: A mixed-methods study. Collegian. 2018;25(2):171-9.

41. Pollard K. How midwives' discursive practices contribute to the maintenance of the status quo in English maternity care. Midwifery. 2011;27:612-9.

42. Peters DH, Adam T, Alonge O, Agyepong IA, Tran N. Implementation research: what it is and how to do it. BMJ : British Medical Journal. 2013;347:f6753.

43. Handley MA, Lyles CR, McCulloch C, Cattamanchi A. Selecting and Improving QuasiExperimental Designs in Effectiveness and Implementation Research. Annual Review of Public Health. 2018;39(1):5-25. 
$\frac{1}{4}$ 


\section{General Discussion}

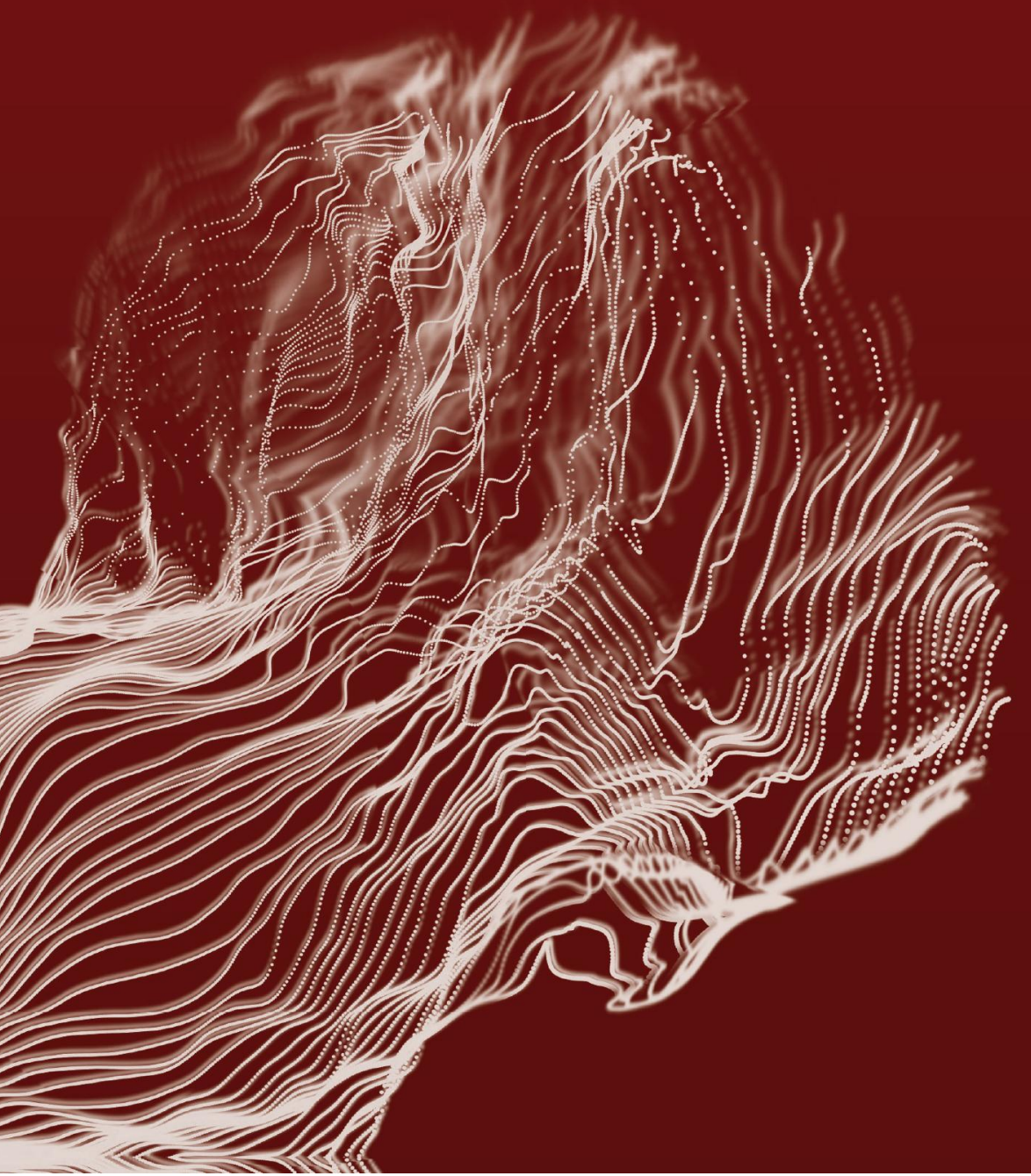




\section{| Chapter 8}

\section{Introduction}

The challenges midwives are facing, in the Netherlands and elsewhere, threaten to weaken the identity of midwifery as the profession that promotes and protects healthy physiological pregnancy and childbirth. Increasing medicalisation ${ }^{1,2}$, partisan science ${ }^{3}$, insufficient influence in policymaking, ${ }^{4-6}$ and internal division ${ }^{7}$, 8 are combining to diminish the important role of midwifery in the provision of maternity care that is high quality, safe, satisfying, and economical. In an effort to respond to these developments, we set out to create, implement, and evaluate an educational programme that supports student midwives in developing their personal agency as midwifery advocates for physiological childbirth.

As a necessary first step, we explored the attitudes of midwives in the Netherlands toward their role as advocates of healthy physiological childbirth in both community and hospital settings, together with the factors that inhibit or facilitate their advocacy role (chapter 2). Next, we interviewed student midwives in the Netherlands about their attitudes toward physiological childbirth. In particular, we focused on what student midwives' considered necessary in midwifery education in order to prepare them for their (future) role as advocates of physiological childbirth (chapter 3). Building on what we learned, we did an in-depth investigation of one aspect of student midwives' educational needs - role models to help students learn how to best advocate for physiological childbirth (chapter 4). Taken together, these three studies provided us with a comprehensive needs assessment, offering valuable insight into the elements of midwifery education that will strengthen the agency of midwives.

One of the elements we identified from this needs assessment was a tool to support midwives in using the evidence base to promote physiological - or optimal - childbirth. The Optimality Index (OI) - which originated in The Netherlands - is such a tool. The Optimality Index measures the degree to which evidence-based care practices that support physiological childbirth are applied in practice. As such, childbirth in which no interventions are necessary is considered optimal, as any intervention would indicate that the healthy physiology either required intervention, or that physiology was disturbed by the application of obstetric interventions.

The OI was already validated for use in several countries. Additionally, a small study illustrated the OI's value as an educational tool. We validated an updated version of this tool for the Netherlands, resulting in the Dutch Optimality Index (chapter 5). In order to create a midwifery education initiative, we identified key stakeholders and worked with them to develop a prototype that could be tested in a real-life setting (chapter 6). Finally, we developed the prototype and tested it among a cohort of 
student midwives in the Netherlands, allowing us to examine and describe the effect of this initiative on student midwife agency for advocating for physiological childbirth (chapter 7).

In this chapter we reflect on the implications of our findings for midwifery education and practice and we review the strengths and limitations of our research. We also suggest directions for further research, needed to ensure that midwives are equipped with the skills required to meet the challenges of reproductive care in the 21st century.

\section{A reflection on the main findings of this thesis}

Central to our work is the consideration of how we prepare student midwives for the complexities of inter-professional collaboration in maternity care. The challenge here is finding a way to equip midwives for effective collaboration whilst at the same time ensuring that in the process of learning to collaborate, they do not lose their professional identity as 'guardians' of the physiological domain of childbirth.

\section{Professional collaboration - Great minds DON'T think alike}

Collaboration is, according to Downe et al. ${ }^{9}$, a shared and dynamic function requiring the will to work together, rather than the expectation that it will somehow 'just happen'. Effective collaboration happens when collaborators actively develop a culture marked by mutual respect for professional differences, a culture dedicated to a common goal - in this case, excellent maternity care - while simultaneously acknowledging that 'great mind's don't think alike'..$^{10}$ This kind of professional culture allows for innovations in care and in the education of the next generation of professionals.

\section{Midwifery professional identity}

Midwives strongly identify the promotion of physiological childbirth as a fundamental aspect of midwifery professional identity (chapter 2). Student midwives, too, echo the centrality of physiological childbirth for their own perception of themselves as aspiring midwives (chapters 3 and 4). For the midwives and student midwives in our studies, it would appear that inter-professional settings influence the expression of the midwifery professional identity. Our findings illustrate that, for midwives, 'being' physiological is one thing, advocating for physiological childbirth - especially in collaborative maternity care settings - is another (chapter 2). 


\section{| Chapter 8}

The professional identity of midwifery - as described in official documents, research and everyday practice - is clear-cut. According to the international definition of a midwife (from the International Confederation of Midwives), one of the key roles of the midwife is the guardian of physiological childbirth. ${ }^{11,12}$ Midwifery expertise in physiological childbirth is also central to the evidence that supports the effectiveness of midwifery and is explicit to midwifery policy in many countries. ${ }^{14-18}$ When asked about their professional identity, midwives describe themselves as professionals with a holistic approach to physiological childbirth, ${ }^{19}$ reflecting the image that our participants put forward of 'being' physiological in their approach to childbirth.

In general terms, professional identity is defined as 'the sense of being a professional'. ${ }^{20}$ However, Paterson et al. note that professional identity development is more than the combination of technical and interpersonal skills, it also involves professional judgement, reasoning, critical self-evaluation, an understanding of responsibilities, professional knowledge and expertise, and the ability to reflect. Applying this concept of professional identity to midwifery, the composite elements would be knowledge, thought, reflection and 'handcraft', or ambacht in Dutch. ${ }^{21}$ Our work (chapter 2, 3 and 4), however, points to an additional element of professional identity: midwifery experience. The midwives and student midwives in our studies highlighted gaining experience as an essential factor in developing their professional identity. In our work with midwives and studentmidwives, experience was often gained through being able to identify with role models, either to demonstrate exemplary physiological childbirth practices (chapter 2) or to more broadly model a midwifery professional identity (chapter 3 and 4). Role models can have an important bearing on professional socialization and on the development of professional identity. Ulrich ${ }^{22}$ recognizes this fact, stressing the importance of internships for helping student midwives internalize midwifery values. Trede et al. ${ }^{23}$ note that, while universities are tasked with preparing students for a professional life following graduation that this preparation is sometimes inadequate, lacking emphasis on the on-going development of professional identity, particularly once educational focus moves from theory to practice. Moreover, exposure to clinical or practice settings often undermines what students have attempted to internalize in university and higher education settings. ${ }^{24}$

This link between experience and one's professional identity is confirmed in our findings (chapter 3), underscoring the notion that, as educators, we must pay attention to the development of professional identity during theoretical education and during internships. Hutchinson et al's $\mathrm{s}^{10}$ maxim that 'great minds don't think alike' - noted above - is reflective of the different professional identities of the midwife 
and the obstetrician. These different identities should be strengthened, while at the same time emphasizing mutual respect for differing approaches to care, facilitated and encouraged by 'lively debate" 10 about evidence-based approaches to care. Some of our participants told us that feelings of power were associated with the ability to have these kinds of interactions with other members of the inter-professional team (Chapter 2 and 4). Providing midwifery education that provides an evidence-informed framework for these conversations, coupled with the skills for 'lively debate $^{10}$ is essential.

\section{Knowledge}

Historically, midwives recognized the need to speak the language of other professionals involved in maternity care. In the seventeenth and eighteenth centuries, they did this by reading treatises and incorporating new medical terminology into their dialogue while continuing to express ideas based on their experience, observations of childbirth, and ancient childbirth wisdom. ${ }^{25}$ In the twenty-first century, the language of evidence-based practice is key to articulating and promoting a healthy physiological childbirth philosophy of care.

We identified the Optimality Index-US (OI-US) ${ }^{26}$ as a valid and reliable measure of physiological childbirth practices ${ }^{27-29}$ and a promising educational tool for discussing and reflecting on healthy physiological childbirth practices. ${ }^{30}$ This led us to create and validate the Dutch Optimality Index (OI-NL) reflecting the practice of midwifery in the Netherlands (chapter 5). We considered the OI-NL to be a useful tool measuring an evidence based approach to physiological childbirth. Its use, in clinical placements, allows students to reflect on their own - and other professionals' approaches to maternity care. Moreover, it allows students to reflect on aspects of maternity care that are perhaps routinized in clinical practice - the use of non-supine birthing positions is one such example - and to explore evidence-informed alternatives. The OI-NL is a useful tool that is based on a synthesis of evidence underpinning midwifery knowledge about physiological childbirth and may, as such, be a helpful framework for education and training of midwifery students as they gain clinical experience. However, the articulation of a physiological approach to childbirth requires other skills, including the personal power, or agency, to discuss, debate, and to convince others of its value and effect.

\section{Agency}

While acknowledging a physiological approach to childbirth as a central element of the professional identity of midwifery, midwives and student midwives occasionally have difficulties with advocacy work in this area. One such difficulty is advocating 


\section{| Chapter 8}

for physiological childbirth within the established medical hierarchy, either as a professional (chapter 2) or as a learner (chapter 3). Both midwives and student midwives express caution when advocating physiological approaches to care, for fear of imposing 'midwifery doctrine' on women (chapter 2 and 3).

Much has been written about the marginalization of midwifery by the medical profession. Historically, however, Dutch midwives were a well-integrated part of the Dutch maternity care system and considered the experts in the domain of physiological childbirth. ${ }^{31}$ The profession was established early and was well-regulated. Dutch midwifery largely escaped the marginalization that resulted from the domination of obstetrics over midwifery elsewhere in Europe. ${ }^{32}$ However, on-going debates about competence of midwives, ${ }^{31}$ coupled with a reduction in her role and responsibilities have resulted in the devaluation of the professional status of Dutch midwives. ${ }^{3}$

In our conversations with midwifery stakeholders it became clear that an effective strategy for equipping midwives as advocates within the medical hierarchy would be teaching the skills of discussion and debate, supplemented by grounding in the science informing physiological childbirth (chapter 6). These elements were incorporated in our educational programme, known as ESSENTIAL. The midwives and student midwives that participated in our studies described the feelings of personal power they experienced in situations in which they felt powerful enough to debate or challenge contentious areas of practice (Chapter 2 and 3).

The word 'power' often has negative connotations, particularly when conceptualized as power over others. ${ }^{33}$ In their work on citizen advocacy, Veneklasen and Miller ${ }^{34}$ explore expressions of power that are positive and are reflective of a collaborative way of exercising and using power. The power to - the potential of each individual to shape her own world - reflects a positive use of power to advocate for change. Another important expression of power is power within, an individual's sense of self-worth and self-knowledge. Power within allows the individual to recognize individual differences while respecting others. Combined, power to and power within are components of agency - the ability to act and change the world. In effect, agency gives midwives and student midwives the 'voice' to express the essence of midwifery professional identity. We observed promising results in being able to quantify the development of this 'voice' (Chapter 7). We found a significant increase in general self-efficacy in the participants in the study of student midwives who participated in the ESSENTIAL programme $(n=19)$ when compared to a control group. Self-efficacy for discussing and debating practice was also significantly higher.

The studies that comprise this thesis lead us to conclude that midwifery 
education must target and support the development of agency if the next generation of midwives are to promote and protect the physiological domain of childbirth. Our studies illustrate that midwives and student midwives who feel they have agency are able to mitigate the effects of medical hierarchy on their practice and on their relationships with other members of the medical team. Agency, in particular in situations that allow for the capacity to act in defiance of social structures ${ }^{35}$ that minimize the expertise and value of midwifery can facilitate the guardianship of physiological childbirth and negate the professional dissonance experienced by midwives ${ }^{36}$ within the hierarchical setting of biomedical obstetric care.

\section{Persuasion - power to convince}

If agency gives power to the voice of midwives, it is important that their voice is not only heard but is able to put forth convincing arguments supporting physiological childbirth. It appears that midwives are in possession of the evidence that underpins physiological birth (Chapter 2, 3, 4 and 5) but they lack the skills to effectively promote it in a way that convinces others. Our work with midwifery stakeholders (chapter 6) also focused on the need to teach persuasive styles of communication.

Much has been written about persuasive communication, in particular, in its application to marketing. ${ }^{37}-39$ Marketing strategies driven by persuasive communication aim to promote a product, in order to sell it. Gass and Seiter ${ }^{38}$ note the importance of persuasive communication as a 'two way street', in which both agent and target participate. This 'two-way street' is important. Criticisms levelled at persuasive communication include one-sidedness and equation with manipulation. To avoid these, the agent must be credible and mutual respect between the agent and the target are essential. Examples of these could be the respectful relationship between the midwife and her clien ${ }^{40}$ and collaborative relationships between midwives and obstetricians ${ }^{10}$ In teaching student midwives the art of persuasion, it is necessary to develop credibility together with strong rhetorical communication skills.

In a small study, Domajnko et al..$^{41}$ argue that rhetorical skills - i.e., skills that allow a speaker to illustrate personal credibility (ethos), stir the emotions of the listener (pathos), and offer persuasive argument suitable to the actual situation (logos) - can contribute to inter-professional collaboration and promote women-centered care. They conclude that these communication strategies (which also have commonalities with Gass and Seiter's work) should be an integral part of midwifery education. Our findings support the position of Domajnko et al., although we consider that the teaching of rhetorical argument alone is not enough. Rhetorical skills will be more effective when acquired as part of a broader educational programme aimed at 


\section{| Chapter 8}

increasing agency, such as our ESSENTIAL programme (Chapter 6). In following the ESSENTIAL programme, students were encouraged to develop a sense of their own personal power (credibility) and to learn to convince others before integrating these skills in the formation and rebuttal of rhetorical discussion about midwifery related aspects of care or viewpoints. These steps represented the broad needs of midwives and students (chapter 2 and 3) translated into educational goals, objectives, and activities in collaboration with midwife stakeholders (chapter 6). Even though the programme was not mandatory, a majority of the cohort offered participation in the ESSENTIAL programme actually attended, a remarkable feat given the demands on student time (Chapter 7).

\section{The future - powerful advocates of physiological childbirth}

These components of midwifery education - the development of personal credibility, the acquisition of rhetorical discussion skills, underpinned by the evidence for healthy optimal childbirth outcomes - will produce midwives who are able to collaborate with other maternity care professionals in the provision of high quality, appropriate midwifery care. Having been educated to understand and articulate the value of the guardianship of physiological childbirth as a safe and effective approach to childbirth, the next generation of midwives will become essential advocates of evidence-informed physiological childbirth. As advocates, midwives will recognize that 'great minds don't think alike'. ${ }^{10}$ They will respect the differences between midwives and obstetricians and will have the skills to elicit discussion and debate about which care practices constitute safe and effective maternity care - and which do not. Midwives with a developed sense of their own professional identity, coupled with the agency to articulate this, will have more than a place at the table, they have a voice at the table: a voice that can be used to influence policy and care practices within the collaborative spheres of practice in which twenty-first century midwives find themselves. Agency gives power to the midwifery voice. A voice which, essentially, can and must be used, together with women's voices to advocate for childbirth experiences that women want. ${ }^{42}$

\section{A reflection on the methodological strengths and limitations of this thesis}

Like all research, our combined studies have both strengths and limitations. In an effort to help those who want to build on the work we have done, we identify and discuss those strengths and limits here. 


\section{Rapid Prototyping}

An important strength of our research is its use of Rapid Prototyping (RP) design methodology. All six studies presented here involve some elements of RP. RP is a design methodology with participation at its core. While RP is used in other fields, it is only now gaining traction as a method for educational design. ${ }^{43}$ We chose to use RP because it was the most appropriate approach for studying, and intervening in, a professional domain that is evolving quickly. Additionally, involving stakeholders increasing ownership on the part of the stakeholders and gives voice to stakeholder needs. The RP approach allowed us to establish student midwives' needs and create an appropriate educational response to these needs.

Midwifery education has a mission to prepare professionals who are 'future-proof', making ESSENTIAL an approach to designing education that reflects the dynamism of the midwifery domain. The iterations needed to create a final educational initiative allowed for stakeholder input and feedback on each of the steps needed to arrive at a programme that was ready for testing. This process gave stakeholders an active role in designing and refining the programme, increasing feelings of ownership, as a result. ${ }^{44}$ While midwifery educators strive to involve stakeholders in programme design by inviting midwives and student midwives to participate in various aspects of educational development, more often than not, their role is limited to an advisory one. Using RP as an approach allows stakeholders to become partners in midwifery education, ensuring that their valuable insights and experience are reflected in the design and educational content of the curriculum.

\section{The qualitative research paradigm}

When creating new approaches to education, a thorough understanding of the needs of stakeholders is essential. In order to explore the needs of midwives and student midwives in the Netherlands, we needed to have conversations with them and to hear their voices. These conversations, qualitative in design and conducted in focus groups and in individual interviews, produced significant amounts of rich data. These data gave us valuable insights into the challenges midwives and student midwives face and the factors that will help them to mitigate those challenges.

\section{Limitations}

In designing the series of studies that comprise this thesis, care was taken to ensure that stakeholder needs were given due consideration. A number of the studies allow the reader to hear the expressed needs of midwives and student midwives. One voice, however, is absent - the woman served by midwives. We did not, 


\section{| Chapter 8}

however, consider involving client stakeholders. Patient/client involvement in health professions education is not new. There is, however, scant literature about the involvement of maternity service users at an educational development level. This may be due to factors such as the transient nature of maternity care or the limited time that services users may have to spare. ${ }^{45}$ Like midwives, women themselves may experience difficulties challenging areas of care that they are not comfortable with or the use of routine practices that women wish to avoid. ${ }^{46}$ These shared experiences challenging the medical hegemony of birth may mean that women are appropriate as stakeholders - and teachers.

Another possible point of concern is the decision to focus a programme to strengthen agency on student midwives, rather than midwives themselves or a combination of both. This is an interesting consideration, given the evidence that underlines the importance of adequate professional socialization ${ }^{22}$ and the importance of role models, ${ }^{47,}, 48$ particularly in modelling ideals of physiological childbirth practice. ${ }^{49}$ The design and implementation of the studies presented here are representative of the author's background as a midwifery educator, meaning that for her, a student focus was a logical step. Moreover, implementing the ESSENTIAL programme among student midwives offers the unique opportunity to create 'agents of change ${ }^{50}$ in greater numbers than if ESSENTIAL were to be offered as an optional post-graduate educational programme. A consideration for the future would be to optimize educational opportunities for professionals to increase and maintain self-efficacy in the physiological childbirth domain.

\section{Implications for future research}

As far as we are aware, the studies contained in this thesis are the first to respond to the need for an approach to promoting physiological childbirth that encourages self-efficacy. As pointed out in chapter 7, a validated midwifery self-efficacy scale was not available for use and the scope of the study did not allow for the development of such a scale. Future research should focus on the development and validation of a midwifery self-efficacy scale. This would allow for the collection of more robust data, which in turn, will offer more insights into this important aspect of midwives' personal agency. Furthermore, as noted above, our work did not include women as stakeholders in assessing the educational needs of student midwives. Tailoring advocacy to the concerns and desires of women would likely enhance the success of midwives as advocates of physiological birth; future research should explore this aspect of advocacy education. 


\section{Conclusion}

The goal of the research described here was to design, develop, implement, and evaluate an educational initiative aimed at supporting student midwives in the acquisition of personal agency for the promotion of physiological childbirth. We believe we have achieved this goal, gaining valuable insights into how midwifery education can best prepare midwives for the future. We created an evidence-informed programme that we consider to be a 'missing piece of the puzzle' in midwifery education for physiological childbirth. This programme is currently in use and is making a contribution towards a new future for midwives. This is a future in which the midwife, in her collaborative partnership with other maternity care professionals, has a strong professional identity and an influential voice, and is valued and respected as the champion of physiological childbirth.

The next generation of midwives will have a set of skills to support their role as champions of physiological childbirth. These skills include not just theoretical and clinical knowledge, but the ability to communicate persuasively when needed, whether in a lively discussion with colleagues, an evidence-informed debate about appropriate care practices, or - most important of all - in dialogue with a woman, helping to facilitate the childbirth experience that she wants. 


\section{| Chapter 8}

\section{References}

1. Requejo J, Victora C, Bryce J. Data Resource Profile: Countdown to 2015: Maternal, Newborn and Child Survival. International Journal of Epidemiology. 2014;43(2):586-96.

2. Topçu S, Brown P. The impact of technology on pregnancy and childbirth: creating and managing obstetrical risk in different cultural and socio-economic contexts. Health, Risk \& Society. 2019;21(3-4):89-99.

3. De Vries R, Nieuwenhuijze M, Buitendijk SE. What does it take to have a strong and independent profession of midwifery? Lessons from the Netherlands. Midwifery. 2013;29(10):1122-8.

4. Keating A, Fleming VEM. Midwives' experiences of facilitating normal birth in an obstetric-led unit: a feminist perspective. Midwifery. 2009;25(5):518-27.

5. Schölmerich VL, Posthumus AG, Ghorashi H, Waelput AJ, Groenewegen P, Denktaș S. Improving interprofessional coordination in Dutch midwifery and obstetrics: a qualitative study. BMC Pregnancy and Childbirth. 2014;14(1):145.

6. van der Lee N, Driessen EW, Scheele F. How the past influences interprofessional collaboration between obstetricians and midwives in the Netherlands: Findings from a secondary analysis. Journal of Interprofessional Care. 2016;30(1):71-6.

7. Romijn A, Teunissen PW, de Bruijne MC, Wagner C, de Groot CJM. Interprofessional collaboration among care professionals in obstetrical care: are perceptions aligned? BMJ Qual Saf. 2018;27(4):279-86.

8. Cronie D, Rijnders M, Jans S, Verhoeven CJ, de Vries R. How good is collaboration between maternity service providers in the Netherlands? Journal of multidisciplinary healthcare. 2019;12:21 - 30 .

9. Downe S, Finlayson K, Fleming A. Creating a Collaborative Culture in Maternity Care. Journal of Midwifery \& Women's Health. 2010;55(3):250-4.

10. Hutchison MS, Ennis L, Shaw-Battista J, Delgado A, Myers K, Cragin L, et al. Great Minds Don't Think Alike: Collaborative Maternity Care at San Francisco General Hospital. Obstetrics \& Gynecology. 2011;118(3):678-82.

11. International Confederation of Midwives. International Definition of the Midwife. Core Document. The Hague. 2017.

12. Horton R, Astudillo O. The power of midwifery. Lancet. 2014;384.

13. Sandall J, Soltani H, Gates S, Shennan A, Devane D. Midwife-led continuity models versus other models of care for childbearing women.

Cochrane Database of Systematic Reviews. 2016(4).

14. New Zealand College of Midwives. Consensus Statement: Normal Birth. 2005.

15. Maternity Care Working Party. Making normal birth a reality. Consensus statement from the Maternity Care Working Party. 2007.

16. American College of Nurse-Midwives. Supporting healthy and safe physiologic birth: A consensus statement by ACNM, MANA and NAPCM. Journal of Midwifery and Women's Health [Internet]. 2012; 57:[529-32 pp.].

17. Aitink M, Goodarzi B, Martijn L. Beroepsprofiel Verloskundige. 2014. 
18. Australian College of Midwives. Midwifery Philosophy and Values 2019 [Available fro $\mathrm{m}$ : https://www.midwives.org.au/midwifery-philosophy-values.

19. Pollard K. How midwives' discursive practices contribute to the maintenance of the status quo in English maternity care. Midwifery. 2011;27:612-9.

20. Paterson M, Higgs, J, Wilcox, S, Villeneuve, M. Clinical reasoning and self-directed learning: Key dimensions in professional education and professional socialisation. Focus On Health Professional Education Journal. 2002;4(2):184-9.

21. Larsson M, Aldegarmann U, Aarts C. Professional role and identity in a changing society: Three paradoxes in Swedish midwives' experiences. Midwifery. 2007;25:373-81.

22. Ulrich S. First Birth Stories of Student Midwives: Keys to Professional Affective Socialization. Journal of midwifery \& women's health. 2004;49:390-7.

23. Trede F, Macklin R, Bridges D. Professional identity development: a review of the higher education literature. Studies in Higher Education. 2012;37(3):365-84.

24. West C, Chur-Hanson, A. Ethical enculturation: the informal and hidden ethics curricula at an Australian Medical School. Focus On Health Professional Education Journal. 2004;6(1):85-99.

25. Allotey JC. English midwives' responses to the medicalisation of childbirth. Midwifery 2011;27(4):532-8.

26. Murphy PA, Fullerton JT. Measuring Outcomes of Midwifery Care: Development of An Instrument To Assess Optimality. Journal of Midwifery \& Women's Health. 2001;46(5):274-81.

27. Low LK, Miller J. A Clinical Evaluation of Evidence-Based Maternity Care Using the Optimality Index. Journal of Obstetric, Gynecologic \& Neonatal Nursing. 2006;35(6):786-93.

28. Sheridan M, Sandall J. Measuring the best outcome for the least intervention: can the Optimality Index-US be applied in the UK? Midwifery. 2010;26(6):e9-e15.

29. Yucel C, Taskin L, Low LK. Validity and reliability of the Turkish version of the Optimality Index-US (OI-US) to assess maternity care outcomes. Midwifery. 2015;31(12):1135-42.

30. van Olphen Fehr J. Using the Optimality Index-US to Teach Midwifery Students to Recognize and Implement Evidence-Based Practices That Promote Optimal Outcomes in Perinatal Health. Journal of Midwifery \& Women’s Health. 2013;58(5):531-7.

31. Marland H. Questions of Competence: The Midwife Debate in the Netherlands in the Early Twentieth Century. Medical History [Internet]. 1995 22nd November 2019; 39:[317-37 pp.].

32. Cahill HA. Male appropriation and medicalization of childbirth: an historical analysis. Journal of Advanced Nursing. 2001;33(3):334-42.

33. French J, Raven B. The bases of social power.1959.

34. Veneklasen L, Miller V. A New Weave of Power, People and Politics: Practical Action Publishing; 2002.

35. Hitlin S, Elder Jr. GH. Time, Self, and the Curiously Abstract Concept of Agency*. Sociological Theory. 2007;25(2):170-91.

36. McFarland A, Jones J, Luchsinger J, Kissler K, Smith DC. The experiences of midwives in integrated maternity care: A qualitative metasynthesis. Midwifery. 2020;80:102544. 


\section{| Chapter 8}

37. Cialdini R. Influence: The Pyschology of Persuasion: Collins Buisiness; 2007.

38. Gass RH, Seiter J. Persuasion: Social Influence and Compliance Gaining. 6th ed. New York NY: Routledge; 2018.

39. van Goethem P. True Persuasion: The Logic of Charisma. Amsterdam: True Persuasion Publishing; 2018.

40. Humenick SS. The Life-Changing Significance of Normal Birth. J Perinat Educ. 2006;15(4):1-3.

41. Domajnko B, Drglin Z, Pahor M. Rhetorical skills as a component of midwifery care. Midwifery. 2011;27(2):125-30.

42. Downe S, Finlayson K, Oladapo OT, Bonet M, Gülmezoglu AM. What matters to women during childbirth: A systematic qualitative review. PLoS One. 2018;13(4):e0194906-e.

43. Hillen S, Landis M. Two Perspectives on E-Learning Design: A Synopsis of a U. S. and a European Analysis. International Review of Research in Open and Distance Learning. 2014;15:199-225.

44. Mayfield P. Managing Relationships and Mobilizing Stakeholders. Smith S, King, D, Sidhu, R, Skelsey, D, editor. London Philadelphia New Delhi: Kogan Page; 2015.

45. Davis D, McIntosh C. Partnership in education: The involvement of service users in one midwifery programme in New Zealand. Nurse education in practice. 2005;5:274-80.

46. Crossley ML. Childbirth, Complications and the Illusion of 'Choice': A Case Study. Feminism \& Psychology. 2007;17(4):543-63.

47. Bluff R, Holloway I. The efficacy of midwifery role models. Midwifery. 2008;24(3):301-9.

48. Byrom S, Downe S. 'She sort of shines'. Accounts of good midwifery and good leadership. Midwifery. 2010;26(1):126-37.

49. Lange G, Kennedy HP. Student Perceptions of Ideal and Actual Midwifery Practice. Journal of Midwifery \& Women's Health. 2006;51(2):71-7.

50. Mitchell G. Selecting the best theory to implement planned change. Nurs Manag (Harrow). 2013;20:32-7. 
General Discussion | 
$\frac{1}{4}$ 


\section{Summary}

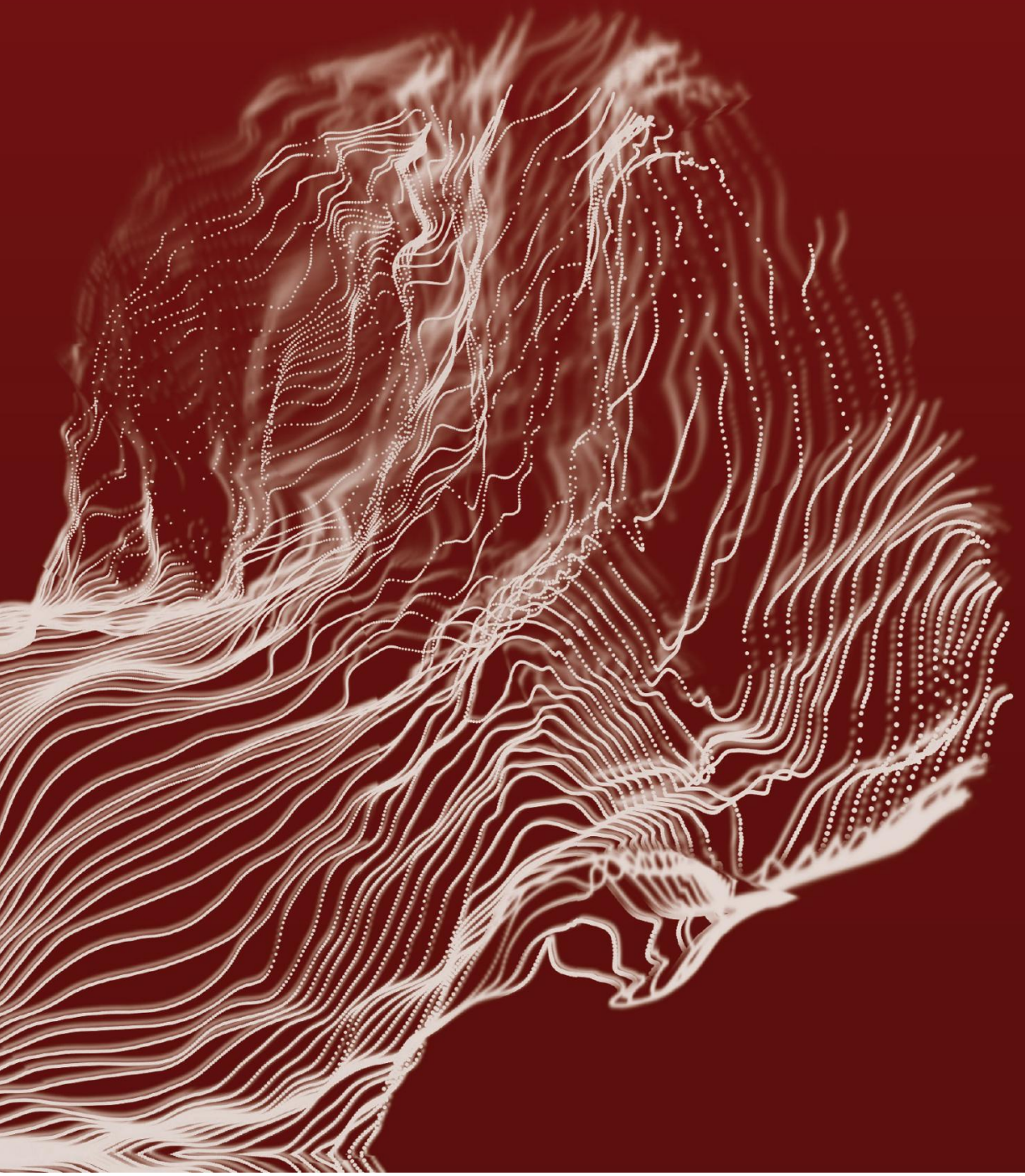




\section{| Chapter 9}

\section{Chapter 1 | Introduction}

There is increasing consensus about the value and effectiveness of midwifery care for women and their families. Recognizing that the childbirth as more than a series of medical procedures, midwifery care takes into account the biological, psychologi$\mathrm{cal}$, and social processes of childbirth, an approach that optimizes a woman's capacity for childbirth and strengthens her subsequent role as a mother. The second half of the twentieth century saw an escalation in a medicalized approach to childbirth, together with the global diminishment of midwives and the professional identity of midwifery. This has left midwives facing difficulties in advocating for physiological approaches to childbirth. Harm to the professional identity of midwives may have consequences - not only for midwives, but for women - particularly in light of an emphasis on closer collaboration with obstetricians in integrated systems of maternity care. In preparing student midwives for future practice, midwifery education needs to focus on supporting learners to develop the competencies necessary for effective collaboration with other professionals in the childbirth domain without losing their own unique professional identity as advocates for physiological childbirth.

The aim of this thesis was to use Rapid Prototyping design methodology to design, develop and pilot-test a midwifery educational initiative that supports student midwives in developing personal agency for the promotion of physiological childbirth. To do this, we conducted six studies in the Netherlands with important midwifery stakeholders, including student midwives, midwives working in community- and hospital-based settings and midwifery educators. Two studies explored the perspectives of midwives and student midwives with regard to their role as advocates of physiological childbirth, identifying factors that facilitated or hindered them in expressing this role, and examining their needs in strengthening their capacity for physiological childbirth. Educational need - in particular the need for midwifery role models - was explored in a third study, and a fourth study focused what practicing midwives need to identify optimal, evidence-based care processes. These four studies, together with stakeholder input, were used to design and develop an educational initiative, which was then assessed for its effect.

\section{Chapter 2}

In focus groups, we explored the attitudes of 37 hospital- and community-based midwives towards their role as advocates for physiological childbirth. We examined factors that facilitate or inhibit midwives in advocating for physiological childbirth. The midwives in our study viewed the promotion and support of physiological childbirth as a core aspect of midwifery professional identity. Midwives described 
physiological childbirth along a continuum which was related to the setting in which they practiced. A number of facilitating factors that strengthen midwives in their role as advocates for physiological childbirth were identified. These included using evidence-based practice as a means of facilitating discussions with other care providers. Midwives mentioned the use of shared decision-making as a means of discussing physiological childbirth with women. In doing this, they felt they could empower women but at the same time, expressed caution, wary of imposing midwifery philosophy of care onto women. Factors that inhibited midwives included the routinized care that predominates in hospital culture. Not all midwives felt that they had the personal agency to challenge and discuss areas of practice for which they felt there was evidence supporting physiological childbirth. When midwives did discuss or challenge practice, doing so sometimes depended on external factors, such as the composition of the team on duty or the length of time left in the shift.

This study illustrates that in order to become competent and confident practitioners of physiological childbirth, midwives need to be aware of the factors that inhibit and encourage practices that support this way of giving birth. For midwifery practice, it is important that midwives consciously employ strategies that promote physiological birth in both home and hospital settings.

Midwifery education and midwifery science research should focus on developing strategies that support midwives in this endeavor.

\section{Chapter 3}

We explored student midwives attitudes towards physiological childbirth, and in particular, what student midwives feel they need from their education in order to advocate for physiological childbirth. In five focus groups, we interviewed 37 fourthyear student midwives from each of the Netherlands' midwifery programmes.

Student midwives described the importance of being able to internalize a midwifery philosophy of care and express this in practice. They noted that being able to do this increased their feelings of personal power and agency as advocates of physiological childbirth, but they also identified challenges in expressing agency and power. One such challenge lies in the dilemma associated with supporting woman-centred care and actively promoting physiological childbirth. Like practicing midwives, student midwives expressed concern about not wanting to 'impose' midwifery philosophy of care on women. Another challenge they face is related to the hierarchy of clinical settings. This leads students to practice in accordance with the norms of midwife preceptors, even if this is in conflict with the midwifery philosophy of care. As students, midwives feel a lack of agency to speak out and give voice to the 


\section{| Chapter 9}

midwifery philosophy of care. Exposure to positive examples of physiological childbirth care during clinical practice and opportunities to discuss and reflect on these in the classroom help student midwives to internalize a midwifery philosophy of care and voice their own 'powerful vision' of this philosophy of care.

We concluded from these findings that midwifery education should focus on strategies that include navigating dilemmas in practice and helping students to develop the necessary agency to express the midwifery philosophy of care in communication with other professionals and with women. Preceptors need support to be able to facilitate student midwives opportunities to realize the midwifery philosophy of care, especially when this differs from preceptor practice.

\section{Chapter 4}

In this descriptive, qualitative study, we used focus groups and in-depth interviews to explore perceptions of student midwives about the midwifery role models students experience and how these influence student learning and practice. In the Netherlands and Iceland, 33 students participated in five focus groups and 12 student midwives participated in in-depth interviews.

Student midwives learn by seeking and emulating role models. Often, there is not a single role model as such; rather, student midwives assimilate desirable professional qualities into what they consider an 'ideal' midwife. Role models facilitate learning, making it easier for student midwives to develop their skills and give them the confidence to experiment with alternative approaches to care. Moreover, midwifery role models are important for students' exploration of their own philosophy of good midwifery practice. Positive role models portrayed woman-centered care, while negative models displayed behaviors students identified as not fitting with good care. Although, learning by doing was valued by student midwives, equally important to student midwives was learning through story telling.

The impact that a positive role model has on a student midwife feeling confident to develop her own professional identity and trust in physiological childbirth is significant. Student midwives indicate that they value role models (midwives and obstetricians) who show confidence in the birth process and who are not directed by fear. They described professionals who were alert, present and patient with the physiology of birth. 
More explicit and critical attention to how and what students learn from role models can enrich midwifery education programmes. This can support the development of students' philosophy of midwifery and their practice in real life.

\section{Chapter 5}

The Optimality Index is a valid, evidence-based tool, designed to measure optimal perinatal care processes and outcomes. It is a tool with two parts; the perinatal background Index (PBI) that measures pre-existing maternal risk characteristics, and the Optimality Index (OI) assigns scores on the management of pregnancy, birth and postnatal period. Our validation process of the Dutch Optimality Index (OI-NL) was based on the already validated OI-US (United States). Native speakers conducted forward and backwards translations to render a Dutch language OI-NL. This was then presented to a panel of Dutch maternity care experts $(n=10)$ who assessed the items in the OI-NL for face validity. Based on their feedback, we removed and added a few items. Face validation produced an Optimality Index-Netherlands that consisted of a PBI (15 items) and OI (42 items).

Subsequently, we assessed inter-rater reliability and discriminant validity of the Optimality Index. The OI-NL was used prospectively to collect data on 266 women who commenced intrapartum care under the responsibility of a midwife, in one of 15 primary midwifery care practices throughout the Netherlands. Two cohorts were compared, based on parity and on care setting at birth. Mean scores between these groups, corrected for perinatal background factors were assessed for discriminant validity. Multiple regressions analyses for parity $(\beta=6.21, \mathrm{P}=0.00)$ and for care setting $(\boldsymbol{\beta}=12.1, \mathrm{p}=0.00)$ confirmed discriminant validity of the OI-NL. Inter-rater reliability was $98 \%$, with one item (Apgar score) sensitive to scoring differences.

OI-NL is a valid and reliable tool for use in the Dutch maternity care setting. In addition to its value for assessing evidence-based maternity care processes and outcomes, there is potential for use for learning and reflection. Against the backdrop of a changing maternity care system, and due to the specificity of its items, OI-NL is a valuable tool for detecting subtle changes indicative of escalating medicalisation of childbirth in the Netherlands. 


\section{| Chapter 9}

\section{Chapter 6}

In this chapter, we described the development of an educational prototype aimed at increasing student midwife agency as an advocate of physiological birth. We did this using Rapid Prototyping (RP) methodology, in which important stakeholders gave input and feedback during the educational design and development process.

This process included a needs assessment of midwives and student midwives. This assessment explored the attitudes of midwives and student midwives towards physiological birth and identified educational needs. These were reported in separate studies presented in chapters $2,3,4$ and 5 of this thesis.

Midwifery stakeholders, including student midwives ( $\mathrm{n}=4$ ), midwifery lecturers $(n=4)$ from the bachelor program, and midwife preceptors in practice settings $(n=4)$ (community and hospital) were interviewed in order to generate content for an educational prototype. Stakeholder groups generated a significant amount of input for the prototype, including the formulation of intended learning outcomes, educational activities about physiological birth designed to support students in developing a personal expression of the midwifery philosophy of care, discussion and debating skills in order to better communicate evidence based practice, and peer to peer reflective learning activities. We used this input to design an initial prototype, which was then presented to the stakeholders for their feedback.

Using rapid feedback from stakeholders, three iterations were needed in order to arrive at a finalized prototype, ready for testing in the bachelor program. Input from stakeholders led to the inclusion of persuasive communication strategies and discussion and debate as teaching methodologies, tools needed to increase student midwife agency to argue for physiological birth. Reflective evidence-based practice, using the Optimality Index-NL, gave students the opportunity to reflect on their practice while providing a framework for discussion.

Working with the RP methodology allowed for the development of a prototype, which we called the ESSENTIAL (Increasing self-efficacy in student midwives for physiological childbirth) programme.

\section{Chapter 7}

We assessed the effect of ESSENTIAL programme on student midwife selfefficacy in their role as advocates of physiological childbirth. To do this, we recruited two cohorts of third year student midwives at an educational facility in the 
Netherlands. Students were asked to complete questionnaires at two points in time (T1 and T2); one cohort followed the prescribed programme of study for third year students; the other cohort followed the same programme of study, supplemented by the ESSENTIAL programme. Our primary outcome was self-efficacy. We used the General Self-Efficacy Scale (GSES) and supplemented this with a midwifery-related self-efficacy questionnaire consisting of 7 items related to physiological childbirth practices in home and hospital settings, the communication of evidence, and ability to challenge practice. We used an independent samples t-test to compare mean scores between the control group and intervention group. A p-value $<.05$ was considered statistically significant. Student midwives in the intervention group reported significantly higher levels of general self-efficacy ( $\mathrm{p}=.001$ ), in contrast to the control group. Student midwife self-efficacy for challenging practice and debating aspects of midwifery practice with women, midwifery preceptors and other professionals in the maternity care domain showed an increase, with the intervention group demonstrating significantly higher self-efficacy at T2 when compared to the control group ( $\mathrm{p}=.029$ ).

These findings suggest that education that focuses on strengthening self-efficacy has effect, prepares student midwives for the clinical setting, ameliorating the forces that make it difficult to advocate for physiological approaches to birth.

Our findings should be interpreted with caution. Limitations include the small number of participants and the lack of a validated midwifery self-efficacy instrument. However, these results do create the foundation for building future interventions within midwifery education. Other research has confirmed the importance of selfefficacy for the development of professional identity and our study shows how increasing student midwife self-efficacy can help midwives to maintain their unique and important professional identity as champions of physiological birth.

\section{Chapter $8 \mid$ General Discussion}

This thesis considers how we can best prepare student midwives for effective collaboration with other professionals whilst at the same time ensuring that in the process of learning to collaborate, they do not lose their professional identity as advocates of physiological childbirth. We reflect on the necessity of effective collaboration with other professionals in the maternity care domain, in order to provide high quality, effective maternity care. Collaboration means recognizing each profession's unique contribution to safe, effective maternity care. These different identities should be strengthened, while at the same time emphasizing mutual respect for differing approaches to care, facilitated and encouraged by 'lively debate' about evidence-based approaches to care. 


\section{| Chapter 9}

Our findings suggest that feelings of power experienced by midwives and student midwives were associated with the ability to have these kinds of interactions with other members of the inter-professional team.

We also reflect on the proposition that the articulation of a physiological approach to childbirth requires other skills, including the personal power, or agency, to discuss, debate, and to convince others of its value and effect.

To develop these skills, we advocate for midwifery education that focuses on the development of communication skills based on personal credibility, the acquisition of rhetorical discussion skills, underpinned by the evidence for healthy optimal childbirth outcomes. Having been educated to understand and articulate the value of the advocacy of physiological childbirth as a safe and effective approach to childbirth, the next generation of midwives will become essential advocates of evidence-informed physiological childbirth. They will respect the differences between midwives and obstetricians and will have the skills to elicit discussion and debate about which care practices constitute safe and effective maternity care - and which do not. Maternity care systems need midwives with a developed sense of their own professional identity coupled with the agency to articulate this, midwives with a voice that can be used to influence policy and care practices within the collaborative spheres of practice in which twenty-first century midwives find themselves. Agency gives power to the midwifery voice. It is important that this voice is heard and able to put forth convincing arguments supporting physiological childbirth in order to advocate for high quality, acceptable midwifery care. 
Summary | 
$\frac{\text { ปั }}{\frac{1}{0}}$

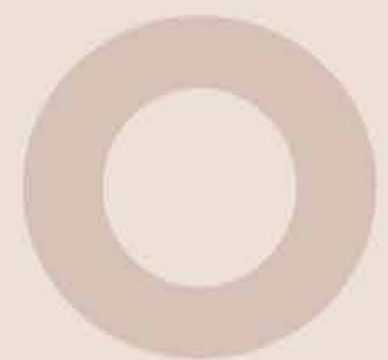




\section{Samenvatting}

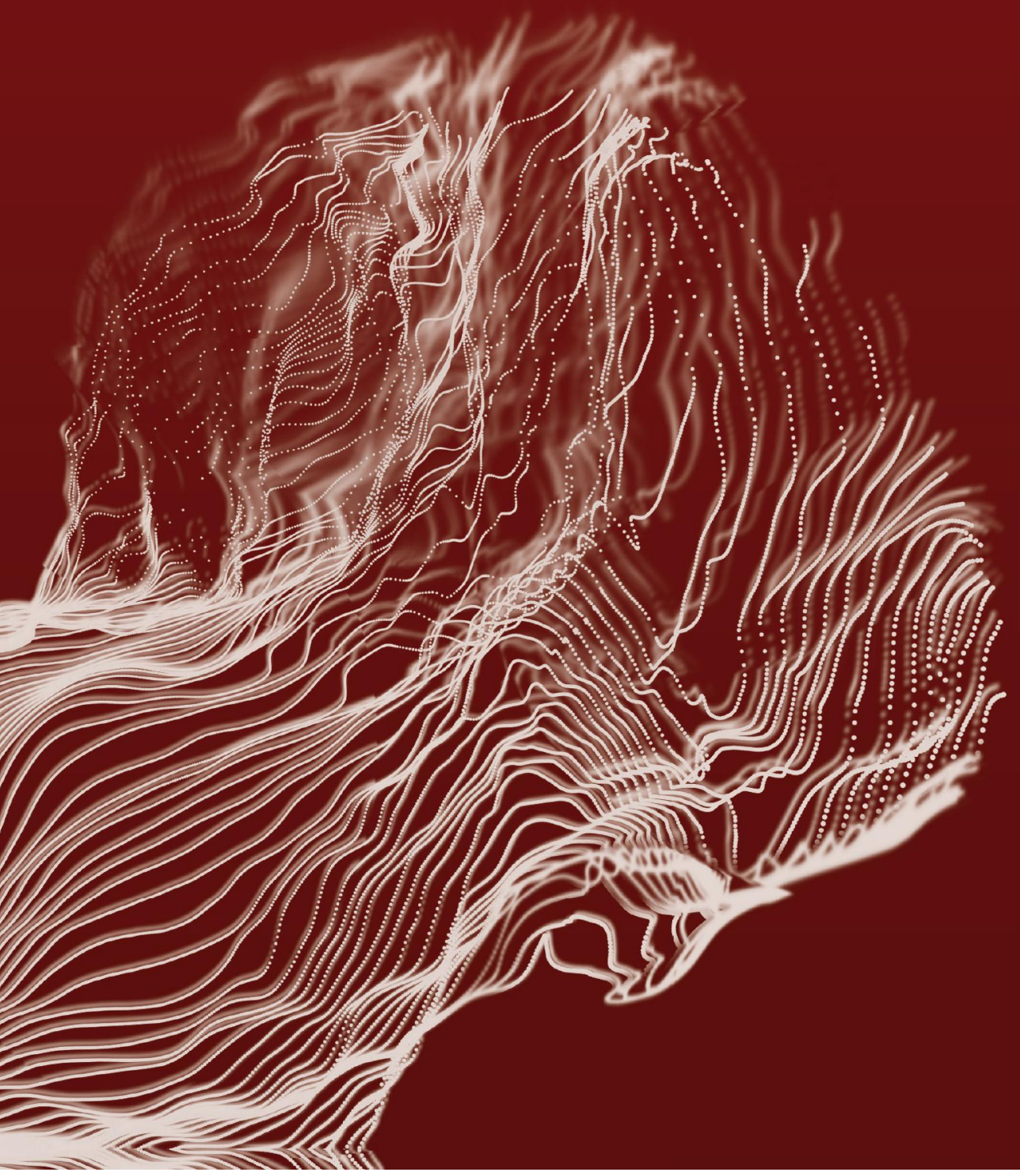




\section{| Chapter 10}

\section{Hoofdstuk 1 | Introductie}

Er is toenemende consensus over de waarde en effectiviteit van zorg door verloskundigen (midwifery) voor vrouwen en baby's. Deze zorg erkent dat de geboorte van een kind meer is dan een reeks medische handelingen. Midwifery houdt rekening met de biologische, psychologische en sociale processen van zwangerschap en geboorte. De midwifery benadering optimaliseert het vermogen van een vrouw om haar kind te baren en versterkt haar latere rol als moeder. In de tweede helft van de twintigste eeuw escaleerde de medicalisering van de geboortezorg, samen met een wereldwijde verzwakking van de professionele identiteit van verloskundigen. Dit heeft het voor verloskundigen moeilijker gemaakt om voor een fysiologische benadering van de verloskunde te pleiten. Afbreuk van de professionele identiteit van verloskundigen heeft grote gevolgen in het kader van samenwerken binnen de integrale geboortezorg; niet alleen voor verloskundigen, maar ook voor vrouwen. Onderwijs aan toekomstbestendige verloskundigen richt zich op het ondersteunen van studenten om de competenties te ontwikkelen die nodig zijn voor effectieve samenwerking met andere professionals in geboortezorg.

Het aangaan van samenwerkingsrelaties zonder afbreuk te doen aan de unieke beroepsidentiteit van de verloskundige als pleitbezorger voor de fysiologie, staat daarbij centraal.

Het doel van dit proefschrift was de ontwikkeling van een onderwijsprogramma dat eigen-effectiviteit in promoten en ondersteunen van fysiologie tijdens de geboorte bij studenten verloskunde vergroot. Daarbij werd de methode van Rapid Prototyping als middel voor de ontwikkeling ingezet. We voerden zes onderzoeken uit met belangrijke verloskundige stakeholders: verloskundigen-in-opleiding, eerste- en tweedelijns verloskundigen en opleiders van verloskundigen. In twee studies onderzochten we de meningen van verloskundigen en verloskundigen-in-opleiding over hun rol als pleitbezorgers van de fysiologische geboorte. In die studies werden ook ondersteunende en belemmerende factoren bij het uiten van deze rol verkend, samen met de behoeften rondom het versterken van hun vermogen voor de fysiologie. Onderwijsbehoeften, met name de behoefte aan verloskundige rolmodellen, werden onderzocht in een derde studie. In een vierde studie werd gefocust op een verloskundig instrument om optimale, evidence-based zorgprocessen te identificeren. Deze vier studies gebruikten we als input om samen met stakeholders een onderwijsinitiatief te ontwerpen, implementeren en evalueren. 


\section{Hoofdstuk 2}

In focusgroepen onderzochten we de houding van 37 eerste- en tweedelijns verloskundigen ten opzichte van hun rol als pleitbezorgers voor de fysiologische geboorte. We onderzochten de factoren die verloskundigen ondersteunen of belemmeren in deze verloskundige rol. De verloskundigen in onze studie beschouwden de bevordering en ondersteuning van de fysiologie als een kernaspect van de professionele identiteit van de verloskundige. Verloskundigen beschreven de fysiologische geboorte als een continuüm in relatie tot de setting waarin ze werkten.

Evidence-based practice werd genoemd als middel om de discussie met andere zorgverleners aan te gaan, en gezamenlijke besluitvorming (shared decision-making) als middel om fysiologische benadering met zwangere vrouwen te bespreken, ondersteunen verloskundigen in hun rol als pleitbezorgers van de fysiologische geboorte. Zij waren echter ook huiverig om hun fysiologische visie op te leggen aan vrouwen die hier geen behoefte aan hebben.

Belemmerende factoren waren onder meer vanzelfsprekendheden in de geboortezorg, in het bijzonder de ziekenhuiscultuur. Verloskundigen vonden het lastig om in deze cultuur routineaspecten van de zorg ter discussie te stellen en fysiologische aspecten aan te dragen als alternatief. De bereidheid om de discussie aan te gaan hing soms af van externe factoren, zoals de samenstelling van het dienstdoende team of de resterende tijd in de dienst.

Om op competente en zelfverzekerde wijze de fysiologie te bewaken en bevorderen, moeten verloskundigen zich bewust zijn van factoren die daarbij faciliteren of belemmeren. In de praktijk is het van belang dat verloskundigen bewust strategieën toepassen die de fysiologische geboorte ondersteunen en bevorderen in alle geboorte settings. Verloskundige onderwijs en wetenschappelijk onderzoek moeten gericht zijn op het ontwikkelen van strategieën die verloskundigen ondersteunen bij dit streven.

\section{Hoofdstuk 3}

In deze studie exploreerden we de attitude van studenten ten aanzien van het promoten en ondersteunen van de fysiologische geboorte. We focusten op wat studenten denken nodig hebben van de opleiding om de rol van pleitbezorger van de fysiologische geboorte effectief vorm te geven. In vijf focusgroepen interviewden we 37 derde- en vierdejaars studenten verloskundigen afkomstig van de drie verloskundige opleidingen. 


\section{| Chapter 10}

Studenten beschreven het belang van het kunnen ontwikkelen en internaliseren van een (eigen) verloskundige visie en het kunnen uiten van deze visie in de praktijk. Studenten associeerden het uitdragen van een eigen verloskundige visie met gevoelens van persoonlijke kracht en versterken van de rol als voorstanders van de fysiologische benadering van de zorg. Studenten voelden ook uitdagingen, met name in het spanningsveld tussen promoten van de fysiologische geboorte enerzijds en de keuzevrijheid van de vrouw anderzijds. Studenten uitten net als de verloskundigen uit studie 1 hun bezorgdheid over het feit dat ze geen fysiologische verloskundige visie willen 'opleggen' aan een vrouw die dat misschien niet wil. Daarbovenop ervaren studenten hiërarchie op de werkvloer (zowel in eerste- als tweedelijns settings). Studenten voelen druk om zich te conformeren aan de normen en waarden van de verloskundigenpraktijk of klinische setting waar zij hun stages lopen, zelfs als dit in strijd is met hun eigen verloskundige visie. Blootstelling aan voorbeelden van fysiologische geboortezorg tijdens de stages en mogelijkheden om deze te bespreken en hierop te reflecteren tijdens het theoretische onderwijs, ondersteunen studenten om een eigen visie te internaliseren en deze 'krachtige visie' op de verloskundige zorg te uiten tijdens hun stages.

Verloskundige onderwijs zich zou moeten richten op strategieën die studenten in staat stellen, om te gaan met de spanningsvelden tussen theorie en de praktijk en de benodigde kracht en eigen-effectiviteit te ontwikkelen om hun verloskundige visie te uiten in de communicatie met andere professionals in de geboortezorg en in gesprekken met vrouwen.

Bij het inrichten van onderwijs in klinische settings hebben verloskundige stagebegeleiders ondersteuning nodig om ruimte en mogelijkheden te creëren voor studenten om een eigen visie te uiten en te realiseren, ook wanneer deze verschilt van de visie van de stagebegeleider.

\section{Hoofdstuk 4}

In dit beschrijvende, kwalitatieve onderzoek onderzochten we met focusgroepen en diepte-interviews percepties van verloskundigen-in-opleiding met betrekking tot rolmodellen in de verloskunde en hoe deze het leren van studenten beïnvloeden. In Nederland en IJsland namen 33 studenten deel aan vijf focusgroepen; 12 studenten namen deel aan diepte-interviews. Verloskundigen-in-opleiding leren door verloskundige rolmodellen te zoeken en deze na te streven. Vaak is dat niet één enkel specifiek rolmodel. Studenten verweven de gewenste beroepskwaliteiten tot wat zij als de 'ideale' verloskundige zien. Rolmodellen faciliteren het leren, waardoor studenten makkelijker vaardigheden ontwikkelen. Rolmodellen geven vertrouwen waardoor de student ruimte neemt en krijgt om te experimenteren met alternatieve 
benaderingen van de zorg. Bovendien zijn verloskundige rolmodellen belangrijke klankborden voor studenten in het exploreren van een eigen verloskundige visie en kritisch analyseren van goede zorg. Positieve rolmodellen lieten voorbeelden van vrouwgerichte zorg zien, terwijl negatieve modellen gedrag vertoonden dat studenten identificeerden als niet passend bij goede zorg. Studenten waardeerden leren door te doen, maar zagen leren door het luisteren naar verhalen (storytelling) als net zo belangrijk voor hun leerproces.

Positieve verloskundige rolmodellen hebben een aanzienlijke invloed op het vermogen van de student om zich te ontwikkelen tot een beroepsbeoefenaar die zich zelfverzekerd genoeg voelt om haar eigen professionele identiteit te uiten. Verloskundigen-in-opleiding geven aan dat ze rolmodellen (verloskundigen en gynaecologen) waarderen om hun getoonde vertrouwen in het natuurlijke verloop van het geboorteproces en de afwezigheid van angst.

Ze beschreven deze professionals als alert, aanwezig en geduldig tijdens een baring. Meer expliciete en kritische aandacht voor hoe en wat studenten leren van rolmodellen kan verloskundige onderwijsprogramma's verrijken. Dit ondersteunt tevens de ontwikkeling van de verloskundige visievorming van studenten.

\section{Hoofdstuk 5}

De Optimaliteitsindex is een valide, evidence-based tool, ontworpen om optimale perinatale zorgprocessen en uitkomsten te meten. De Optimaliteitsindex bestaat uit twee delen: een perinatale achtergrondindex (PBI) die bestaande maternale risicokenmerken meet, en de Optimaliteitsindex (OI) die items meet over zorgprocessen en uitkomsten van de zwangerschap, baring en kraambed. In deze studie valideerden we de Optimaliteitsindex voor de Nederlandse geboortezorg.

Ons validatieproces van de Nederlandse Optimaliteitsindex (OI-NL) baseerden we op de reeds gevalideerde OI-US (Verenigde Staten). Mensen met Engels of Nederlands als moedertaal vertaalden de vragenlijst naar het Nederlands en weer terug naar het Engels om een Nederlandstalige Optimaliteitsindex te krijgen. Dit werd vervolgens gepresenteerd aan een panel van deskundigen uit verschillende gremia in de geboortezorg $(n=10)$. De experts beoordeelden de items in de OI-NL op indruksvaliditeit. Op basis van hun feedback verwijderden we een aantal items en voegden we andere items toe. Dit proces resulteerde in een OptimaliteitsindexNederland (OI-NL) die bestond uit een PBI met 15 items en OI met 42 items. Vervolgens hebben we de interbeoordelaarsbetrouwbaarheid en discriminante validiteit beoordeeld. We verzamelden met behulp van de OI-NL gegevens over 266 vrouwen die onder verantwoordelijkheid van eerstelijns verloskundigen, werkzaam bij één van 15 verloskundigenpraktijken verspreid over Nederland, aan hun bar- 


\section{| Chapter 10}

ing begonnen met. Twee groepen werden tweemaal vergeleken, eenmaal op basis van pariteit en eenmaal op basis van de geplande plaats van de bevalling. Gemiddelde scores tussen deze groepen, gecorrigeerd voor perinatale achtergrondfactoren, werden beoordeeld op hun onderscheidend vermogen. Meerdere regressieanalyses voor pariteit $(\beta=6.21, P=0.00)$ en voor plaats bevalling $(\beta=12.1, p=0.00)$ bevestigden discriminante validiteit van de OI-NL. De interbeoordelaars betrouwbaarheid was 98\%, met één item (Apgar-score) gevoelig voor discrepantie in scoren. De OI-NL is daarmee een valide en betrouwbaar hulpmiddel voor gebruik in de Nederlandse verloskundige zorg.

Naast de waarde voor het beoordelen van evidence-based zorgprocessen en -uitkomsten, is er potentie voor gebruik bij opleiden en reflectie. In het kader van de overstap naar een integraal zorgstelsel en vanwege de specificiteit van de items, is OI-NL een waardevol hulpmiddel bij het opsporen van subtiele veranderingen die wijzen op toenemende medicalisering van de verloskundige zorg in Nederland.

\section{Hoofdstuk 6}

In dit hoofdstuk beschreven we de ontwikkeling van een onderwijsinterventie die zich richt op het vergroten van de eigen-effectiviteit van studenten als pleitbezorger van de fysiologische geboorte.

We gebruikten Rapid Prototyping (RP) als ontwikkel-methode voor het onderwijs -programma ESSENTIAL (increasing self-efficacy in student midwives for physiological childbirth, acroniem), waarbij belangrijke stakeholders input en feedback gaven tijdens het ontwerp- en ontwikkelingsproces. Dit proces omvatte een behoefteanalyse van verloskundigen en verloskundigen-in-opleiding. Deze analyse bracht de attitudes van verloskundigen en studenten ten opzichte van fysiologische geboorte in kaart en identificeerde onderwijsbehoeften. Deze onderwijsbehoeften rapporteerden we in afzonderlijke studies in hoofdstukken 2, 3, 4 en 5 van dit proefschrift.

We interviewden belangrijke stakeholders om de onderwijsinterventie te kunnen ontwikkelen, namelijk studenten $(n=4)$, verloskundige docenten $(n=4)$ en verloskundige stagebegeleiders $(n=4)$ (eerste- en tweedelijns). Deze interviews genereerden de onderdelen voor een prototype onderwijsinterventie, waaronder de formulering van beoogde leerdoelen, onderwijsactiviteiten over fysiologische geboorte die ondersteunend zijn bij het ontwikkelen van verloskundige visie, discussie- en debatvaardigheden, en peer-to-peer reflectieve leeractiviteiten. We ontwierpen een eerste prototype op basis van deze input, presenteerden dit prototype aan de respondenten en vroegen om hun feedback. 
Snelle (rapid) feedbackrondes (drie iteraties) van stakeholders hebben geresulteerd in een afgerond prototype die we testten in één van de Nederlandse bacheloropleidingen Verloskunde. Input van stakeholders leidde tot de inclusie van overtuigende communicatiestrategieën en discussie- en debatvaardigheden als onderwijsmethoden. Dit zijn hulpmiddelen voor het vergroten van de eigeneffectiviteit van studenten bij het pleiten voor de fysiologische geboorte.

Het toepassen van de OI-NL in de beroepspraktijk bood studenten de mogelijkheid tot evidence based reflectie op het eigen fysiologisch handelen. Tegelijkertijd bood de OI-NL een kader voor reflectie en discussie over de benaderingen in de verloskundige zorgverlening in het theoretische onderwijs.

\section{Hoofdstuk 7}

In deze studie evalueerden we het effect van het ESSENTIAL-programma op de eigen-effectiviteit van studenten verloskunde in relatie tot hun rol als pleitbezorger van een fysiologische benadering van het geboorteproces. We rekruteerden twee cohorten van derdejaars verloskundigen-in-opleiding van de bacheloropleiding Verloskunde van de Academie Verloskunde Maastricht. Studenten werd gevraagd om op twee momenten vragenlijsten in te vullen (T1 en T2). Eén cohort volgde het voorgeschreven studieprogramma voor derdejaars studenten, het andere cohort volgde hetzelfde studieprogramma, aangevuld met het ESSENTIAL-programma. Onze primaire uitkomstmaat was eigen-effectiviteit. We gebruikten de General Self-Efficacy Scale (GSES) en vulden deze aan met een verloskundig gerelateerde eigen-effectiviteit vragenlijst. De 7 items voor deze vragenlijst relateerden aan fysiologische zorgprocessen (thuis of in het ziekenhuis), het aandragen van evidence-based practice en het vermogen om onderwerpen bespreekbaar te maken met andere zorgverleners, stagebegeleiders of met vrouwen. We gebruikten de Student's t-test om de gemiddelde scores van de controlegroep en de interventiegroep te vergelijken. We beschouwden een $p$-waarde van $<0,05$ als statistisch significant.

Studenten in de interventiegroep rapporteerden significant hogere scores van algemene eigen-effectiviteit ( $p=.001)$, in vergelijking met de controlegroep. De eigen-effectiviteit van studenten voor het aangaan van discussies over aspecten van verloskundige zorg met vrouwen, stagebegeleiders en andere professionals in het zorgdomein nam toe, waarbij in de interventiegroep sprake was van een significant hogere eigen-effectiviteit bij T2 in vergelijking met de controlegroep (p $=0,029)$. Deze bevindingen suggereren dat onderwijs wat focust op het versterken van eigen-effectiviteit bijdraagt aan het voorbereiden van studenten op hun stageomgeving, waarin het soms moeilijk is om te pleiten voor de fysiologie. 


\section{| Chapter 10}

Onze bevindingen moeten met voorzichtigheid worden geïnterpreteerd. Beperkingen zijn onder meer het kleine aantal deelnemers en het ontbreken van een gevalideerd meetinstrument voor verloskundige eigen-effectiviteit. Deze resultaten leggen wel de basis voor het bouwen van toekomstige interventies binnen het verloskundige onderwijs. Andere onderzoeken laten eveneens het belang van eigen-effectiviteit voor de ontwikkeling van professionele identiteit zien. Ons onderzoek laat zien hoe het vergroten van de eigen-effectiviteit van student-verloskundigen hen kan helpen in het bekrachtigen van hun unieke en belangrijke professionele identiteit.

\section{Hoofdstuk 8 | Algemene discussie}

Dit proefschrift onderzoekt hoe verloskundigen-in-opleiding optimaal kunnen worden voorbereid op effectieve samenwerking met andere professionals in de geboortezorg rondom het bevorderen van de fysiologische bevalling. Dit zonder het inleveren of verlies van de eigen, unieke verloskundige identiteit. In dit hoofdstuk, reflecteren we op de noodzaak van effectief en gelijkwaardige samenwerking met andere professionals met als doel het leveren van hoog kwaliteit zorg.

In een gelijkwaardige samenwerking wordt de unieke bijdrage van elk beroep aan veilige, hoogwaardige verloskundige zorg erkend. Deze verschillende beroepsidentiteiten moeten worden versterkt, terwijl tegelijkertijd de nadruk wordt gelegd op wederzijds respect voor de verschillende benaderingen van zorg, gefaciliteerd en aangemoedigd door een 'levendig debat' op basis van evidence-based benaderingen van de zorg. Onze bevindingen suggereren dat gevoelens van macht (en kracht) die verloskundigen en studenten ervaren, gelinkt zijn aan het vermogen om dit soort interacties (oftewel 'levendig debat') aan te gaan met andere professionals. We stellen dat het articulatie en uitdragen van een fysiologische verloskundige visie extra vaardigheden vereist, waaronder de persoonlijke eigen-effectiveit om te discussiëren, debatteren en anderen te overtuigen van de waarde en het effect van deze zorgbenadering. Om deze vaardigheden te ontwikkelen, pleiten wij voor verloskundig onderwijs dat zich richt op de ontwikkeling van communicatievaardigheden met een focus op persoonlijke geloofwaardigheid, het verwerven van retorische gespreksvaardigheden, ondersteund door het wetenschappelijke bewijs voor optimale zorguitkomsten.

De toekomstbestendige verloskundige is opgeleid om de fysiologische geboorte te begrijpen, op waarde te schatten en deze uit te dragen en uit te voeren als een veilige en effectieve benadering van de verloskundige zorg. Ze respecteert de verschillen tussen verloskundigen en gynaecologen en beschikt over de vaardigheden om discussie en debat op gang te brengen over de verschillen en overeenkomsten van zorg door gynaecologen en verloskundigen. Het integrale zorgstelsel van de toekomst 
heeft verloskundigen nodig met een duidelijk professionele identiteit in combinatie met eigen-effectiviteit om dit te uiten. Verloskundigen moeten hun stem laten horen om beleid en zorgprocessen in het voordeel van de vrouw te beïnvloeden binnen de integrale geboortezorg. Eigen-effectiviteit geeft kracht aan deze stem. Het is belangrijk dat verloskundigen worden gehoord en in staat zijn overtuigende argumenten naar voren te brengen ter ondersteuning van de fysiologie en om te pleiten voor hoogwaardige midwifery zorg. 
ปั) 


\section{Valorisation}

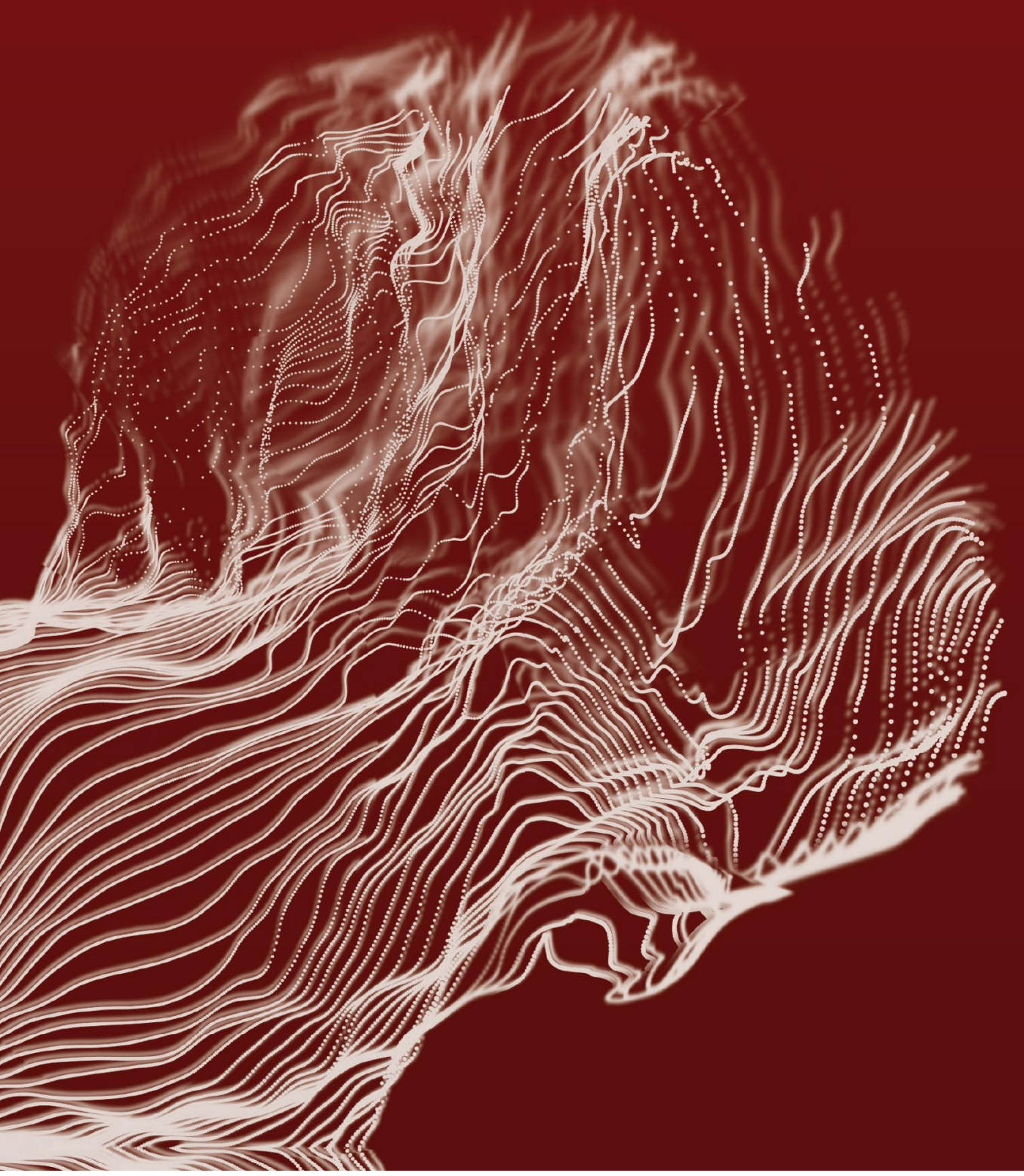




\section{| Chapter 11}

The findings of our research have important implications for midwifery education specifically, and for the education of health professions more broadly.

Our research provides new insights regarding midwives' capacity for their role as guardians and practitioners of physiological childbirth and, equally important, regarding the need for further education of student midwives for this role. Fulfilling this role is a vital contribution to the provision of maternity care that is effective, informed by evidence, and acceptable to women. To assume the role of promoters and protectors of physiological childbirth student-midwives need to strengthen their self-efficacy and agency. Coincidently, the development of educational strategies that strengthen self-efficacy of other students intending careers in maternity care will result in better care for women. The delivery of high-quality, safe and effective maternity care is facilitated when all professionals collaborate ${ }^{1,2}$ as equal partners.

Our work has also produced new insights regarding effective ways to design educational programmes for those working in maternity health care. There is an increasing need to produce good quality, evidence-informed educational programmes that can accommodate the dynamic, changing nature of many of the health professions, including midwifery. Our work illustrates that in order to reflect the needs of a profession faced with constant change, input from, and dialogue with, stakeholders is a workable approach. Moreover, our process of developing educational content that is mindful of available human and material resources will be of interest to educators generally beyond health care.

\section{Relevance to maternity care}

Health care in the Netherlands currently consumes 13\% of Gross Domestic Product (GDP) and the cost of health care will continue to increase in the 21st century. ${ }^{3}$ Providing health care that is of a high quality and economically sustainable is a challenge for governments, policy-makers and insurers. Improvement in maternal and perinatal health over the 20th century are, in part, a result of the use of medical interventions ${ }^{4}$, although we now know that the over-use of medical intervention in childbirth - 'too much, too soon ${ }^{5}$ - causes iatrogenic harm to women and babies and increases the economic burden of maternity care. ${ }^{6}$

The future of quality maternity care lies in another approach to care, in which women receive the 'right care at the right time'. De Jonge et $\mathrm{al}^{7}$ argue that a system in which precise maternity care, tailored to the needs of individuals, rather than a 'one size fits all' approach would benefit women, many of whom express preferences for care that avoids the unnecessary use of medical intervention. ${ }^{8}$ Value-based maternity 
care requires a systemic shift in health care provision with the tailoring of care to the individual need by enacting maternity care that is centred on the needs of the individual and that uses resources optimally and equitably. This would ensure care provision that is preventive and supportive, that strengthens a woman's capacity for physiological childbirth, and prepares a woman and her partner for their role as parents, while allowing for acute obstetric care for those who need it. This approach results in optimal outcomes - the best possible outcome with a minimum of unnecessary medical intervention ${ }^{9}$ and an equitable and sustainable solution to the issues of increasing need and decreasing resources for health care.

Significant issues remain in maternity care. While the integrated approach to maternity care can improve collaboration, it also involves care processes that are protocolized. ${ }^{10}$ The protocolization of maternity care is likely to lead to what Scamell and Alaszewski1 describe as the 'ever narrowing window of normality', with a possibility of increased intervention that may not be necessary. In a time in which there is an escalating shortage of beds in Dutch labour wards ${ }^{12}$ and focus on maternity care in the media - including a non-evidence based proposition that increasing the rates surgical birth may spare women from later life trauma ${ }^{13}$ - de Jonge et al's argument for the optimal, equitable and evidence-based use of resources resonates strongly.

The work contained in this thesis contributes towards the systemic shift called for by Jonge et al. ${ }^{7}$ It does this by providing innovative and evidence-based educational strategies that support midwives to identify optimal care processes and to promote optimal outcomes. Education that focuses on strengthening personal agency is innovative in character, as it shifts midwifery competency for physiological childbirth beyond the realm of 'knowing' to being able to promote physiological childbirth as part of effective, evidence- and, value-based maternity care for women and babies. Promotion of this approach to care means advancing, moving forward, publicising, and increasing public awareness of the value of physiological birth.

While our work focused on student midwives, we would argue that it is applicable to the education of each of the actors in the maternity care domain. Midwives, obstetric nurses and obstetricians who understand and know how to support healthy childbirth physiology, and who are able collaborate with each other effectively, will produce professionals who are able to provide appropriate, sustainable, acceptable maternity care that is neither 'too much too soon' or 'too little too late'. ${ }^{5}$ Rather these professional will deliver judiciously applied, evidence-based, sustainable maternity care that is mindful of avoiding the over- or under treatment of women and their babies.., 14, 16 


\section{| Chapter 11}

\section{Relevance for higher education}

In 2018, the Dutch government spent 6.5 billion euros on higher vocational education. Like health care, these costs are predicted to increase, due in part to extra numbers of students expected to follow some kind of higher vocational education into the next decennia, combined with the rising costs of staff salaries. ${ }^{17}$ Sustainability of higher education is an issue of societal relevance, ${ }^{18}$ as, increasingly, higher education will be expected to do more with less. Universities will need to prioritise programmes of study that meet the needs of the workforce in order to continue to be financially viable. ${ }^{18}$

In educating health care professionals it is of utmost importance that educational programmes create professionals who meet the demands placed on the health professions. While health care is dynamic, health professions education often fails to keep up with curricula which are often outdated and static. ${ }^{19}$ There is increasing traction for a movement that moves the education of health professionals beyond the traditional and problem-based curricula, towards system-based training that encourages learning in locally responsive and globally connected teams. ${ }^{20}$ At the same time, health professions institutes should broaden their focus from isolated places of knowledge to becoming partners within professional networks and consortia, able to access and apply new knowledge and innovations in teaching and learning. ${ }^{19}$ In short, the university becomes a part of the professional community and must seek new strategies to respond to the needs of that professional community.

Rapid Prototyping ${ }^{21}$ (RP) - the methodology we used to inform and guide this the development of the ESSENTIAL programme presented in chapter 6 , offers an approach to the design of health professions education that meets the needs of the changing contexts ${ }^{22,23}$ of health care. RP can reduce the sometimes lengthy, linear design processes often used in educational settings, cutting development time and costs. Moreover, RP works together with stakeholders, establishing their needs and working with their input and feedback to create solutions that can be applied to the dynamic health care setting. Working with health care professionals and students and collating their input to design educational programmes is a means of realising educational design and development that is evidence-informed, responsive to need and fit for purpose.

We are confident that Rapid Prototyping design methodology, applied to midwifery education and to other health professions will provide an innovative approach to educational content development that is sustainable and cost-effective, and responsive to professional need. 


\section{Target groups}

The findings of this thesis are relevant for student midwives, for students of other medical and health care professions and health professions educators.

In their recent concept analysis, ${ }^{24}$ Greenway et al. highlight a number of aspects of the complexity of the theory-practice gap that are relevant for a range of students preparing for health care careers. Aspects include the prevalence of routinized care practices and the difficulties encountered in challenging supervisors because of a need to 'fit in' with the dominant culture of the clinical setting. Education that strengthens self-efficacy and personal agency, as described here, will support learners in midwifery and other health professions to bridge the theory-practice gap in their own health care domain. Improving self-efficacy and agency will allow new professionals to challenge routinized care practices, identify optimal, evidence-based practices, and discuss and debate the merits of these. Educating health care professionals with the skills to do these things will contribute to healthcare that is optimal, equitable and sustainable for the future.

Universities often fail to anticipate the changing context of the health professions ${ }^{19}$ and as health care changes, universities may struggle to keep up. There is often scarce time and resources for research into health professions education. ${ }^{20}$ The work presented in this thesis offers health professions educators an evidence-based approach to educational design and development ensures a good 'fit' between university and the professional context and the effective partnering of educators and professionals in shaping the health care professional of the future.

\section{Activities}

We focused on a number of activities in order to disseminate the findings generated by the projects presented in this thesis. These included the international, peer-reviewed publications that comprise this thesis.

We disseminated our findings at conferences and symposia, in the Netherlands and beyond, relating to midwifery, physiological childbirth and higher education. These are listed below.

\section{Poster Presentations}

November 2019: CAPHRI PhD Day: 'Creating Guardians of Physiologic Birth: The development of an educational initiative for student midwives in the Netherlands 


\section{| Chapter 11}

\section{Oral Presentations}

February 2020: Kennispoort Verloskunde, Utrecht, The Netherlands: 'Increasing self-efficacy in student midwives for physiological childbirth. The design and development of a midwifery education initiative, The ESSENTIAL programme'

November 2019: Nederlandse Vereniging Medische Onderwijs, Rotterdam, The Netherlands: 'Het gebruik van Rapid prototyping als ontwerpmethodologie van onderwijseenheid binnen het hbo-onderwijs'

October 2019: Festival of Idea's, Pembroke College, University of Cambridge, United Kingdom: 'Are babies pizzas to be 'delivered'?'

June 2018: Normal Labour and Birth Conference, Ann Arbor, MI, USA: 'Increasing self-efficacy in student midwives for physiological childbirth'

October 2017: Normal Labour and Birth Conference,

Grange-over-Sands, United Kingdom: 'What do student midwives need to become confident, competent practitioners of physiological childbirth?'

June 2017: ICM Triennial Congress, Toronto, Canada:

'Validating the Optimality Index for use in the Netherlands'

May 2016: Inauguration symposium Professor Marianne Nieuwenhuijze, Maastricht, The Netherlands: 'De Optimality Index - Nederland:

Een validatie onderzoek

January 2016: Kennispoort Verloskunde, Utrecht, The Netherlands:

'Hoe zien Nederlandse verloskundigen hun rol als bewaker en bevorderaar van de fysiologische geboorte?’

June 2015: Normal Labour and Birth Conference,

Grange-over-Sands, United Kingdom:

'Dutch midwives' views on their role as promoters of physiological childbirth' 


\section{Publications}

Thompson, SM; Kane Low, L; Budé, L; de Vries, R; Nieuwenhuijze, M. Evaluating the effect of an educational intervention on student midwife self-efficacy for their role as physiological childbirth advocates, submitted

Nieuwenhuijze, M.J.; Thompson, S.M., et al. Midwifery students' perspectives on how role models contribute to becoming a midwife: A qualitative study, Women and Birth 2019, S1871-5192(19)30210-0

Thompson, S.M.; Nieuwenhuijze, M.J.; Kane Low, L.; De Vries, R. Creating Guardians of Physiologic Birth: The development of an educational initiative for student midwives in the Netherlands, Journal of Midwifery and Women's Health 2019, 64(5):641-648

Thompson, S.M.; Nieuwenhuijze, M.J.; Kane Low, L.; De Vries, R. "A powerful midwifery vision": Dutch student midwives' educational needs as advocates of physiological childbirth, Women and Birth 2019, 32(6):e576-e583

Thompson, SM.; Nieuwenhuijze, M.J.; Budé, L.; De Vries, R.; Kane Low, L. Creating an Optimality Index - Netherlands: A Validation Study, BMC

Pregnancy andChildbirth 2018, 18:100

Thompson, S.M.; Nieuwenhuijze, M.J.; Kane Low, L.; De Vries, R.

Exploring Dutch Midwives Attitudes to Physiological Childbirth: A Qualitative Study, Midwifery 2016, 42:67-73 


\section{| Chapter 11}

\section{References}

1. Cronie D, Rijnders M, Jans S, Verhoeven CJ, de Vries R. How good is collaboration between maternity service providers in the Netherlands? Journal of multidisciplinary healthcare. 2019;12:21 - 30.

2. Weller J, Boyd M, Cumin D. Teams, tribes and patient safety. overcoming barriers to effective teamwork in healthcare. Postgraduate Medical Journal. 2014;90(1061):149-54.

3. van Ewijk C vdHA, Besseling P. Gezondheid Loont: Tussen Keuze en Solidariteit. In: Planbureau C, editor. Den Haag: 2017.

4. Renfrew MJ, McFadden A, Bastos MH, Campbell J, Channon AA, Cheung NF, et al. Midwifery and quality care: findings from a new evidence-informed framework for maternal and newborn care. The Lancet. 2014;384(9948):1129-45.

5. Miller S, Abalos E, Chamillard M, Ciapponi A, Colaci D, Comandé D, et al. Beyond too little, too late and too much, too soon: a pathway towards evidence-based, respectful maternity care worldwide. The Lancet. 2016;388(10056):2176-92.

6. Requejo J, Victora C, Bryce J, to obotSRGoC. Data Resource Profile: Countdown to 2015: Maternal, Newborn and Child Survival. International Journal of Epidemiology. 2014;43(2):586-96.

7. De Jonge A, Downe S, Page L, Devane D, Lindgren H, Klinkert J, et al. Value based maternal and newborn care requires alignment of adequate resources with high value activities. BMC Pregnancy and Childbirth. 2019;19(1):428.

8. Downe S, Finlayson K, Oladapo OT, Bonet M, Gülmezoglu AM. What matters to women during childbirth: A systematic qualitative review. PLoS One. 2018;13(4):e0194906-e.

9. H P. The Optimality Concept. Early HUman Development [Internet]. 1980; (4):[201-5 pp.].

10. Struijs JN, de Vries E, van Dorst HDCA, Over EAB, Baan CA. Geboortezorg in beeld: een nulmeting en eerste ervaringen met het werken met integrale bekostiging. RIVM, Den Haag 2019.

11. Scamell M, Alaszewski A. Fateful moments and the categorisation of risk: Midwifery practice and the ever-narrowing window of normality during childbirth. Health, Risk \& Society. 2012;14(2):207-21.

12. KNOV. Zorgen om Capaciteitsproblematiek [press release]. 2020.

13. de Visser, E. 'Een vaginale bevalling is gewoon niet voor elke vrouw geschikt'. Volkskrant. 2020, 7 th February.

14. ten Hoope-Bender P, de Bernis L, Campbell J, Downe S, Fauveau V, Fogstad H, et al. Improvement of maternal and newborn health through midwifery. The Lancet. 2014;384(9949):1226-35.

15. Homer C, Friberg I, Dias M, ten Hoope-Bender P, Sandall J, Speciale A, et al. The projected effect of scaling up midwifery. Lancet. 2014;384.

16. van lerberghe W, Matthews Z, Achadi E, Ancona C, Campbell J, Channon A, et al. Country experience with strengthening of health systems and deployment of midwives in countries with high maternal mortality. Lancet. 2014;384.

17. Centraal Bureau voor de Statistiek. Hogere onderwijsuitgaven met name door groei studenten 2016 [Available from: https://www.cbs.nl/nl-nl/nieuws/2016/13/hogere-onderwi jsuitgaven-met-name-door-groei-studenten. 
18. van der Zwaan B. Higher Education in 2040: A Global Approach: Amsterdam University Press; 2017

19. Frenk J, Chen L, Bhutta ZA, Cohen J, Crisp N, Evans T, et al. Health professionals for a new century. transforming education to strengthen health systems in an interdependent world. The Lancet. 2010;376(9756):1923-58.

20. Raffoul M, Bartlett-Esquilant G, Phillips RLJ. Recruiting and Training a Health Professions Workforce to Meet the Needs of Tomorrows Health Care System. Academic Medicine. 2019;94(5):651-5.

21. Tripp SD, Bichelmeyer B. Rapid prototyping: An alternative instructional design strategy. Educational Technology Research and Development. 1990;38(1):31-44.

22. Hillen S, Landis M. Two Perspectives on E-Learning Design: A Synopsis of a U. S. and a European Analysis. International Review of Research in Open and Distance Learning. 2014;15:199-225.

23. Gross Davis B. Tools for Teaching. 2nd ed. San Francisco Jossey-Bass; 2009.

24. Greenway K, Butt G, Walthall H. What is a theory-practice gap? An exploration of the concept. Nurse Education in Practice. 2019;34:1-6. 

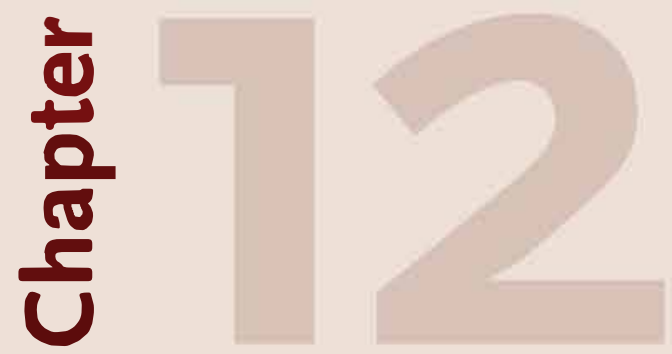

I have proved by actual trial that a letter that takes an hour to write, takes only about three minutes to read!

- Lewis Carroll - 


\section{Acknowledgements}

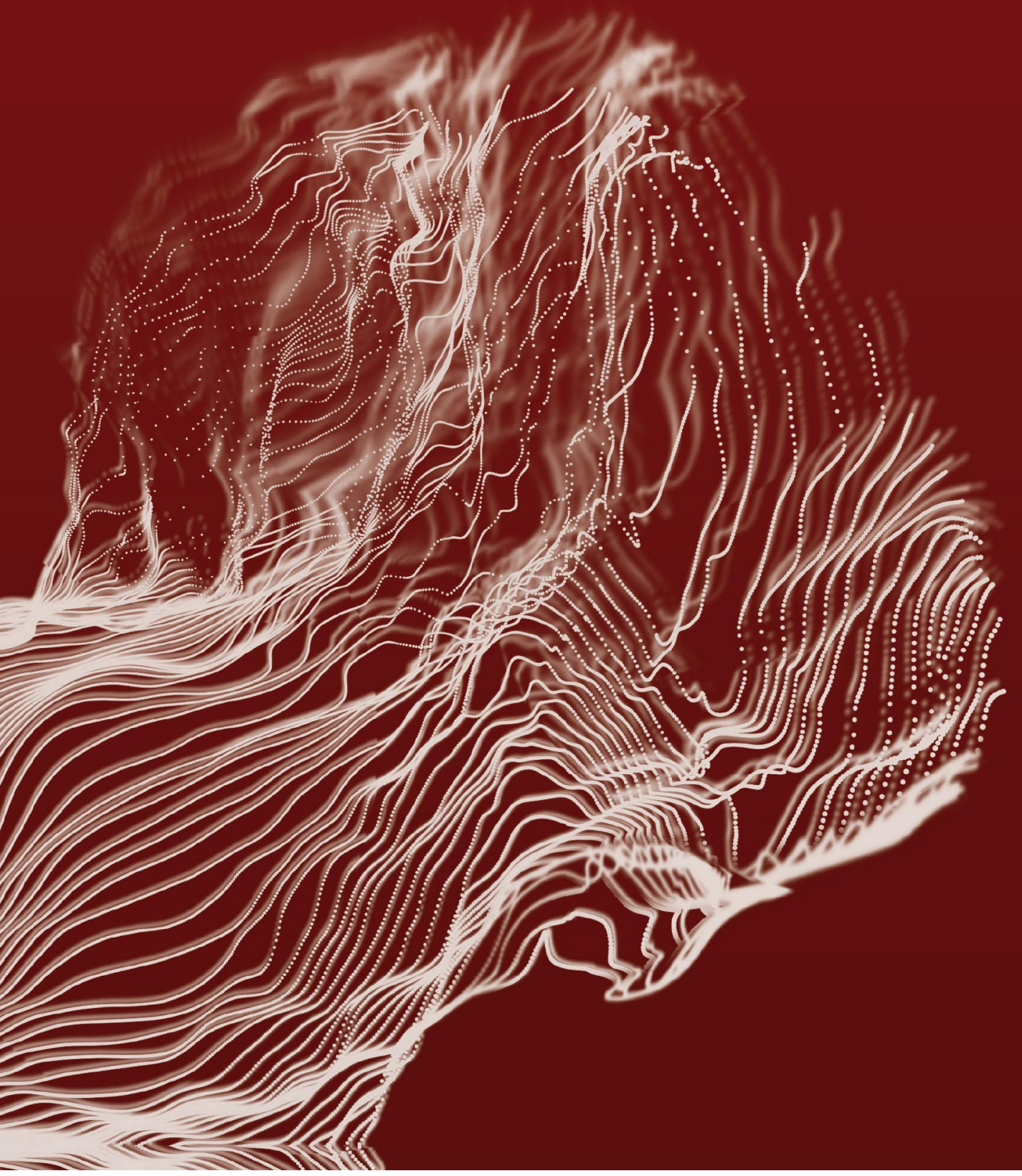




\section{| Chapter 12}

Finding adequate words to thank the many people who have been involved in this PhD has taken a while. Drafting and redrafting these short words of thanks took considerably longer than an hour to write. It is, however, a three-minute read ():

I would like to thank everyone who played a part in this PhD. If you asked how I was getting on; if you encouraged me away from my desk for coffee or wine; if you helped me shape my thoughts; if you corrected my drafts or generally cheered me on: Thank you.

In particular, I would like to thank the midwives and student midwives who trusted me to listen to them and hear their needs and concerns. Your conversations are the entire point of this book and I believe your words paint a picture about the future of midwifery. Your words have helped shaped education for the future of the profession.

I am grateful to the board of directors at Zuyd University of Applied Sciences for generously funding this $\mathrm{PhD}$ and by doing so, recognizing the importance of using research to inform midwifery - and health professions education.

My thanks and appreciation to the members of the assessment committee who assessed and approved this thesis.

My promotor and co-promotors: Professor Raymond De Vries, Professor Lisa Kane Low and Professor Marianne Nieuwenhuijze - the 'Dream Team'.

Raymond - What a great experience it has been, being your PhD student! You encouraged me to 'think for myself and question authority'. You were interested and engaged as a promotor, generous with support and feedback. Our discussions and your questions helped me in shaping my own ideas. At the beginning of this $\mathrm{PhD}$, you said I might be one of the last students you would see all the way through and you were right! Thank you for everything, it's been very cool!

Lisa - You encouraged me very early on to think about a PhD. Throughout our many discussions, you encouraged me and provided vital expertise, in particular with the Optimality Index. Without you, there would be no OI-NL!

Marianne - You were at the very inception of this project on that sunny morning on a terrace in Prague. At each step of this journey, you encouraged, supported, challenged my assertions, made me think (and then think some more when needed!). Thank you for helping me get to where I am now. Your passion for midwifery and midwifery education, combined with an awesome work ethic inspired me to push just that bit further. 
The 'Dream Team' also has to include Charlotte De Vries - who first planted the idea of doing a PhD when she asked me, back in 2011, if I was planning to 'go all the way'. Charlotte, I wasn't planning on going all the way but, hey, here we are!

My midwifery science colleagues - Irene, Evelien, Bert, Luc, Tamar, Marijke, Astrid, Anneke, Pien, Darie - Thank you for being a sounding board for ideas and providing practical support from your many and diverse research skills.

There were many times when I needed help, reassurance and a dose of humour and you generously gave me these. Thank you.

In particular, Luc, statistische held: Without your patient and humorous coaching, I would have been lost early on. (Thank you ${ }^{2}$

Thanks are also due to the entire team at the AVM for your interest and support during this PhD - in particular, my 'train buddies' - Ina, Frans, Marjolein and Elske; and my internationalization colleagues, Meike and Meta. You guys encouraged me to get the thing done as well as providing a listening ear, coffee, humour and treinborrels. Thank you!

Only other PhD students truly understand how the PhD journey works. It is a little known fact that $\mathrm{PhD}$ is an abbreviation of 'piled higher and deeper'. At various points in my PhD journey, Franka, Maaike and Joyce shared their peaks and pitfalls with me. Thank you for sharing various parts of the PhD journey with me while being on your PhD journey.

Motherdear and Daddy - Thank you for all your love, encouragement and the gift of books and reading. Thank you for all the opportunities you afforded me. The maths lessons didn't help, but a book a week from WH Smith seems to have paid dividends (:)

Family and friends, in the Netherlands and overseas - your interest and support were important to me. You cheered me on - by phone, by social media and in person.

Molly and David, you guys deserve a special mention - our friendship, our evenings full of food, drinks, prime numbers (-) and deep discussions about various aspects of midwifery in general and this $\mathrm{PhD}$ in particular were (and still are) wonderful, supportive and encouraging. 


\section{| Chapter 12}

Moll, thanks for being my true friend these last 25 years. We started a dialogue on the Labour Ward of the King Fahad National Guard Hospital that is still ongoing. You had my back then and, as my paranimf, you still have my back - literally!

Charlotte*, Anouska, Celsy and Harvey - the role you played in getting me out from behind my desk to go for walks in all weathers cannot be under-estimated. Parks are a good place to think and it is quite likely that a muttering woman and a gang of dogs surprised more than one jogger!

Jeroen - My ' $M$ ' - Quite simply, without you, none of this would have been possible.

You were my earliest cheerleader for academic high-jinx and you encouraged me to see and take opportunities as they arose. Your unwavering support - in our domestic life and in this PhD journey - was expressed in manifold ways, too many to mention. Thank you for every single time you stepped up to ensure that I could write, revise, re-write, meet a deadline, push out an abstract just before submissions closed, or nip off to some presentation somewhere while you maintained our home life. The words 'Thank you' hardly seem enough - thank you. I love you and love the high-jinx

I96 (academic and otherwise) that we share.

Joachim יואכים Ever present. Ever loved. Ever missed. 
Acknowledgements | 
$\frac{\text { d }}{\frac{1}{0}}$

"Saturday's child works hard for a living"

- English nursery rhyme, 1838 - 


\section{Curriculum Vitae}

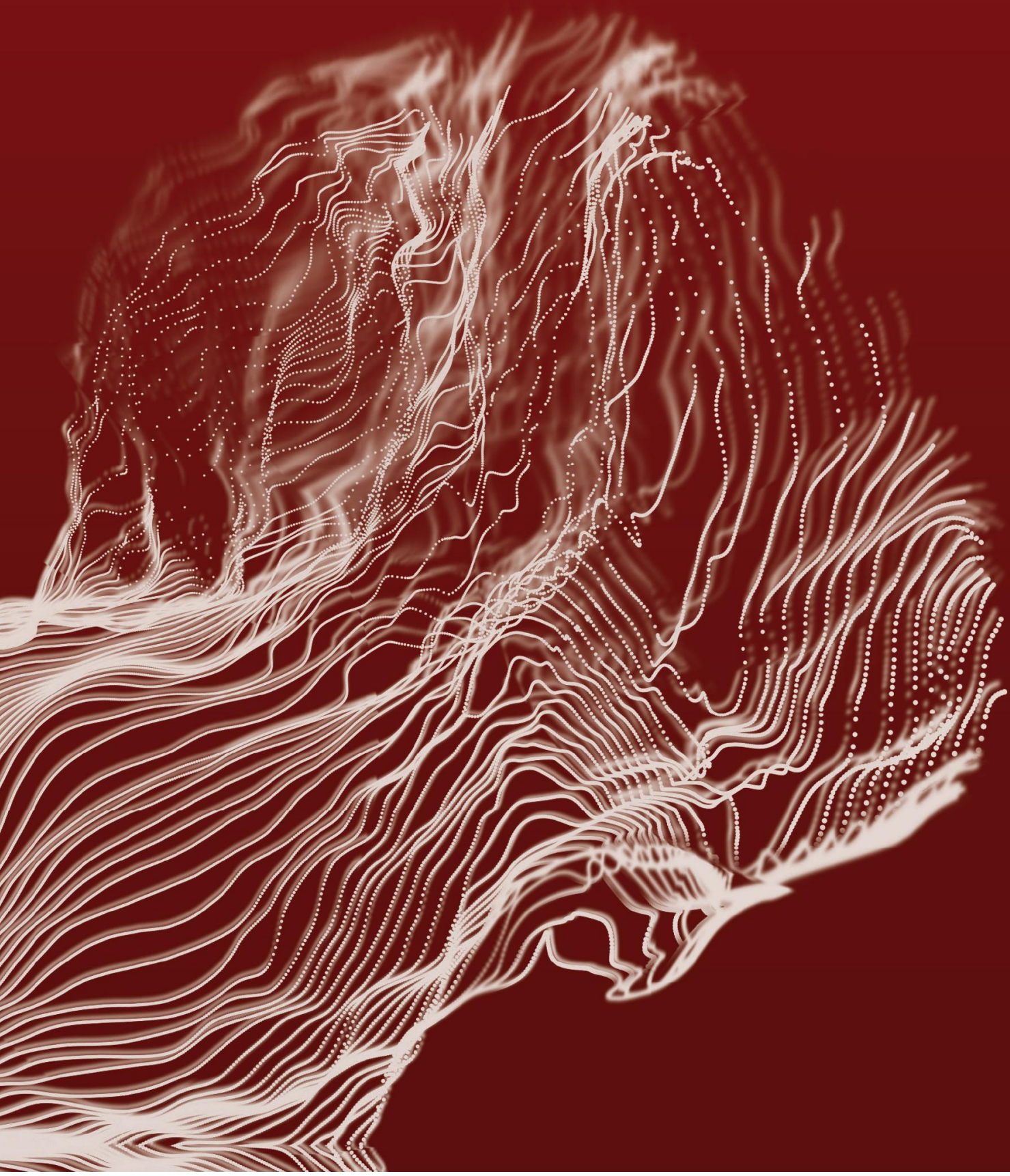




\section{| Chapter 13}

Suzanne M Thompson was born on Saturday April 11th 1970, at Exeter, provincial capital of Devon, in the West of England. Her arrival, following two failed external cephalic versions and a vaginal breech delivery, was hard work for all concerned.

Suzanne attended primary and secondary schools in Exeter. A stint at Exeter College of Further Education shifted Suzanne's focus from university to practical studies. Suzanne trained as a nurse at St Bartholomew's Hospital, London and worked briefly in paediatrics, first in London and then, as a volunteer nurse in Romania, shortly after the end of communist rule in that country.

In 1992, Suzanne started midwifery training at Mid-Trent College of Nursing and Midwifery, based at Derby City General Hospital.

In 1993 as a Registered Midwife, Suzanne worked in London and Nottingham. On a rainy day in March 1995, a persuasively worded recruitment pitch in the Nursing Times lead Suzanne to apply for a job in Saudi Arabia. As part of the Saudi Arabian National Guard at King Fahad National Guard Hospital, Suzanne was involved in the design and implementation of the first midwife-led model of care in the Middle East.

In 1998, Suzanne made the move to the Netherlands with her then-partner. She worked as a community midwife in Almere, The Hague, the Westland area and Amsterdam, before being employed as a midwifery educator in 2004 .

In this role, Suzanne taught Bachelor and Master studies, was involved in educational development work in Sierra Leone and Ghana and has shaped internationalisation policy, creating the possibility of overseas experiences for student midwives. Professional activities include chairing the organization Midwives for Mothers and assessing midwifery registration requests from midwives outside of the EU for the Dutch Ministry of Health.

Deciding to catch up with neglected university education, Suzanne started a Bachelor of Science at Glasgow Caledonian University in 2008 and followed this up with a Master of Science in 2011 - 2013. Realising that she enjoyed academic study, she commenced Doctoral studies in 2015.

Suzanne lives in Eindhoven, the Netherlands and shares her life with her husband Jeroen, a gang of dogs and a Cornish Rex. 
Curriculum Vitae |

- You are holding the result of this 'Saturday child's' hard work in your hands - 